\title{
Gas Composition Effects in a CI Engine Converted to SI Natural Gas Operation
}

Hemanth Kumar Bommisetty

Follow this and additional works at: https://researchrepository.wvu.edu/etd

\section{Recommended Citation}

Bommisetty, Hemanth Kumar, "Gas Composition Effects in a CI Engine Converted to SI Natural Gas Operation" (2017). Graduate Theses, Dissertations, and Problem Reports. 5230.

https://researchrepository.wvu.edu/etd/5230

This Thesis is protected by copyright and/or related rights. It has been brought to you by the The Research Repository @ WVU with permission from the rights-holder(s). You are free to use this Thesis in any way that is permitted by the copyright and related rights legislation that applies to your use. For other uses you must obtain permission from the rights-holder(s) directly, unless additional rights are indicated by a Creative Commons license in the record and/ or on the work itself. This Thesis has been accepted for inclusion in WVU Graduate Theses, Dissertations, and Problem Reports collection by an authorized administrator of The Research Repository @ WVU. For more information, please contact researchrepository@mail.wvu.edu. 


\title{
Gas Composition Effects in a CI Engine Converted to SI Natural Gas Operation
}

\author{
Hemanth Kumar Bommisetty
}

\author{
Thesis submitted to the \\ Benjamin M. Statler College of Engineering and Mineral Resources at \\ West Virginia University \\ in partial fulfillment of the requirements for the degree of \\ Master of Science \\ in \\ Mechanical Engineering
}

Cosmin Dumitrescu, Ph.D., Chair

Arvind Thiruvengadam, Ph.D.

Vyacheslav Akkerman, Ph.D.

Department of Mechanical and Aerospace Engineering

\author{
Morgantown, West Virginia
}

2017

Keywords: IC Engines, Natural Gas Engines, Efficiency, Composition Effects

Copyright 2017 Hemanth Kumar Bommisetty 


\section{Abstract \\ Gas Composition Effects in a CI Engine Converted to SI Natural Gas Operation}

\section{Hemanth Kumar Bommisetty}

Low-carbon fuels such as natural gas (NG) have the potential to lower the demand of petroleum-based fuels, reduce engine-out emissions, and increase IC engine thermal efficiency. One of the most rapid and efficient use of NG in the transportation sector would be as a direct replacement of the diesel fuel in compression ignition (CI) engines without any major engine modifications to the combustion chamber such as new pistons and/or engine head. An issue is the large variation in NG composition with the location and age of the gas well across U.S., which would affect engine operation, as well as the technology integration with emissions after treatment systems. This thesis describes the use a conventional CI engine modified for spark ignition (SI) NG operation to investigate the effects of methane and a $\mathrm{C}_{1}-\mathrm{C}_{4}$ alkane blend on main combustion parameters like in-cylinder pressure, apparent heat release rate, IMEP, etc. Steady-state engine experiments were conducted at several operating conditions that changed spark timing, engine speed, and equivalence ratio. The study found that $\mathrm{C}_{1}-\mathrm{C}_{4}$ alkane blend operation increased peak pressure, IMEP, and indicated thermal efficiency compared to methane, for all the operating conditions investigated in this work. This suggests caution when translating methane-based experimental observations to real world NG operation, even for NG with high methane percentage as the one used in this work. As many NG studies in the literature used methane as an NG surrogate, a better understanding of real fuel effects in diesel-like combustion environments could be important for the successful conversion of conventional diesel engines to NG operation. 


\section{Dedication}

This thesis is dedicated to my family and my friends 


\section{Acknowledgements}

Firstly, I would like to thank my family, especially to my mother - Uma Maheswari, sister - Nikitha Bommisetty and my grandfather - Eswaraiah, for all the support (morally and financially) they provided me, which drove me all the way till here. Their love and sacrifices are the main reasons which made it possible to continue my higher studies abroad, for which I'm very grateful to them.

I also thank my advisor, Dr. Cosmin Dumitrescu, for providing me an opportunity to work with him on engines. I would only be dreaming about it, if I have not met him. His expertise has helped me to overcome a lot of troubles in my initial stages. And without him, this thesis would not have been written and completed. I thank him for all the encouragement, support and knowledge he shared with me. I am also very thankful for the trust he had in me, which allowed me to run my experiments even in his absence.

I would also like to thank my committee members, Dr. Arvind Thiruvengadam and Dr. Vyacheslav Akkerman, for their valuable advices and support that assisted me in betterment of my thesis. Both of them are highly intelligent in their respective fields, but are very modest, and are eager to help whoever approach them. Their proficiency in combustion and emissions, has assisted me in better tackling of the difficulties faced during my project.

My special thanks to Dr. Ross Ryskamp, a research assistant professor at WVU and also a very good friend of mine, who would never let me down, no matter how hard the situation is. He used to stay with me in the lab, sometimes until late in the night, trying to fix the things I didn't even know about. And the best part was, he would also teach me how exactly they work and their significance, while fixing them. I always admired his way of approach to solve a problem, which I'm trying to inherit. Thank you, Ross.

My testing would not have been completed, if there was no support from CAFEE. I sincerely thank Dan Carder, the Director of CAFEE, and all the professors, engineers, technicians, and my graduate student colleagues of CAFEE; especially, Dr. Marc Besch, Brad Ralston, Richard Atkinson, Dylan Connelly, Phil Korpeck, and Zach Luzader. I would also like 
to thank my research group - Jinlong Liu, Rahul Koora, and Rasik Pondicherry, who helped me out with my experiments.

I also thank Vishnu Padmanaban, another graduate student at WVU, who taught me how to work on this engine and a lot of other things, during the very beginning of my project. Thanks would not be sufficient for all the help he offered me.

Apart from my studies, my life at WVU has been a very pleasant journey, which wouldn't be possible if not for these people - Varshith Vummadi, Sashank Jammalamadaka, Vivek Komarina, Maneesh Jasti, Pushpitha Vudata, Anudeep Paraitham, Madhumitha Ganta, Tapaswi Nandyala, Giri Teja, Ram Nellutla and Znana Tej. I would also like to thank my sisterlike friends - Madhuri Vemulapalli, Pujitha Donepalli, and Bhavana Naredla, who showered unlimited love and affection on me. I have made a bunch of other friends at Morgantown, and I cannot list them all, as the list is exhaustive. I could only imagine my living here without them.

Last but not the least, I would like to thank my undergrad friends - Alle Shruthikanth, Aditya Bheemreddy, Sai Nihanth Reddy, Vaidhya Komura, Sai Raj, Michael Thomas, Abhishek Javvaji, Pratyusha Gujarathi, Shashanka Nalini, Himaja Yedithi, Maneesha Pothuraju and Sowmya Adiraju, for all their encouragement. 


\section{Contents}

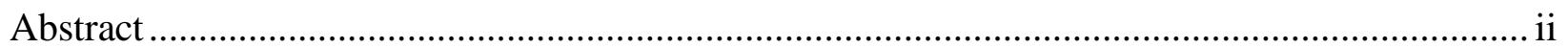

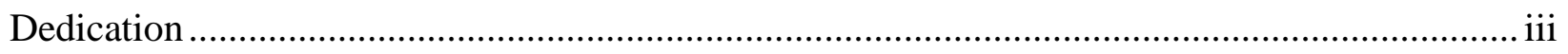

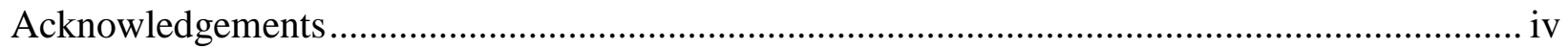

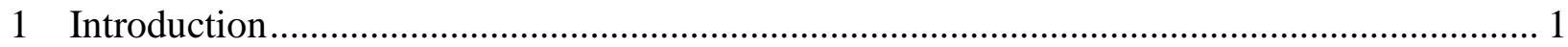

1.1 Natural Gas as Alternative Fuel for IC Engines.................................................. 1

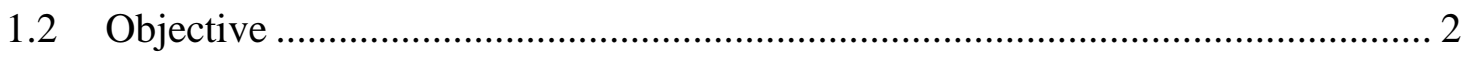

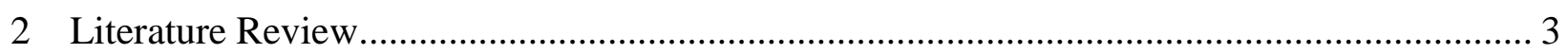

$2.1 \quad$ Natural gas characteristics ........................................................................ 3

2.1.1 Effects of NG composition.................................................................... 4

2.1.2 Effect of NG composition on engine performance ....................................... 5

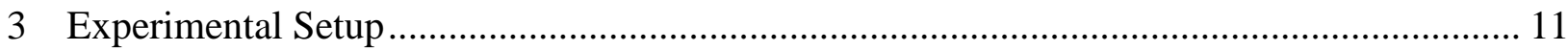

$3.1 \quad$ Test Engine

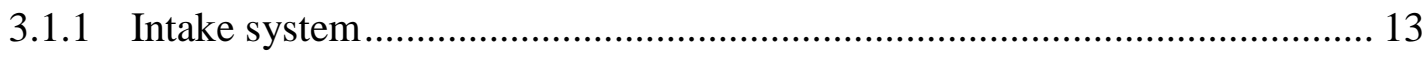

3.1.2 Cooling and lubrication system.............................................................. 14

3.1.3 Dynamometer ………………………………...................................... 15

3.1.4 Engine and dynamometer control console ................................................. 16

3.1.5 Engine control unit ............................................................................... 18

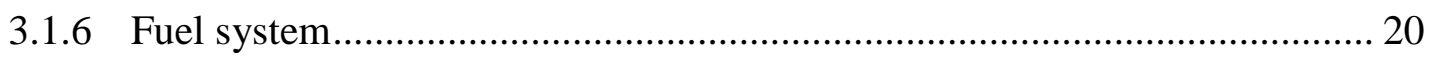

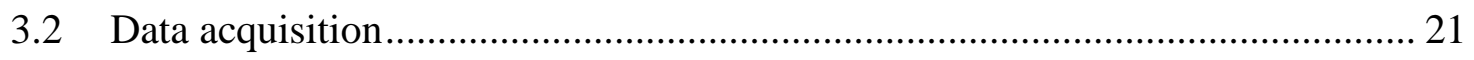

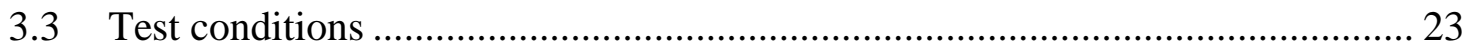

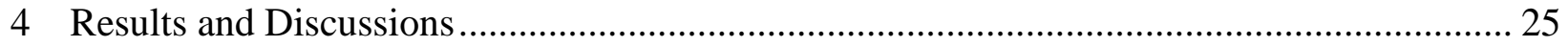

4.1 Effect of spark timing ................................................................................ 27

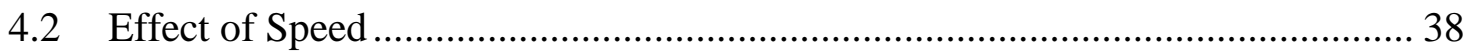

4.3 Effect of Fuel load ............................................................................... 43

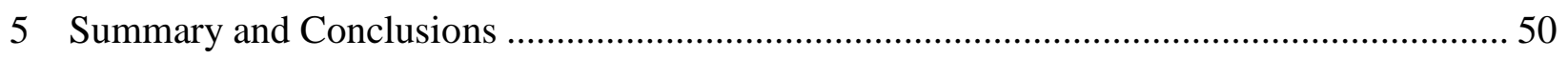

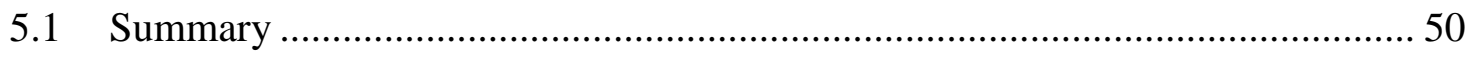

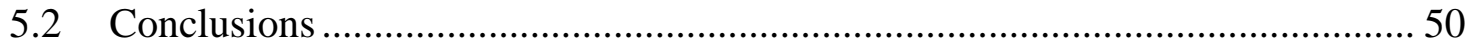

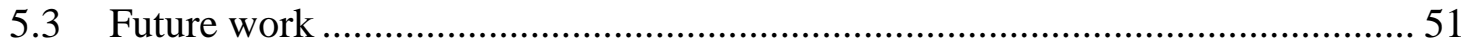

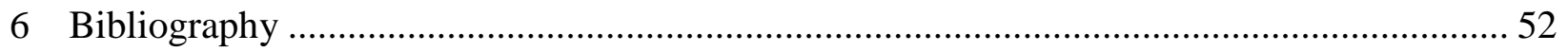

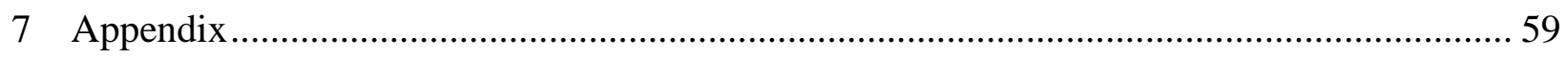




\section{List of Figures}

Figure 1: Distribution of NGV around the world ............................................................. 1

Figure 2: Consumption of NG by sector, 2016 ............................................................. 1

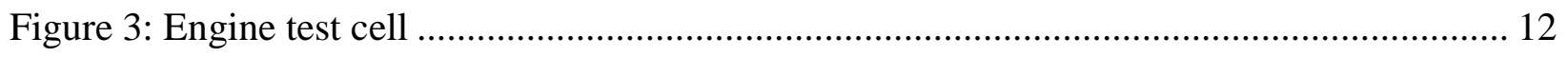

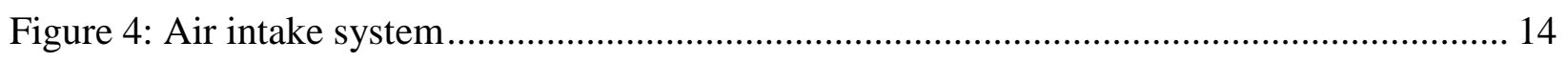

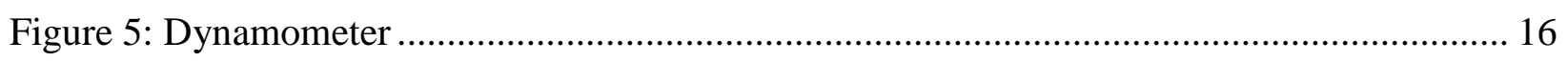

Figure 6: Wiring code for Tedea-Huntleigh model 104H .................................................. 16

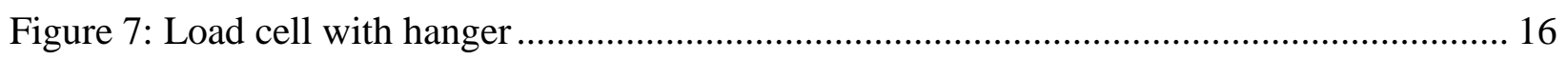

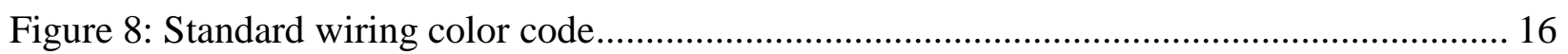

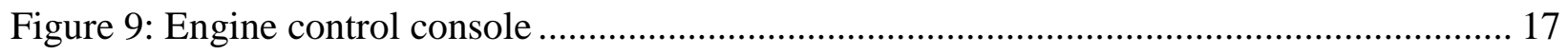

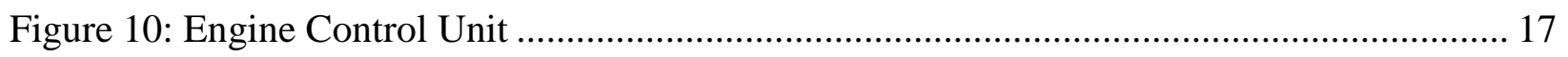

Figure 11: Cam position sensor (Hall Effect Sensor) .......................................................... 19

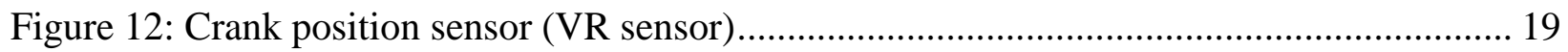

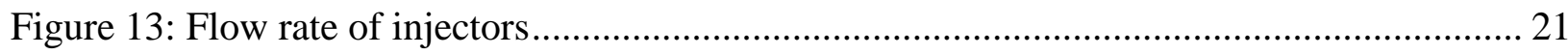

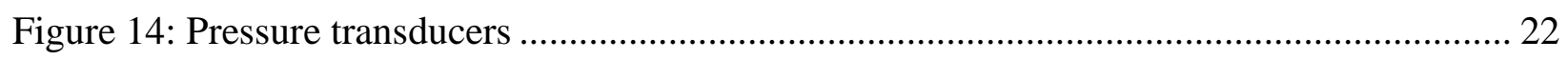

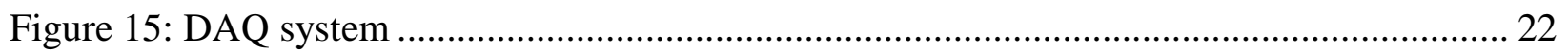

Figure 16: Motored pressure trace illustrating TDC alignment ............................................ 26

Figure 17: Individual and average pressure cycles (methane at $-10^{\circ} \mathrm{CA}$ aTDC spark timing, $80 \%$

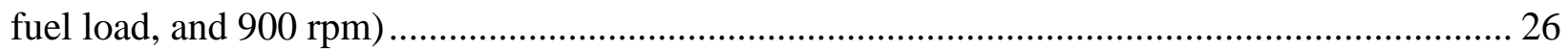

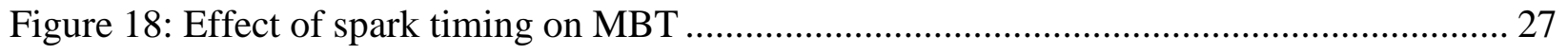

Figure 19: Effect of spark timing on MBT (methane at $900 \mathrm{rpm}$ and $80 \%$ fuel load) ............... 27

Figure 20: Effect of spark timing on cylinder pressure (methane at $900 \mathrm{rpm}$ and $80 \%$ fuel load) 28

Figure 21: Effect of fuel on cylinder pressure (at $900 \mathrm{rpm}$ and $80 \%$ fuel load) ...................... 28

Figure 22: Effect of spark timing on imep (methane at $900 \mathrm{rpm}$ and $80 \%$ fuel load) ................ 30

Figure 23: Effect of spark timing and fuel on imep (900 rpm and 80\% fuel load) ................... 31

Figure 24: Effect of spark timing on heat release rate (methane at $900 \mathrm{rpm}$ and $80 \%$ fuel load) 32

Figure 25: Effect of fuel on AHRR (at $900 \mathrm{rpm}$ and $80 \%$ fuel load) ..................................... 32

Figure 26: Effect of spark timing on NHRR (methane at $900 \mathrm{rpm}$ and $80 \%$ fuel load) ............. 34

Figure 27: Effect of fuel on NHRR (at $900 \mathrm{rpm}$ and $80 \%$ fuel load) ..................................... 34 
Figure 28: Effect of spark timing on mass fraction burnt (methane at $900 \mathrm{rpm}$ and $80 \%$ fuel load) 35

Figure 29: Effect of fuel on mass fraction burnt at $-10^{\circ}$ aTDC (at $900 \mathrm{rpm}$ and $80 \%$ fuel load). 36 Figure 30: Effect of spark timing on indicated thermal efficiency (methane at $900 \mathrm{rpm}$ and $80 \%$

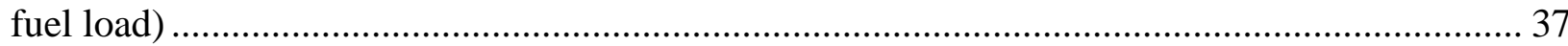

Figure 31: Effect of fuel on indicated thermal efficiency (at $900 \mathrm{rpm}$ and $80 \%$ fuel load)......... 37

Figure 32: Effect of speed on cylinder pressure (at $-10^{\circ} \mathrm{CA}$ aTDC and $80 \%$ fuel load) ............. 38

Figure 33: Effect of engine speed on AHRR (at $-10^{\circ} \mathrm{CA}$ aTDC and $80 \%$ fuel load) ................. 40

Figure 34: Effect of engine speed on NHRR (at $-10^{\circ} \mathrm{CA}$ aTDC and $80 \%$ fuel load) ................. 41

Figure 35: Effect of engine speed on imep (at $-10^{\circ} \mathrm{CA}$ aTDC and $80 \%$ fuel load) .................. 41

Figure 36: Effect of fuel and speed on indicated thermal efficiency (at $-10^{\circ} \mathrm{CA}$ aTDC and $80 \%$ fuel load)

Figure 37: Effect of fuel and speed on mechanical efficiency of the engine (at $-10^{\circ} \mathrm{CA}$ aTDC and

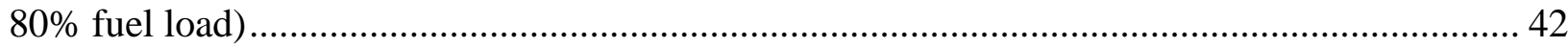

Figure 38: Injector signal variation with change in percentage of fuel load ............................ 44

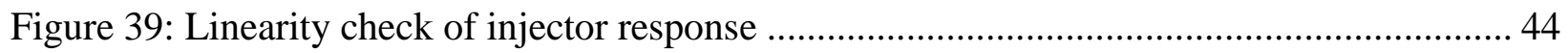

Figure 40: Effect of fuel and fuel load on pressure (at $-10^{\circ} \mathrm{CA}$ aTDC and $900 \mathrm{rpm}$ ) ................ 45

Figure 41: Effect of fuel and fuel load on imep (at $-10^{\circ} \mathrm{CA}$ aTDC and $900 \mathrm{rpm}$ )................... 46

Figure 42: Effect of fuel load on heat release rate (at $-10^{\circ} \mathrm{CA}$ aTDC and $900 \mathrm{rpm}$ )................ 47

Figure 43: Effect of fuel and fuel load on NHRR (at $-10^{\circ} \mathrm{CA}$ aTDC and $900 \mathrm{rpm}$ ).................. 47

Figure 44: Effect of fuel and fuel load on equivalence ratio (at $-10^{\circ} \mathrm{CA}$ aTDC and $900 \mathrm{rpm}$ ) .... 48 Figure 45: Effect of fuel and fuel load on indicated thermal efficiency (at $-10^{\circ} \mathrm{CA}$ aTDC and 900

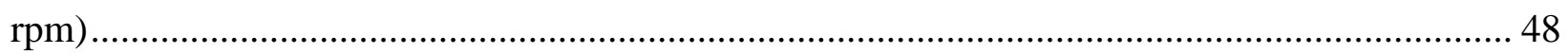

Figure 46: Certificate of Analysis of NG composition ................................................... 59 


\section{List of Tables}

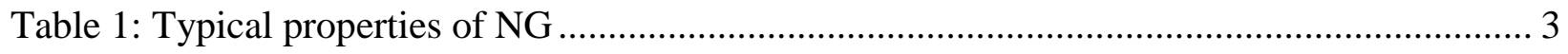

Table 2: Composition of NG in vol (\%) from different wells in West Virginia.......................... 4

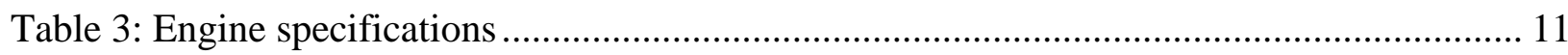

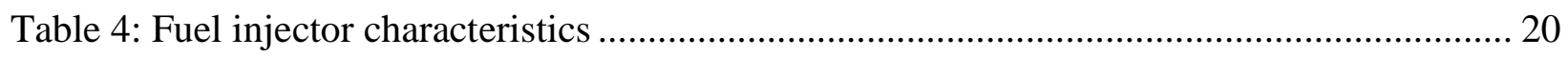

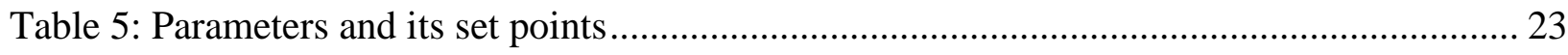

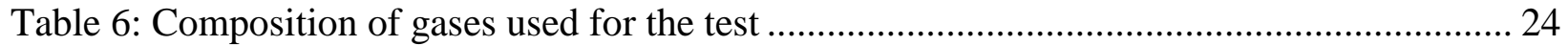

Table 7: Effect of spark timing and fuel on combustion parameters ....................................... 29

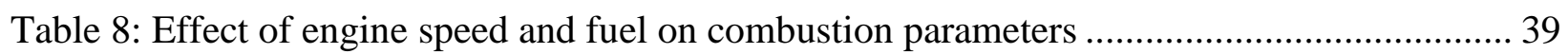

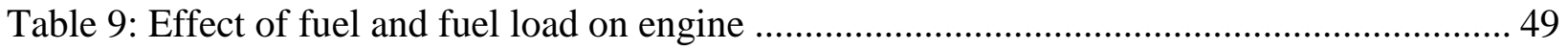




\section{Introduction}

\subsection{Natural Gas as Alternative Fuel for IC Engines}

Internal combustion engine (ICE) is the main power source for on-road and off-road vehicles. While there is an increased interest in vehicle hybridization and electrification, forecasts predict that gaseous and liquid fuels will still provide $99 \%$ of the energy used in the transportation sector in U.S in year 2040 [1], and more than 92\% of the ICEs will still run on petroleum based fuels [2]. Nevertheless, the adverse effects of ICE emissions on human health and environment and the dependence on oil imports will probably result in much stricter future emission regulations, hence the increased interest on finding cleaner alternatives for conventional petroleum-based fuels. Natural gas (NG) is such an alternative due to its increased availability, lower costs, and compatibility with both spark ignition and compression ignition engines [3, 4]. In addition, its higher hydrogen-to-carbon $(\mathrm{H} / \mathrm{C})$ ratio usually lowers engine-out $\mathrm{CO}_{2}$ emissions, which are an important greenhouse gas (GHG) [5]. More advantages of NG are discussed in Chapter 2.

Compressed natural gas (CNG) fuels more than 23.5 million natural gas vehicles (NGV) across the world, but only $0.8 \%$ are registered North America, as shown in Figure 1. However, U.S. EIA mentions a 73\% increase in the use of NG as vehicle fuel over the past 10 years, which accounts to almost $3 \%$ of the total transportation sector [6]. The report also predicts that NG consumption will increase rapidly from 64 billion cubic feet (Bcf) to 658 Bcf by 2040 .

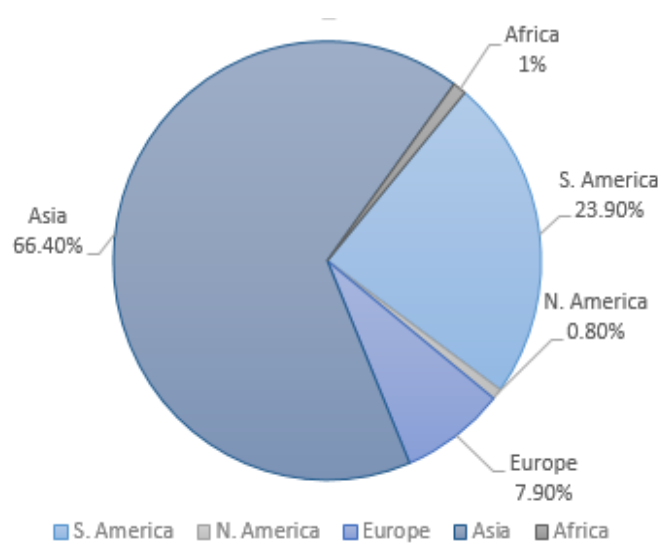

Figure 1: Distribution of NGV around the world [7]

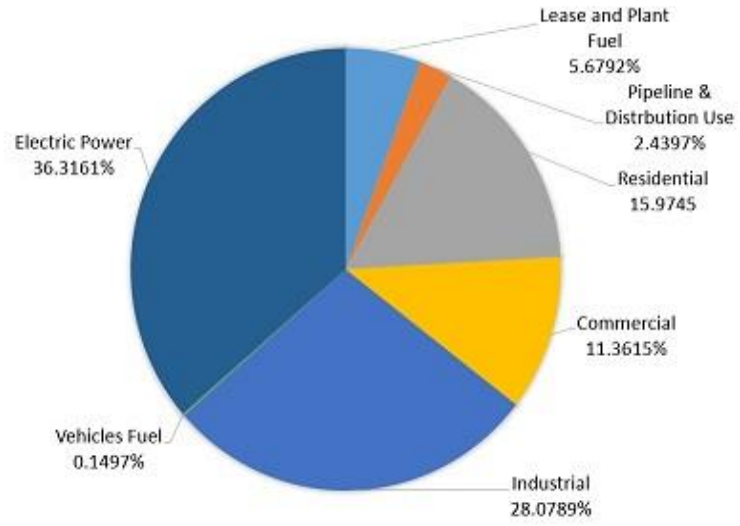

Figure 2: Consumption of NG by sector, $2016[8]$ 
Despite of several advantages, there are still several issues that need addressed before increasing NG's use in the transportation sector. Firstly, there is no proper NG fueling infrastructure, though it is abundantly available across U.S. For example, West Virginia being one of the largest NG producers in the U.S. [9], has only 3 CNG filling stations [10]. Secondly, the supply of dedicated NG engines is limited, which means that most NG engines on the market today are conventional petroleum-fueled IC engines converted for NG operation through the installation of an after-market conversion kit, which is expensive. But the main challenge that NG engines are facing is probably the large variation in the NG composition with location across U.S. The reason is that even a small change in NG composition (i.e., a larger fraction of heavier hydrocarbons or inert components) can greatly affect the engine combustion characteristics. As a result, the increase in NG utilization in the transportation sector will not be possible without better identifying and predicting the effects of varying NG composition on the efficiency and emissions of IC engines.

\subsection{Objective}

The literature review section will show that experimental investigations on NG composition effects is not a new topic. However, there is not enough information on the combustion characteristics of IC engines modified for NG operation without using advanced or specialized hardware [11-14]. More, there is a limited amount of information on the combustion characteristics of conventional heavy-duty (HD) diesel engines converted to NG SI operation. If such information would be readily available, the industry would develop inexpensive conversion kits that would really change the landscape of NG utilization. Consequently, the primary focus of this study was to investigate the effects of NG composition on performance of an HD diesel engine modified for SI NG operation without any major engine modifications to the combustion chamber (e.g., new pistons) and/or specialized injection or ignition hardware. 


\section{Literature Review}

\subsection{Natural gas characteristics}

NG has a higher self-ignition temperature compared to diesel fuel, which requires high energy to initiate combustion when used in a CI engine. This energy is usually provided by a spark plug, glow plug, or pilot fuel injection $[15,16]$. In addition, NG has a higher octane number (ON) (110 - 130) compared to gasoline [17]. The higher ON and self-ignition temperature enable NG engines to run at higher compression ratios (CR), which can increase their efficiency. However, NG cannot directly replace the diesel fuel in CI engines because NG's cetane number $(\mathrm{CN})$ is lower than diesel fuels. NG can replace diesel fuel if an ignition source is added to the engine (e.g., a spark plug) or a pilot diesel fuel injection is used to initiate combustion in diesel-NG dual fuel engines. Another advantage is that NG mixes rapidly with air to form homogeneous air-fuel mixture, which results in a more efficient combustion process and a substantial reduction in harmful emissions [18]. More, NG engines can operate at higher AFRs due to the NG's lower lean limit compared to gasoline. This will increase the thermal efficiency of the engine due to increase in the ratio of specific heats for lean mixtures [19]. Table 1 shows some of the NG properties.

Table 1: Typical properties of NG [20]

\begin{tabular}{|l|l|}
\hline Ignition point & $876 \mathrm{~K}$ \\
\hline Flammability limits & $4-16 \mathrm{vol} \%$ (in air) \\
\hline Theoretical flame temperature (stoichiometric air-fuel ratio) & $2233 \mathrm{~K}$ \\
\hline Maximum flame velocity & $0.3 \mathrm{~m} / \mathrm{s}$ \\
\hline Specific gravity & 0.583 \\
\hline Water vapor content & $16-32 \mathrm{mg} / \mathrm{m}^{3}$ \\
\hline Sulfur content & $5.5 \mathrm{mg} / \mathrm{m}^{3}$ \\
\hline Higher heating value & $36-40.2 \mathrm{MJ} / \mathrm{m}^{3}$ \\
\hline
\end{tabular}

NG SI engines have the potential to reduce $\mathrm{CO}, \mathrm{CO}_{2}, \mathrm{NO}_{x}$, and non-methane hydrocarbon (NMHC) emissions compared to gasoline [21-24]. Baldassarri et al., [21] stated that NG mixes fast and homogeneously mixture with air, which avoids the creation of fuel-rich and helps reducing $\mathrm{PM}$ emissions. Their work showed that $\mathrm{THC}, \mathrm{NO}_{\mathrm{x}}$ and $\mathrm{PM}$ of $\mathrm{CNG}$ engines 
are significantly lower than diesel emissions by $67 \%, 98 \%$ and $96 \%$ respectively. King mentions that light variations in equivalence ratio can have great impact on $\mathrm{NO}_{\mathrm{x}}$ emissions [25]. Dondero and Goldemberg showed that vehicles converted to NG achieved a 53\% reduction in CO emissions, 66\% reduction in NMHC emissions, and 20\% decrease in $\mathrm{CO}_{2}$ emissions [26]. However, there was an increase in $\mathrm{HC}$ emissions by $162 \%$ and $\mathrm{NO}_{\mathrm{x}}$ emissions by $171 \%$. Mello et al. showed that converted NGV had a reduction of about $90 \%$ and $55 \%$ in CO and $\mathrm{HC}$ emissions, respectively, but they also showed a loss of 13-17\% in horsepower [27]. Several studies mentioned that methane's higher $\mathrm{H} / \mathrm{C}$ ratio compared to gasoline decreased $\mathrm{CO}_{2}$ emissions [23, 28]. McCormick et al. [29] investigated several CNG vehicles with two different compositions and found that, the fuel consumption of NGVs was equivalent to diesel on undemanding driving cycles (cycles containing frequent accelerations and halting), and exceeded the diesel fuel consumption by nearly $18 \%$ on demanding driving cycles (varying accelerations, which include highway speeds, changing acceleration rates, and significant idle time), with reduction in $\mathrm{NO}_{\mathrm{x}}$ and $\mathrm{CO}$ emissions by about $10 \%$ while idling.

\subsubsection{Effects of NG composition}

NG composition can change drastically with source/location. Specifically, NG chemical composition depends on the place of extraction, the method of refining, etc., which strongly influences the performance and emissions of an engine. The main constituent of NG is methane $\left(\mathrm{CH}_{4}\right)$, which varies from $75 \%$ to $96 \%$, with balance containing heavier hydrocarbons such as ethane $\left(\mathrm{C}_{2} \mathrm{H}_{6}\right)$, propane $\left(\mathrm{C}_{3} \mathrm{H}_{8}\right)$, butane $\left(\mathrm{C}_{4} \mathrm{H}_{10}\right)$, and inert diluents like molecular nitrogen $\left(\mathrm{N}_{2}\right)$ and $\mathrm{CO}_{2}[15-19,26,30]$. The chemical and thermodynamic properties of non-methane components of NG can strongly influence NG combustion [31]. Table 2 shows the variation of NG composition within West Virginia.

Table 2: Composition of NG in vol (\%) from different wells in West Virginia [32]

\begin{tabular}{|l|l|l|l|l|l|l|l|}
\hline County & $\mathrm{CH}_{4}(\%)$ & $\mathrm{C}_{2} \mathrm{H}_{6}(\%)$ & $\mathrm{C}_{3} \mathrm{H}_{8}(\%)$ & $\begin{array}{l}\mathrm{C}_{\mathrm{n}} \mathrm{H}_{2 \mathrm{n}+2}(\%) \\
\mathrm{n} \geq 4\end{array}$ & $\mathrm{~N}_{2}(\%)$ & $\mathrm{CO}_{2}(\%)$ & $\mathrm{H}_{2} \mathrm{~S}(\%)$ \\
\hline Mingo & 64.31 & 0.92 & 0.17 & 0.17 & 3.10 & 31.1 & 0.23 \\
\hline Wayne & 77.73 & 4.89 & 2.16 & 1.29 & 13.92 & 0.01 & - \\
\hline Boone & 84.96 & 6.00 & 1.79 & 1.33 & 0.35 & 5.57 & - \\
\hline
\end{tabular}




\begin{tabular}{|l|l|l|l|l|l|l|l|}
\hline Kanawha & 92.06 & 2.86 & 0.88 & 1.42 & 2.75 & 0.03 & - \\
\hline
\end{tabular}

\subsubsection{Effect of NG composition on engine performance}

NG composition affects engine's performance such as ignition characteristics, engine and after-treatment durability, fuel economy, engine operability and power output, etc. [33]. Chen [34] found that higher species of hydrocarbon additives can have significant impact on autoignition delay timings. Khalil and Karim [35] studied the variation in composition of NG and its influence on ignition and combustion processes. They found that a small addition of $\mathrm{n}$-heptane to methane can cause substantial changes in auto-ignition and combustion characteristics. More, the addition of ethane, propane, and n-butane to pure methane would result in shorter ignition delays [36]. However, Lamoureux and Paillard [37] showed that butane and other higher alkanes are not as effective as ethane or propane on reducing the ignition delay. In addition to the percentage of higher hydrocarbons, the amount of inert content in the gas mixture also plays a crucial role on engine performance. Higher percentages of inert constituents lead to faster flame extinction, which lowers in-cylinder peak pressures and reduce engine performance.

Various formulas are used to compare NG with different compositions. The most used are the Methane Number (MN), the Wobbe Index (WI), and the Maximum Combustion Potential (MCP).

\section{Methane Number}

The high knock resistance is a major benefit for using NG in SI engines [38]. The knock resistance is specified by $\mathrm{ON}$, while the auto-ignition propensity is measured by $\mathrm{CN}$. For gaseous fuels like NG, MN is used to indicate the knock characteristics for a given NG composition. Higher methane concentrations in NG result in a higher MN. The higher the MN, the more NG's resistance to knock, or NG is less likely to self-ignite. California Air Resource Board (CARB) proposed an equation to relate $\mathrm{MN}$ with the motor octane number (MON) [39]:

$$
M N=1.624 *\left(-406.14+508.04 *\left(\frac{H}{C}\right)-173.55 *\left(\frac{H}{C}\right)^{2}+20.17 *\left(\frac{H}{C}\right)^{3}\right)-119.1
$$


where $\mathrm{H} / \mathrm{C}$ is the ratio of reactive hydrogen atoms to carbon atoms in a mole of gas.

Equation 2.1 shows that the $\mathrm{MN}$ of a fuel decreases with the percentage increase of higher hydrocarbons like ethane or propane, decreasing the fuel's knock resistance [40]. ON is not an appropriate scale for NG, as the ON can go only up to 120 , and methane has $\mathrm{ON}$ more than 120 [41]. Unlike gasoline, NG that is available in the commercial distribution network is not typically regulated to a specific $\mathrm{MN}$, so the probability of providing a sub-optimal or even hazardous fuel to the engine is high. Besides the methane content, the proportion of inert diluents also plays a major role in affecting the knock intensity [42].

\section{Wobbe Index}

WI, a main indicator of interchangeability of gaseous fuels, compares the combustion energy output of different fuel composition [43]. If two fuels have identical WI at any given pressure, then the energy output will also be identical [15]

$$
W I=\frac{\text { heating value }}{\sqrt{\text { specific gravity }}}
$$

\section{Maximum Combustion Potential}

Min et al. [44] proposed another parameter to characterize NG composition, which they called MCP. MCP is defined as

$$
M C P=\frac{1.0 * H_{2}+0.6 *\left(C O+C_{m} H_{n}\right)+0.3 * C_{4}}{\sqrt{d}}
$$

where $\mathrm{H}_{2}, \mathrm{CO}, \mathrm{C}_{m} \mathrm{H}_{n}$, and $\mathrm{CH}_{4}$ are the respective volumetric fractions of each of these species, and $d$ represents specific gravity of fuel.

The amount of energy released by any fuel is determined by its calorific value (CV) per unit volume. For different compositions of $\mathrm{NG}$, the overall $\mathrm{CV}$ depends on the CVs of individual components, and fuels with lower CV contain more non-combustible components, which can affect the performance of an engine [45]. The quantity of nitrogen present in the fuel plays a crucial role in determining the optimum spark timing, because nitrogen can slow down the flame 
propagation [46]. The addition of higher hydrocarbons improves the CV of the mixture. Higher CV can also achieve higher power output and efficiency, at optimum spark timing.

Lee and Kim [47] studied the effect of natural gas composition on the performance and emissions on three NGVs with six different gases. Their work found that the fuel economy was proportional to the lower heating value (LHV) of the stoichiometric mixture. They also observed a difference of $25 \%$ in their results from highest to lowest fuel economy.

Kim et al. [46] found that the cylinder pressure increases proportionally with increase in WI of the fuel composition, resulting in increased power output. Min et al. [44] studied the effect of NG composition on the performance and emissions of a NG engine. This study, which tested eight different NG blends on a 1.5 L gasoline engine, found that the in-cylinder pressure $\mathrm{o}$ increases with increasing MCP of the blend. A new index was also proposed, called Total Lower Heating Value (TLHV), to determine the compatibility of NG with NG engines. Feist et al. [33] observed that the power output of lean-burn gas engines increased with increasing WI and decreasing MN, but no specific trend was established for a stoichiometric engine. Furthermore, the lower WI fuels (i.e., fuels with higher concentrations of diluents) slowed down and cooled the combustion process, while the fuels with lower MN had higher flame speed, thereby causing higher in-cylinder temperatures.

McTaggart et al. [41] experimented with three different NG compositions. He observed that the density of the composition increases as methane was replaced with heavier hydrocarbons. As a result, more fuel mass was injected for a constant injection duration, which increased the chemical energy injected every cycle. This increases the peak combustion pressure and the heat release rate (HRR).

Operating at an optimum spark timing can improve the engine combustion characteristics. The optimum spark timing of an engine is usually the spark timing at which the maximum brake torque (MBT) is achieved. As methane is the main NG component, its percentage usually dictates the optimal spark timing. With methane burning slower than any other hydrocarbon species, the spark advancing increases with increasing $\mathrm{MN}$, which can produce less engine power. Bosschaart and de Goey [48] found that the flame speeds increased from methane to butane to propane to ethane. Ranzi et al. [49] found a similar relationship with 
ethane having the highest and methane having the slowest flame speed at constant temperature, and propane having higher flame speeds that iso- and n-butane. Dirrenberger et al. [50] work supports these findings, showing that ethane burns faster than propane, which burned faster than butane and methane.

The addition of higher hydrocarbons to methane increases the flame speed and reduces the overall combustion duration. For example, Kochar et al. [51] showed that the addition of ethane or propane to methane improves the laminar flame speed. Shock-tube experiments by ElSherif [52] yielded similar results. This study found that higher ethane concentrations increased the burning velocity due to formation of enhanced radicals and more hydrogen particles that accelerated the combustion process. Amirante et al. showed that even small amounts of propane added to methane produced a more stable combustion process compared to methane only [53]. Dirrenberger et al. [50] tested three blends that represented NG produced in different places in the world: Abu Dhabi (15.86\% ethane, 1.89\% propane), Pittsburgh (14\% ethane), and Indonesia (5.44\% ethane, $3.16 \%$ propane). This work found that the gas representing Abu Dhabi had the highest laminar flame velocity due to its highest percentage of ethane. Next highest was the gas from Pittsburgh and the lowest was the gas from Indonesia. Kayadelen [54] found that addition of lower $\mathrm{H} / \mathrm{C}$ ratio compounds like ethane, propane or iso-butane will increase the adiabatic flame temperature, whereas diluents like $\mathrm{CO}_{2}$ and $\mathrm{N}_{2}$ decreases the flame temperature.

Karim and Wierzba [55] showed that as the percentage of propane by volume increased in the fuel composition, the combustion time decreased, leading to lower ignition delays and higher cylinder pressures. Pure methane had the longest combustion duration, and adding a small percentage of propane altered the combustion drastically, including speeding up the combustion process. Spadaccini and Colket [56] found that addition of heavier hydrocarbons to methane had shortened the ignition delay times, with butane being more effective compared to ethane or propane.

Varying the composition of NG can produce significant effects on the fuel stoichiometry [57]. The associated change in equivalence ratio of the mixture will affect both the engine performance and emissions. Increasing the equivalence ratio, $\phi$, produces higher in-cylinder pressures, which increases the products temperature. While the highest temperature is obtained 
with stoichiometric mixtures, this also increases $\mathrm{NO}_{\mathrm{x}}$ emissions, due to higher cylinder temperatures.

\subsubsection{Effect of composition on emissions}

MN and WI are the two primary factors that influence emissions. As the concentration of heavier hydrocarbons increases, the $\mathrm{H} / \mathrm{C}$ ratio decreases, subsequently producing higher $\mathrm{CO}_{2}$ emissions [28]. Crookes [58] found that adding $\mathrm{CO}_{2}$ and $\mathrm{N}_{2}$ to the fuel reduces $\mathrm{NO}_{\mathrm{x}}$ formation, but have a great influence on engine performance. Therefore, fuels with higher concentrations of inert diluents will tend to produce lower $\mathrm{NO}_{\mathrm{x}}$ emissions, but would have negative impact on performance of the engine. Jahirul et al. [23] and Karavalakis et al. [59] showed higher $\mathrm{NO}_{\mathrm{x}}$ emissions associated with an increase in WI or decrease in MN. Higher hydrocarbons increased the flame speed, thereby increasing the cylinder temperatures and forming more $\mathrm{NO}_{\mathrm{x}}$ emissions. Feist et al. [33] found that higher percentages of ethane or propane reduced the MN and increased flame speed, producing more $\mathrm{NO}_{\mathrm{x}}$ emissions. El-Sherif [52] conducted experiments with four different NG blends and found that as the concentration of ethane increased, the $\mathrm{NO}_{\mathrm{x}}$ formation also increased. Hajbabaei et al. [60] tested six different NG blends on lean burn and stoichiometric engines and found that lower $\mathrm{MN}$ fuels produced more $\mathrm{NO}_{\mathrm{x}}$ emissions under lean burn conditions, but there was no clear trend for $\mathrm{NO}_{\mathrm{x}}$ emissions with changes in fuel composition when the engines operated close to stoichiometric conditions. Extended studies by Karavalakis et al. [61] on stoichiometric engines showed that $\mathrm{NO}_{\mathrm{x}}$ emissions decreased with decreasing $\mathrm{MN}$, which was opposite to the lean-burn trend. Their study on a transit buses using five different NG blends concluded that $\mathrm{NO}_{\mathrm{x}}$ emissions increased with increasing WI [62]. However, in another study that tested two NGVs and four different $\mathrm{NG}$ blends the authors found that $\mathrm{NO}_{\mathrm{x}}$ emissions increased with increasing WI for one vehicle, but there was no significant influence of fuels WI

on the second vehicle [28]. Min et al. [44] tested eight NG blends on a 1.5 L gasoline engine, and found higher $\mathrm{NO}_{\mathrm{x}}$ emissions with increased WI.

Karavalakis et al. [59] conducted tests on a waste hauler truck equipped with 2001 Cummins 8.3 L - C Gas plus engine, with seven different NG blends. They found that the NGs with high levels of higher hydrocarbons or low $\mathrm{H} / \mathrm{C}$ ratios produced higher $\mathrm{CO}_{2}$ emissions during high loads, and had exactly the opposite trend on low load conditions. However, Crawford et al. 
[39] did not find a linear relationship between $\mathrm{MN}$ and $\mathrm{CO}_{2}$ emissions. Jahirul et al. [23] found that as the engine speed increases, the fuel conversion efficiency also increases, thereby producing more $\mathrm{CO}_{2}$ emissions and less THC emissions.

$\mathrm{HC}$ emissions for $\mathrm{NG}$ mostly consists of unburned $\mathrm{CH}_{4}$. As a result, $\mathrm{NG}$ with lower $\mathrm{MN}$ produces lower $\mathrm{HC}$ emissions $[39,59]$. Methane is a strong GHG, more powerful than $\mathrm{CO}_{2}$. This is why methane slip (i.e., the emissions of non-combusted methane) has become a topic of concern for NG engines, particularly for the lean-burn SI engines [61]. Feist et al. [33] suggests that fuels with lower MN produces higher cylinder temperatures, thereby causing more oxidation of fuel, which reduced HC emissions. Similarly, Karavalakis et al. [62] showed that NG with lower MN produces higher combustion temperatures, due to higher adiabatic flame temperature. Min et al. [63] tested six different gases on a 1.5 L gasoline engine with modified pistons and found that the amount of HC decreases with increase in WI of the mixture. Since methane is less reactive than higher hydrocarbons [62, 64], higher MN fuels produce high HC emissions [53]. However, Caillol et al. [65] observed a different trend, which was that HC emissions increased with decrease in $\mathrm{MN}$, as the mixture reached lean limits. The authors explained this phenomenon by the flame extinction in the combustion chamber when running lean with low MN fuels. NG with higher concentrations of heavier hydrocarbons has a higher heating values, and THC emissions are generally inversely proportional to heating values. THC emissions decreased with increase in heating values of the mixture [14].

$\mathrm{CO}$ emissions generally decreased with increasing $\mathrm{MN}$ [28, 39]. Amirante et al. [53] found that $\mathrm{CO}$ formation increased for higher concentrations of heavier hydrocarbons in the composition, which suggested that $\mathrm{CO}$ emissions increased with increasing percentage of higher hydrocarbons or decreasing MN. Karavalakis et al. [62] found that $\mathrm{CO}$ emissions increased with decreasing $\mathrm{MN}$ because the fuels with higher $\mathrm{MN}$ had higher octane rating, and hence can achieve more efficient combustion, which reduced $\mathrm{CO}$ emissions. Graboski et al. [14] tested a Cummins B 5.9 G engine with five different NG test fuels at varying altitudes, and found that $\mathrm{CO}$ emissions were independent of composition. However, $\mathrm{HC}$ and $\mathrm{NO}_{\mathrm{x}}$ emissions increased as the heating value of the fuel increased. 


\section{Experimental Setup}

The experiments were conducted at West Virginia University's - Advanced Combustion Laboratory (ACL), which is a part of the Center for Alternative Fuels, Engines and Emissions (CAFEE). This section describes the engine and its various accessories, and the systems used to control the experiments and collect the data.

\subsection{Test Engine}

The experiments were performed in a single-cylinder, four-stroke, port fuel injection, heavy-duty SI engine (Ricardo/Cussons, U.K., Model: Proteus). The original supercharged, direct injection engine configuration (Volvo, Model: TD 120) was converted to a SI engine by replacing the main injector with a spark plug (Stitt, U.S., Model: S-RSGN40XLBEX8.4-2). The engine can be run in two modes - metal configuration and optical configuration. The metal configuration was selected for this investigation, because continuous engine operation can destroy the quartz window on the piston, leading to catastrophic failure of the engine. The metal engine has a classic toroidal bowl-in piston with swirl-producing intake ports. Swirl causes a rotational motion of the air-fuel mixture in the cylinder, which increases turbulence and the burning rate of the mixture [66]. In-cylinder pressure data was collected using a pressure transducer (Kistler, Model: 6011), which was mounted in the glow plug using a special outer sleeve. A charge amplifier (Kistler, Model: 5010) amplified the signal produced by the pressure transducer to a 0-10 V signal, which can be calibrated to bars/volt. More details about the engine geometry is given in Table 3. The engine test cell is shown in Figure 3.

Table 3: Engine specifications

\begin{tabular}{|l|l|}
\hline Number of cylinders & 1 \\
\hline Displaced volume & $1997 \mathrm{cc}$ \\
\hline Bore x Stroke & $130.2 \mathrm{~mm}$ x 150 mm \\
\hline Compression ratio & $13.3: 1$ \\
\hline Fuel injection type / \# of injectors & Port injection / 1 \\
\hline Injector make and model & Rail IG7 Navajo \\
\hline Nozzle diameter & $3.5 \mathrm{~mm}$ \\
\hline Injection Pressure & $35 \mathrm{psi}$ \\
\hline
\end{tabular}




\begin{tabular}{|l|l|}
\hline Number of spark plugs & 1 \\
\hline Inlet valve opens & $12^{\circ} \mathrm{bTDC}$ \\
\hline Inlet valve closes & $40^{\circ} \mathrm{aBDC}$ \\
\hline Exhaust valve opens & $54^{\circ} \mathrm{bBDC}$ \\
\hline Exhaust valve closes & $10^{\circ} \mathrm{aTDC}$ \\
\hline
\end{tabular}

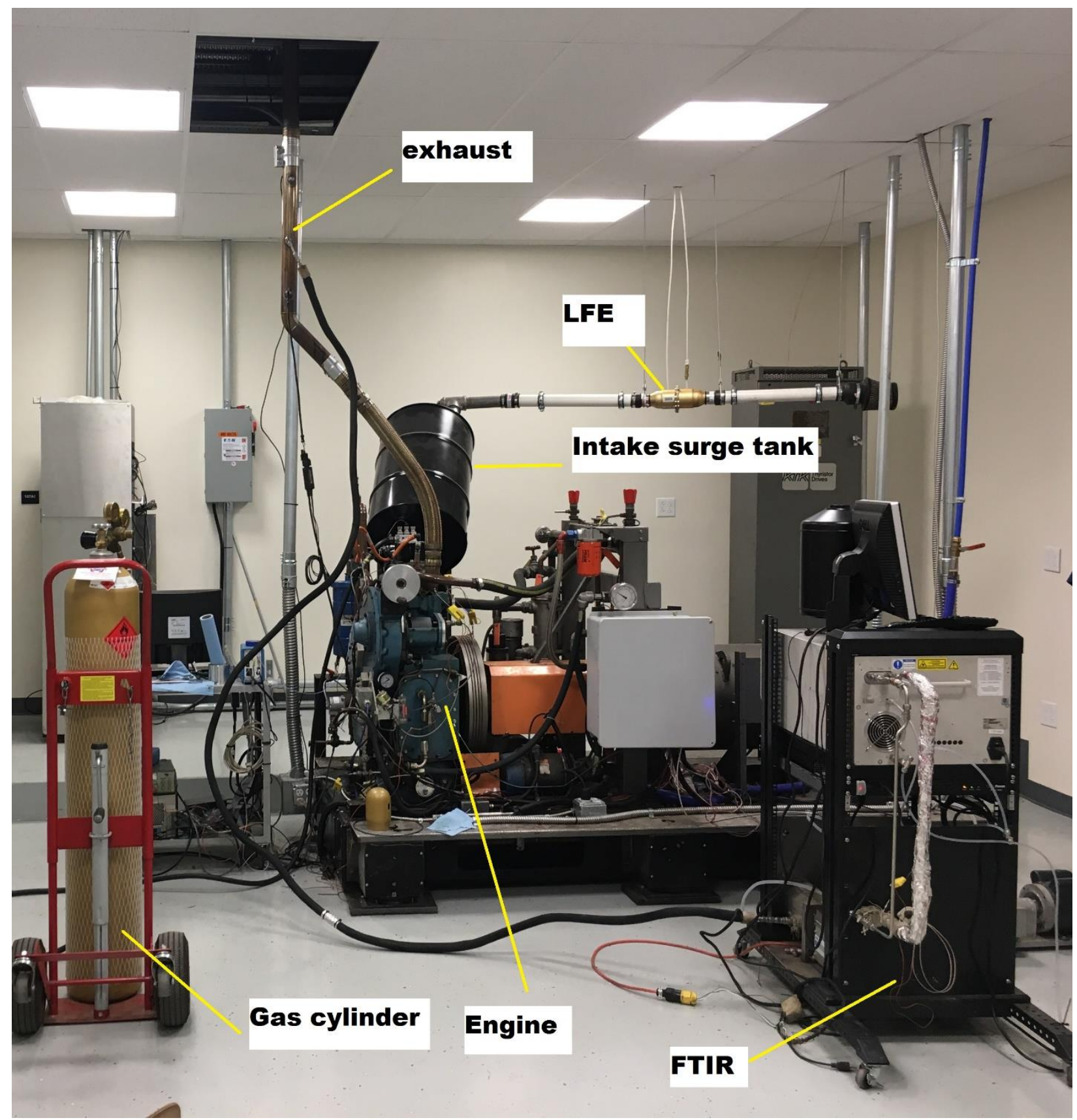

Figure 3: Engine test cell 


\subsubsection{Intake system}

Filtered intake air passed through a laminar flow element (LFE) (Meriam, U.S., Model: Z50MC2-2). This LFE can measure a maximum flow rate of 100 SCFM at a differential pressure of 8 inches of water. To calculate the air volumetric flow rate, the LFE uses two ports which are connected to differential and absolute pressure sensors. A thermocouple is mounted at 2 pipediameters upstream of the LFE to correct for variations in air density. The volumetric flow rate (Q) is given by the equation 3.1:

$$
Q=(B * D P)+\left(C * D P^{2}\right)
$$

where $B, C$ are calibration constants that are specified by the manufacturer, and $D P$ is the measured differential pressure

The corrected volumetric flow rate is calculated by multiplying equation 3.1 with the viscosity correction factor

$$
Q_{\text {corrected }}=\left[(B * D P)+\left(C * D P^{2}\right)\right] *\left(\frac{\mu_{s t d}}{\mu_{f}}\right)
$$

where $\mu_{\text {std }}$ and $\mu_{f}$ are the viscosities of flowing gas at $70^{\circ} \mathrm{F}$ and at flowing temperature, respectively. Equation 3.3 converts SCFM to CFM.

$$
Q=\left[(B * D P)+\left(C * D P^{2}\right)\right] *\left(\frac{\mu_{s t d}}{\mu_{f}}\right) *\left(\frac{T_{s t d}}{T_{f}}\right) *\left(\frac{P_{s t d}}{P_{f}}\right)
$$

where, $T_{s t d}$ and $P_{\text {std }}$ are the standard temperature and pressure, respectively, and, $T_{f}$ and $P_{f}$ are the temperature and pressure of flowing gas, respectively.

Figure 4 show the air intake system. An intake air surge tank was installed after LFE to dampen the pressure pulsations caused by single-cylinder cyclic intake valve opening and closing. Since pressure fluctuations have a negative effect of air flow rate, dampening these perturbations was necessary. Previous studies on this engine without and with surge tank, has proved that adding it can greatly influence the LFE air flow measurements and the air flow into 
the cylinder. Hence, a tank of volume 55 gallons, was installed before the intake port to deliver smooth air flow to the engine.

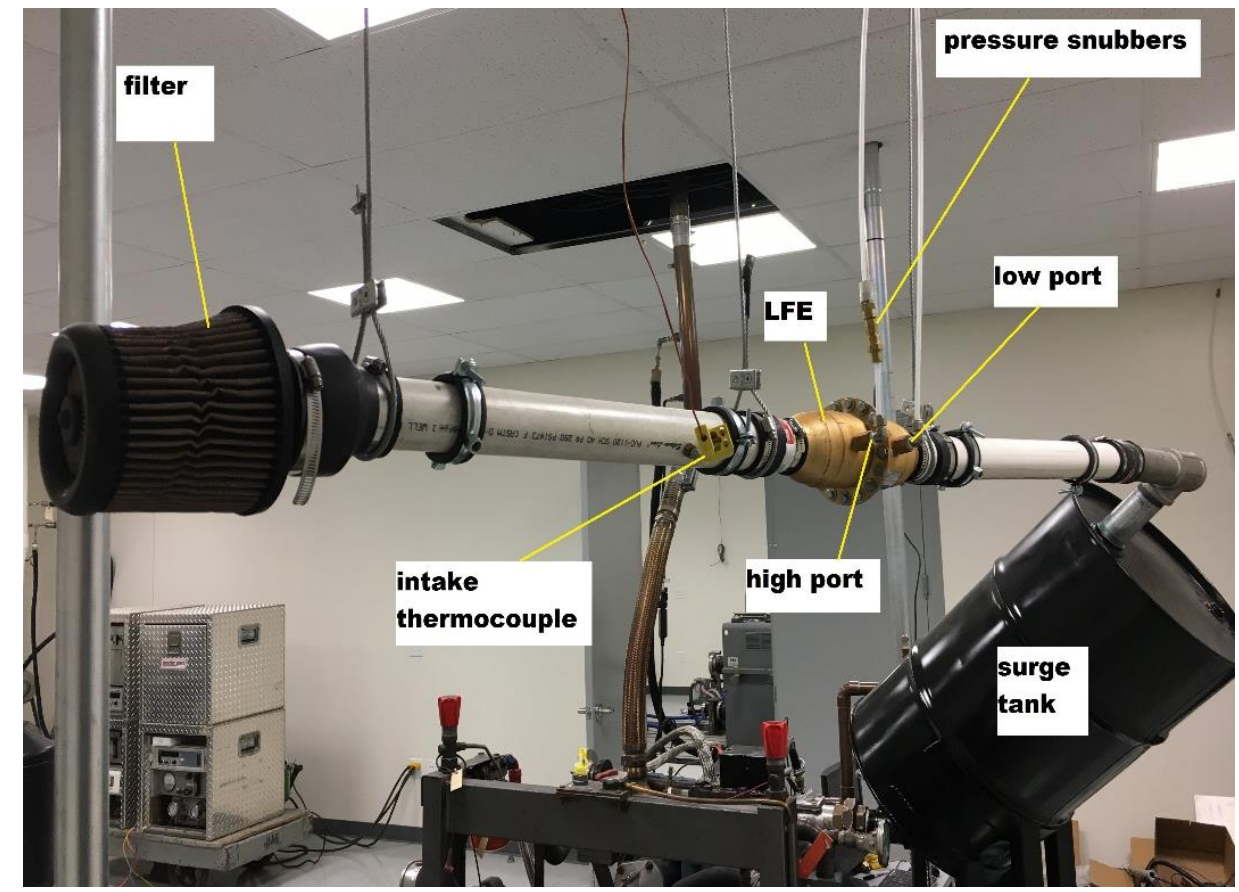

Figure 4: Air intake system

\subsubsection{Cooling and lubrication system}

\subsubsection{Cooling system}

Engine cooling is achieved by a closed system consisting of a pressurized header tank, coolant flow meter, coolant heater and coolant heat exchanger. A 1:1 mixture of demineralized water and commercial anti-freeze is used as coolant for this engine. The header tank is a structure formed from rectangular steel tube constructed as an ' $\mathrm{H}$ ' frame. A low-level coolant sensor and a filler cap with integrated pressure relief valve ( $7 \mathrm{psig}$ ) control the coolant level and pressure inside the header tank. The coolant pump (Boss, Model: BK2507/10B) draws coolant from the bottom of the header tank at 2,850 RPM and supplies it to the cylinder jackets via a coolant heat exchanger. A 6-kW heater is used to rapidly increase the coolant temperature before engine tests. Such approach minimizes engine losses and cold start emissions. Several thermocouples read the coolant temperature before and after exiting the engine, with the readings distributed to main controlling console and to the DAQ system. 


\subsubsection{Lubrication system}

The lubrication system consists of an oil sump or oil reservoir, oil heater, oil pump and oil heat exchanger. Oil is drawn from the crankcase by an electrically actuated oil pump (Brook Crompton Parkinson Motors) that runs at 1120 RPM. The oil is delivered to the oil heat exchanger where is cooled down, then passed through an oil filter before feeding it to the engine. The oil pressure is controlled to 4 bar by a relief valve at the oil distribution manifold. From the manifold, the oil under pressure is supplied to the main bearings, big end bearing, camshaft bearings and cylinder head. The engine sump also has two $1 \frac{1}{2} \mathrm{~kW}$ electrical heaters to rapidly increase oil temperature to optimum conditions. A pressure gage and several thermocouples are providing oil pressure and temperature to the control console and DAQ system.

\subsubsection{Dynamometer}

A 75 kW DC electrical dynamometer (McClure, Model: 4999, Trunnion type), rated at $420 \mathrm{~V}$ and $160 \mathrm{~A}$, controls the engine speed regardless of the engine load, as shown in Figure 5. A 100-kg load cell (Tedea-Huntleigh, Model: 104H) measures the torque applied on the dynamometer using a Wheatstone bridge. Figure 6 and Figure 7 show the strain gage connection and the weigh setup used to load cell signal. Most load cells follow a standard revised wiring code established by Western Regional Strain Gage Committee in May 1960 [67], which is shown in Figure 8.

The electrical signal from the load cell is changed to a continuous display of torque in $\mathrm{Nm}$ on the control console, as seen in Figure 9. The arm radius on the dynamometer has a fixed length, such that each $20-\mathrm{kg}$ calibration mass is equivalent to $80 \mathrm{Nm}$ of torque, and a maximum load of 5 x $20 \mathrm{~kg}$ calibrated masses can be achieved. The dynamometer is forced ventilated by an electrical fan mounted on the base frame adjacent to dynamometer. The dynamometer is operated through a thyristor bank (KTK, Model: 6P4Q75). The dynamometer acts as DC motor to drive the engine during starting and motoring conditions and as a DC generator engine produces power. 


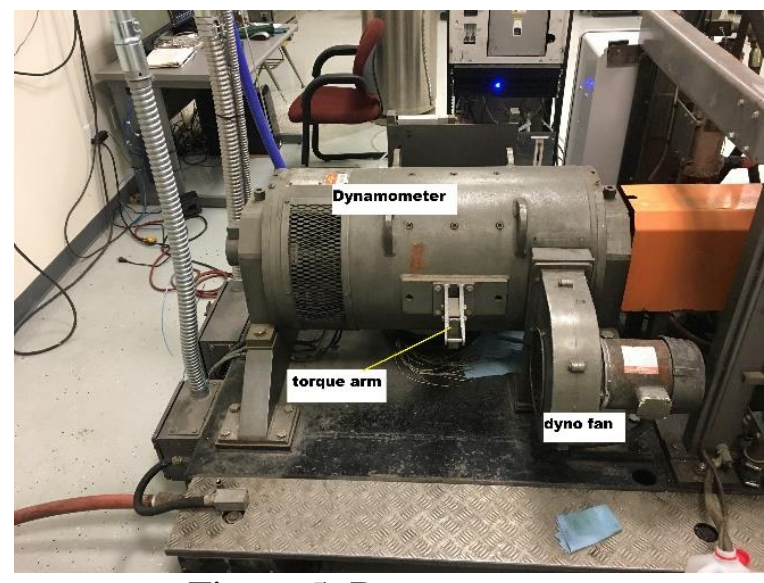

Figure 5: Dynamometer

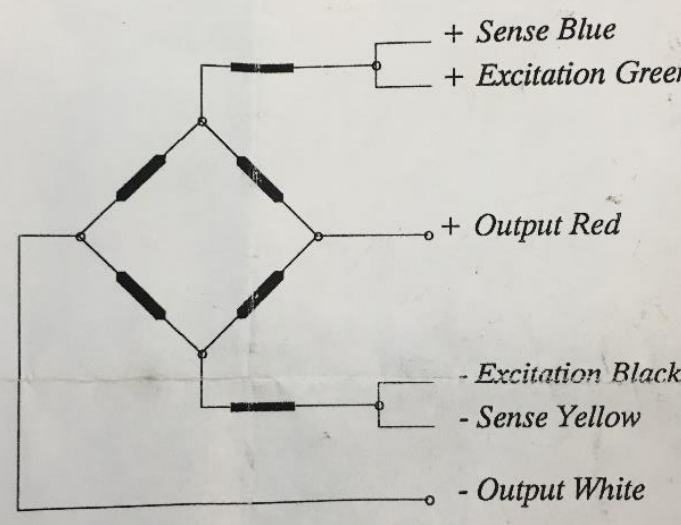

Figure 6: Wiring code for Tedea-Huntleigh model $104 \mathrm{H}$

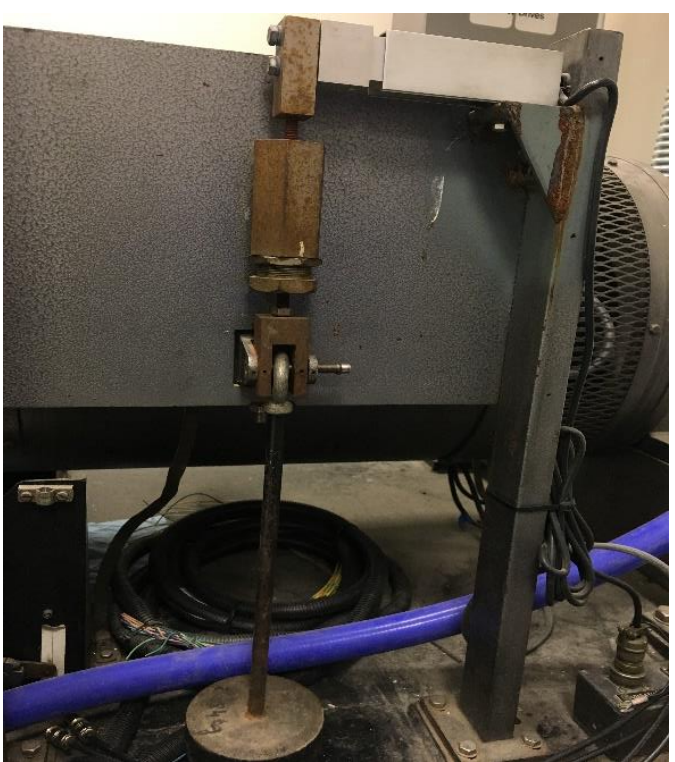

Figure 7: Load cell with hanger

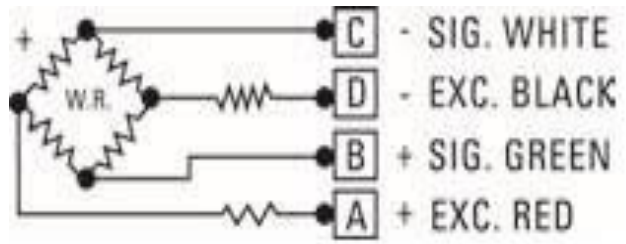

Figure 8: Standard wiring color code

\subsubsection{Engine and dynamometer control console}

Engine and dynamometer control console is divided into three racks: the signal conditioning rack, the dynamometer and speed control unit, and the safety shutdown unit (SSU).

The signal conditioning rack consists of electronic systems which operate in conjunction with engine and dynamometer sensors to provide conditioned and amplified signals to the two analog and digital meters that display engine torque and speed.

The central section consists of speed and dynamometer controls. The dyno control unit has a mode selector switch and start and stop buttons. The mode selector switch can be used to select one of the three modes: START/AUTO, ABSORB and MOTOR. START/AUTO mode is the engine starting position, and the dyno automatically switches from motor to load and vice 
versa to maintain speed setting. In MOTOR mode, the dyno only motors the engine, and in ABSORB mode, the dyno only absorbs the power generated from engine firing. The engine doesn't turn on just by pushing the START button. The dyno fan should be on, SSU should be reset and coolant pump should be running, to run the engine. The speed control unit consists of a 0 to 10 multi-turn dial to set the required speed, and an EMERGENCY STOP push button.

The bottom rack is the SSU. This unit is designed to trip the control system if there is any fault, thereby protecting the engine. There are several fault indicators such as the emergency stop, dyno fault, under speed, over speed, oil pressure low, etc. The system will be tripped if any fault indicators is on. Apart from the SSU, the rack also has coolant and oil temperature indicators, and engine auxiliaries like control switches for pumps and heaters.

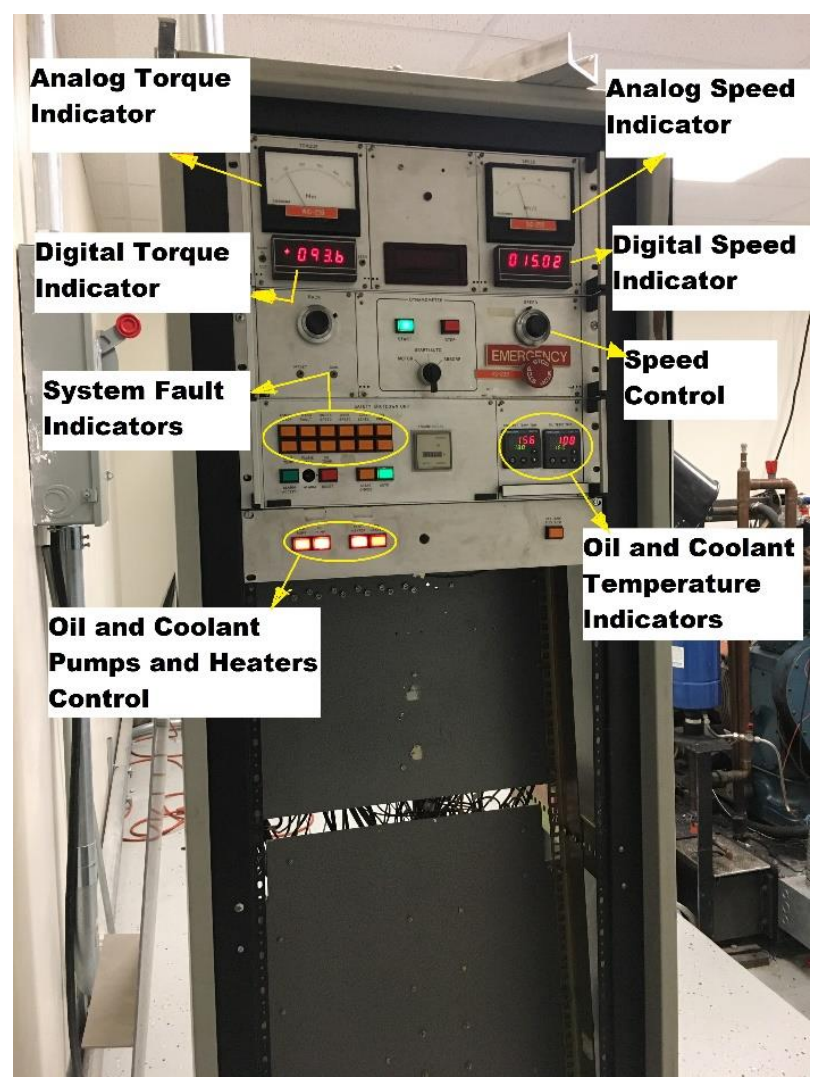

Figure 9: Engine control console

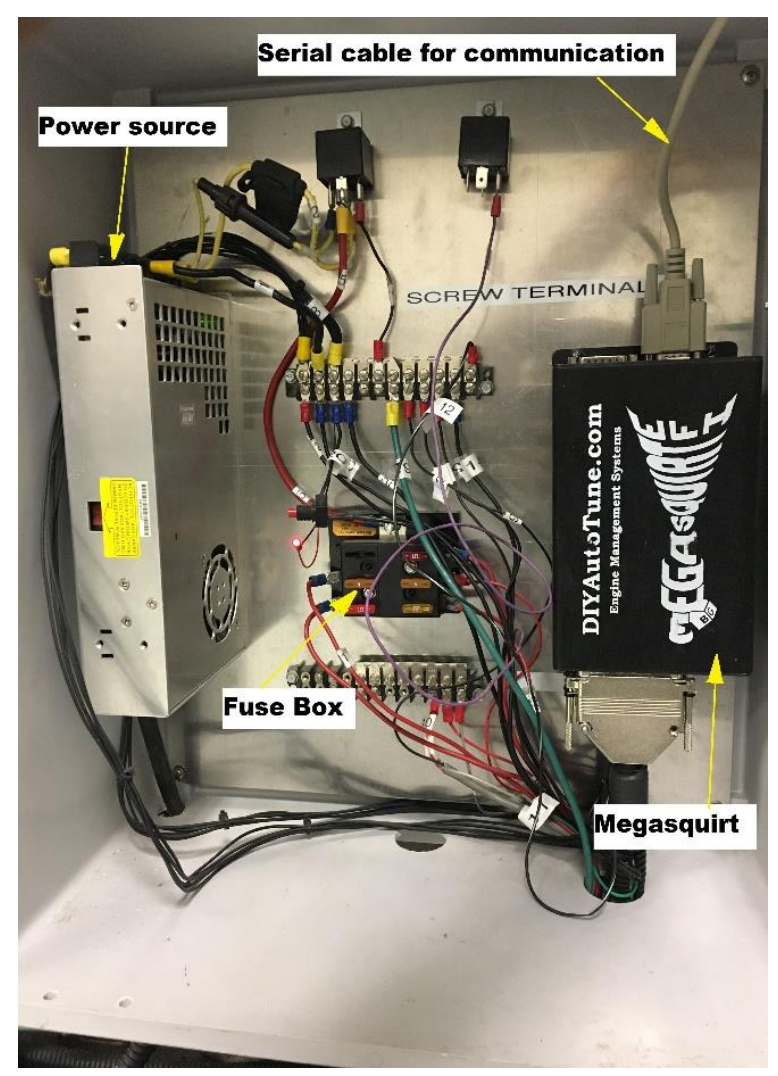

Figure 10: Engine Control Unit 


\subsubsection{Engine control unit}

The Engine Control Unit (ECU; Megasquirt, Model: V3.0 mainboard with MS3X expansion) controls the fuel and spark timings, mass of fuel injected, and several other engine parameters, based on inputs like the position of crankshaft and camshaft, amount of intake air, intake air temperature, coolant temperature, and throttle position. The main ECU board features four injector bank outputs, crank sensor input, coolant temperature sensor input, throttle position sensor input, and oxygen sensor input. The expansion board can support up to 8 high-current injector driver outputs, 8 logic-level spark outputs, 3 analog inputs $(0-5 \mathrm{~V}), 6$ medium level current outputs, 4 switch outputs and a cam sensor input. The ECU is connected to the computer via Ethernet cable or through a serial cable. Specialized software (TunerStudio, Version: 3.0.28) uses many built-in algorithms to determine the correct operating parameters such as, spark timing, injection duration, dwell time for spark, etc. that are then passed to the ECU. For example, there are several control algorithms for calculating the air flow in to the engine [68], such as Speed-Density method, Alpha-N method, Independent Throttle Bodies (ITB) and \%baro mode.

Speed-Density uses manifold absolute pressure (MAP) sensor to determine load and an appropriate value from the fuel table is selected. Another method for determining the amount of fuel required is Alpha-N mode. This method uses a throttle position sensor (TPS) to estimate the amount of air flow to the engine. This method can be useful when there is no availability of MAP sensor. The latter method was employed for this engine, as there is no MAP equipped to the engine. ITB mode combines both Speed-Density (at low engine speeds) and Alpha-N (at high engine loads) for better controlling at given engine load.

The inputs for ECU are intake air temperature, coolant temperature, throttle position, and crankshaft and camshaft position sensors. All sensors, except TPS, provide real time data to the board. TPS is simulated by a three-wire potentiometer. Changing the resistance of the potentiometer changes the signal output. Megasquirt converts this potentiometer signal on a 0 $100 \%$ scale, where $0 \%$ representing fully closed and $100 \%$ representing fully open throttle positions. Based on these inputs and tables (Fuel VE table and Ignition table), ECU calculates 
the spark timing and amount of fuel required. TunerStudio includes an output test mode, where spark and injectors can be tested for their functionality without running the engine.

The engine flywheel has 100 equidistant teeth distributed around its periphery, each tooth representing a $3.6^{\circ}$ crankshaft rotation. A Variable Reluctance (VR) transducer, seen in Figure 11 , is mounted on a bracket off the crankcase to read these teeth and determine the angular position of the crankshaft. The VR sensor works on the principle that magnetic flux is generated when target element passes by the coil. As the target element moves closer to the sensor, the flux intensity increases, and decreases when it is moving away. This flux variation induces a proportional voltage change in the coil, which is then sent to the ECU. A Hall Effect sensor, shown in Figure 12, is mounted high up on the crankcase and turned by the crankshaft using a spur gear train. The Hall Effect transducer which works on the same principle as VR sensors, determines the cam position at any instant, but unlike VR sensors, the Hall Effect sensor can also measure at slow speeds. Most of the Hall Effect sensors produce digital output signals, whereas an extra electronic circuitry is needed to convert the analog signal produced by VR sensor to digital output. Continuous data transmission is done from these sensors to the ECU to calculate engine speed and position relative to the dead center.

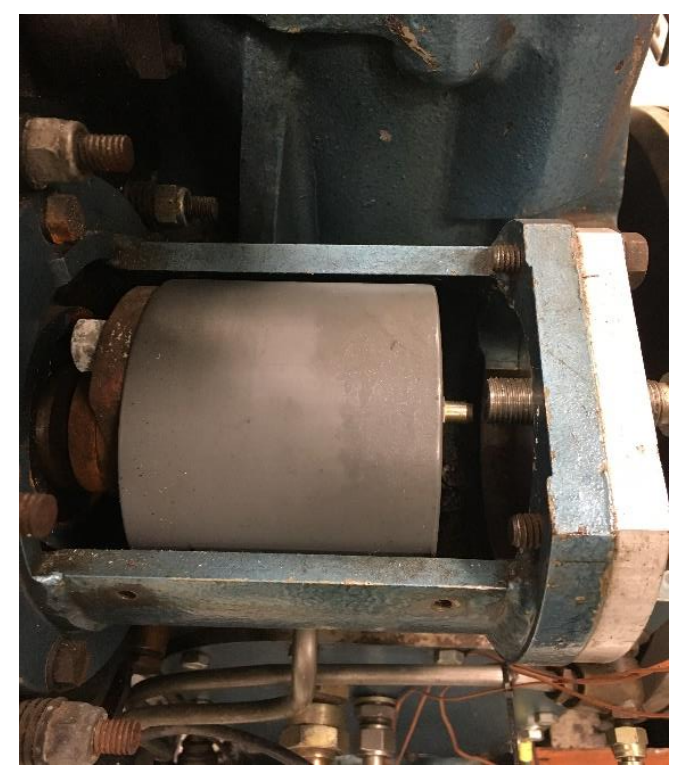

Figure 11: Cam position sensor (Hall Effect Sensor)

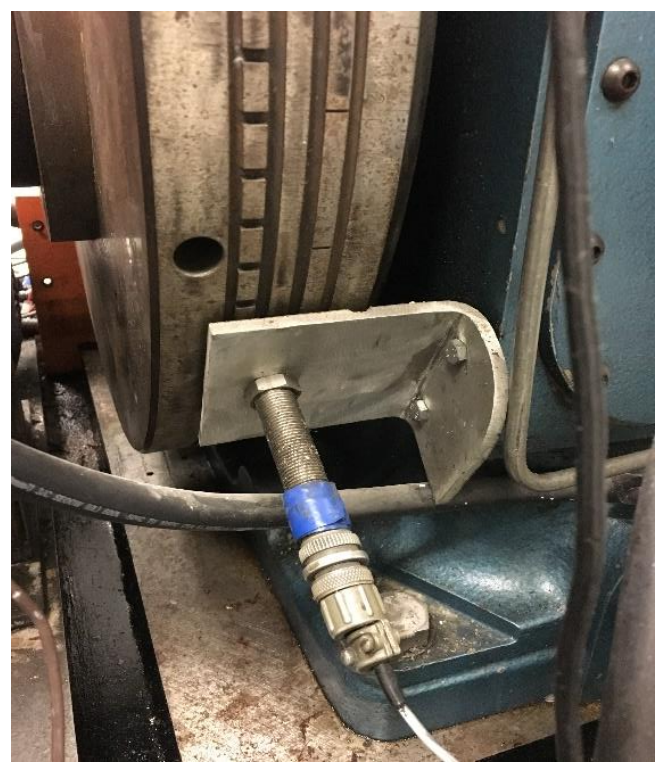

Figure 12: Crank position sensor (VR sensor) 


\subsubsection{Fuel system}

The fuel system consists of a gas cylinder, a pressure regulator and CNG fuel injectors (Rail Spa, Italy, Model: IG7 Navajo). The response of these injectors is very linear, and the noise levels while operating are below $67 \mathrm{~dB}$, as specified by the manufacturer. Gas is drawn from the gas cylinder through a pressure regulator and injected through the injectors mentioned above. Though these injectors have 3 seats, with each seat having a $3.5 \mathrm{~mm}$ diameter nozzle, only one seat was used for this study. More specifications of the fuel injector are given in Table 4.

Table 4: Fuel injector characteristics

\begin{tabular}{|l|l|l|}
\hline Characteristic & Unit & Value \\
\hline Pressure & psi & $7-43$ \\
\hline Rated voltage (at coil) & volt & $10.8-14.4$ \\
\hline Resistance & ohm & 2 \\
\hline Suggested peak current time & $\mathrm{ms}$ & 3.0 \\
\hline Suggested holding current & $\mathrm{A}$ & $1.6( \pm 10 \%)$ \\
\hline Complete opening/closing response time & $\mathrm{ms}$ & $1.9 / 1.4$ \\
\hline Nozzle diameter & $\mathrm{mm}$ & 3.5 \\
\hline Calculated max flow rate & Kg/h & $9.8 @ 2$ bar inlet P \\
& & 13 @ bar inlet P \\
\hline Leakage (with air) & Cc/h & $\leq 15$ \\
\hline Driver stage & Peak and Hold (PWM) & \\
\hline
\end{tabular}

The injector manufacturer provided flow rate charts of the injector at various operating pressures and speeds for 4 seats, is shown in Figure 13. Since only one seat was being used in this investigation, the flow rate has been divided by a factor of 4 . 

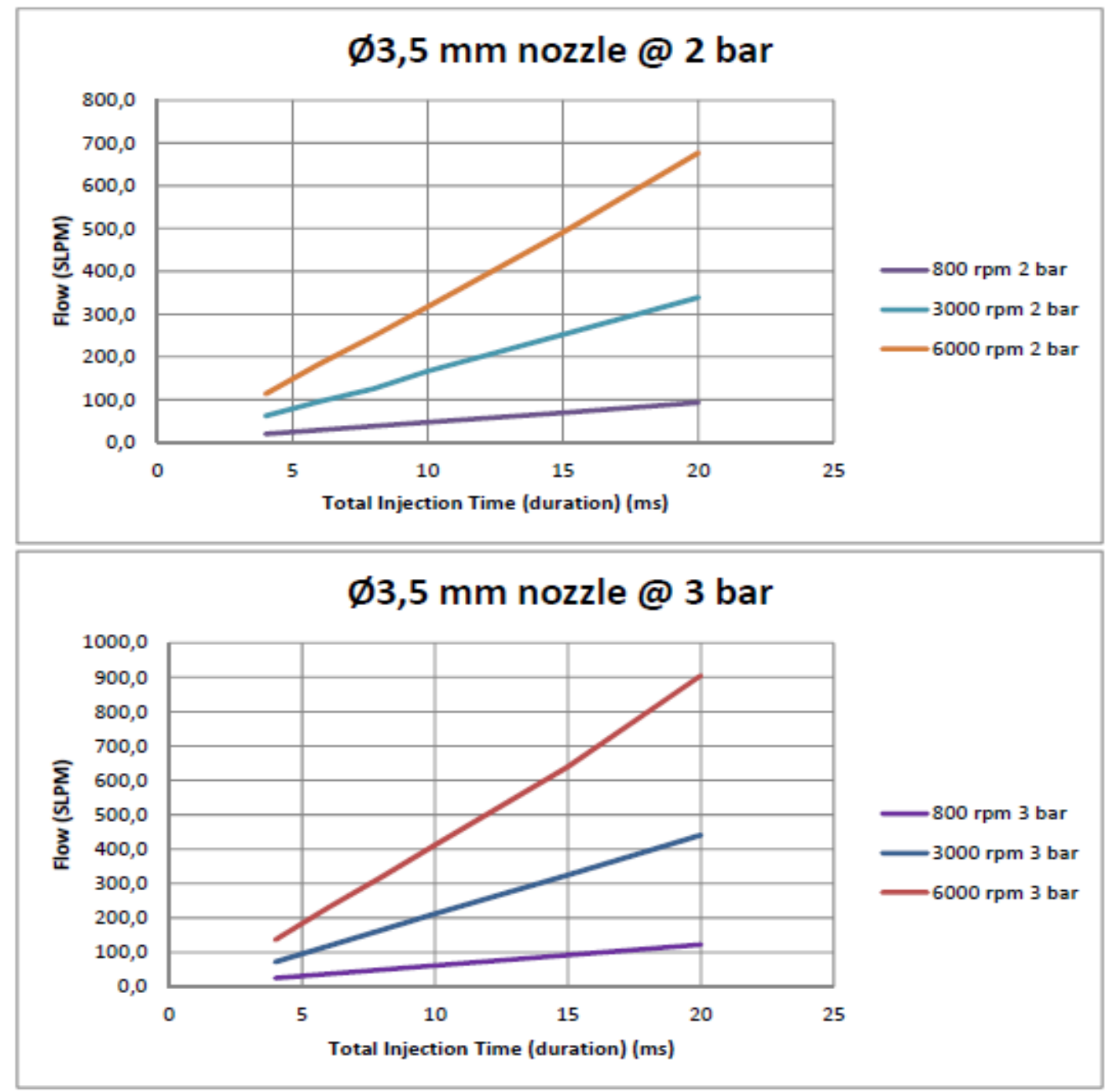

Figure 13: Flow rate of injectors

\subsection{Data acquisition}

Several data acquisition systems (DAQ) collected in-cylinder pressure data, air flow arte, coolant and oil temperatures, engine torque, speed, etc. An in-house built DAQ software (Scimitar) was used to centralize data from different DAQ systems. This program used a $10-\mathrm{Hz}$ data recorder, which is compatible with most of the DAQ devices such as LabJack, ICP DAS, emission analyzers, etc.

LabJack (Model: UE9) and ICP DAS (Model: PET7019Z) are analog to digital converters that acts as the hardware interface for engine data collection. The outputs from the load cell and LFE's two pressure transducers, shown in Figure 14 (differential pressure 
transducer (Ashcroft, Model: XLdc) and absolute pressure transducer (GP 50, Model: 211), were connected to the LabJack, while all thermocouples were connected to ICP DAS, as seen in Figure 15. Scimitar reads the voltages from these two DAQ devices and calibrated them on a suitable scale to produce proportional signals. The most commonly used thermocouples in this system were k-type thermocouples, due to their wide range of temperature measurement $\left(-200^{\circ} \mathrm{C}\right.$ to $1260^{\circ} \mathrm{C}$ ) and cost effectiveness.

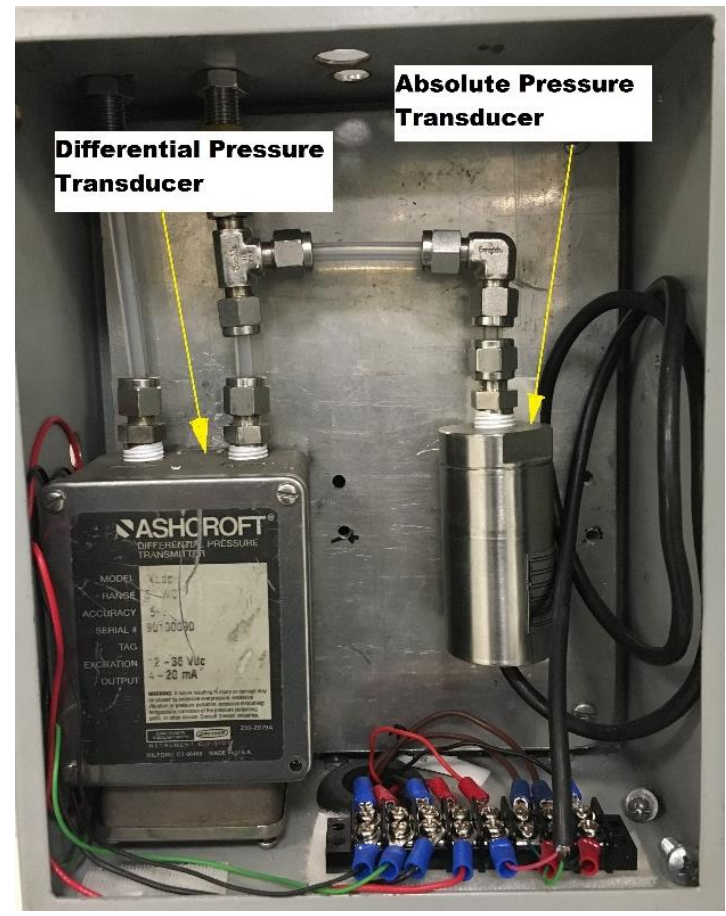

Figure 14: Pressure transducers

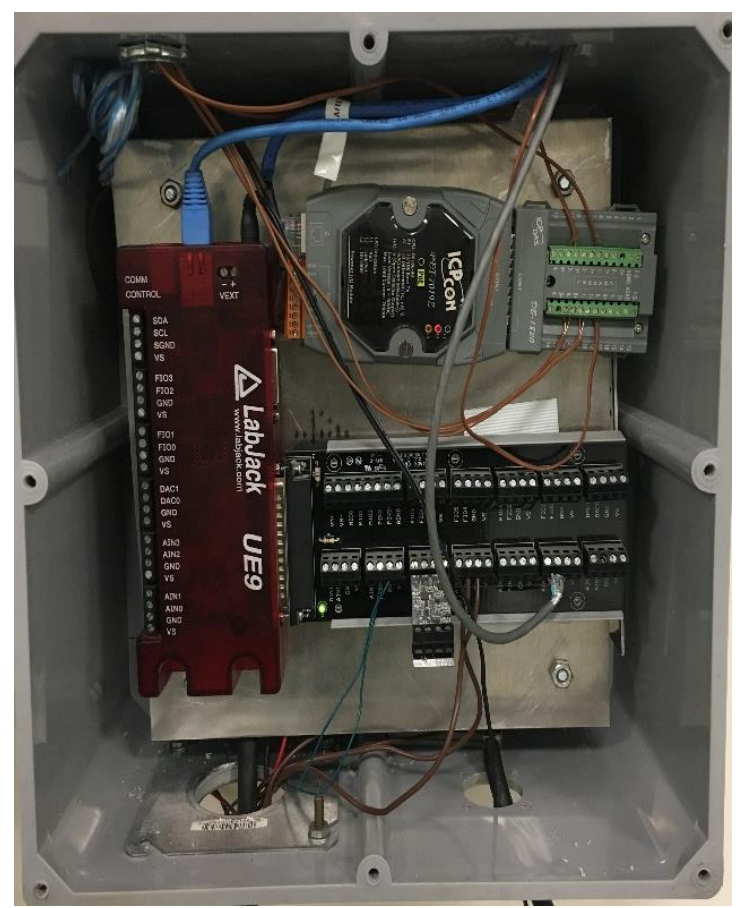

Figure 15: DAQ system

A piezoelectric pressure transducer (Kistler, Model: 6011) measured in-cylinder pressure. Piezoelectricity is defined as linear electromechanical interaction in a material having no center of symmetry [67]. In other words, when an external load or stress is applied on a piezoelectric material, electrical charge or signal is produced. The transducer signal is very small that it cannot be identified directly by the data acquisition system. Therefore, the signal is conditioned through a charge amplifier (Kistler, Model: 5010), where the signal is amplified in to a 0-10 V signal. This is then transmitted to a DAQ card (National Instruments, Model: SCB-68A). An incremental rotary shaft encoder (BEI sensors, Model: H25D, Resolution: 1800) is used to measure engine speed and determine the crankshaft position at any instant. 
In addition to pressure and speed signals, intake and exhaust temperatures are also required by the NI DAQ card to analyze the pressure data. This DAQ card is connected to NI PCIe-6351 on the pressure analysis computer. An in-house built software, developed by WVU CAFEE, process the pressure data into usable combustion information. Post processing the data in Matlab can provide all the additional information required such as rate of pressure rise, heat release rate, etc.

\subsection{Test conditions}

A steady-state parametric study investigated the effects of spark timing, fuel load, and engine speed. Table 5 shows the test conditions. Specifically, the spark timing changed from $30^{\circ} \mathrm{CA}$ aTDC to $-10^{\circ} \mathrm{CA}$ aTDC, fuel load was varied from $75 \%$ to $90 \%$, and speed was changed from 900 RPM to 1300 RPM. Each test varied one parameter while holding the other two constant. The engine was warmed up before testing, and oil and coolant temperatures were maintained constant at $79^{\circ} \pm 2^{\circ} \mathrm{C}$ and $48^{\circ} \pm 2^{\circ} \mathrm{C}$ respectively, to eliminate the effects of different boundary conditions on the combustion process.

Table 5: Parameters and its set points

\begin{tabular}{|l|l|l|}
\hline $\begin{array}{l}\text { Spark timing }\left({ }^{\circ} \mathrm{CA}\right) \\
(\text { Fuel load: } 80 \%\end{array}$ & $\begin{array}{l}\text { Fuel load }(\%) \\
\text { Speed: } 900 \text { RPM }) \\
\text { Speed: } 900 \text { RPM })\end{array}$ & $\begin{array}{l}\text { Speed (rpm) } \\
\text { (Spark timing: }-10^{\circ} \text { aTDC } \\
\text { Fuel load: } 80 \%)\end{array}$ \\
\hline$-30^{\circ}$ aTDC & $75 \%$ & 900 \\
\hline$-25^{\circ}$ aTDC & $80 \%$ & 1000 \\
\hline$-20^{\circ}$ aTDC & $85 \%$ & 1100 \\
\hline$-15^{\circ}$ aTDC & $90 \%$ & 1200 \\
\hline$-10^{\circ}$ aTDC & - & 1300 \\
\hline
\end{tabular}

The fuels investigated were chemically-pure methane and a $\mathrm{C}_{1}-\mathrm{C}_{4}$ alkane blend (hereafter referred to as NG), with compositions given in Table 6. Methane was used as a baseline for comparing the results using NG. Both the gases were injected at 35 psi with the help of a gas regulator. 
Table 6: Composition of gases used for the test

\begin{tabular}{|l|l|l|}
\hline & Methane & NG \\
\hline Methane & $99.5 \%$ & $90.909 \%$ \\
\hline Ethane & $0.1 \%$ & $5.81 \%$ \\
\hline Propane & - & $2.39 \%$ \\
\hline Butane & - & $0.45 \%$ \\
\hline Isobutane & - & $0.421 \%$ \\
\hline Nitrogen & $0.4 \%$ & $0.02 \%$ \\
\hline Total & $100 \%$ & $100 \%$ \\
\hline Molecular weight $(\mathrm{g} / \mathrm{mol})$ & 16.10 & 17.8946 \\
\hline Higher heating value $(\mathrm{kJ} / \mathrm{kg})$ & 55550.57 & 55611.45 \\
\hline Lower heating value $(\mathrm{kJ} / \mathrm{kg})$ & 49832.22 & 49982.26 \\
\hline Specific gravity & 0.5537 & 0.6178 \\
\hline H/C & 3.99 & 3.77 \\
\hline MN & 93.9 & 74.6 \\
\hline
\end{tabular}

Note: A controller malfunction has occurred during the spark-timing sweep test, which was realized during data analysis. And as a result, experiments were repeated with methane, but could not be repeated for NG. Hence, NG results presented next were based on experiments made at one spark timing only (i.e., at $-10^{\circ} \mathrm{CA}$ aTDC). 


\section{Results and Discussions}

This section describes the impact of gas composition on the combustion performance of a single-cylinder, four-stroke, port fuel injected, heavy-duty NG SI engine. Several subsections present and discuss the experimental results. The first subsection discusses the effect spark timing at constant speed and fuel load / equivalence ratio, $\phi$. The analysis included the maximum in-cylinder pressure and its location, the start of combustion (SOC, defined as the crank angle corresponding to $10 \%$ heat release), and the combustion duration (DOC; defined as the difference between the crank angles corresponding to $10 \%$ and $90 \%$ heat release). The next subsection shows the effect of engine speed on combustion phenomena at constant spark timing and fuel load / equivalence ratio. Finally, a parametric study that changed the fuel load / equivalence ratio was performed at constant engine speed and spark timing.

As mentioned before, in-cylinder pressure was measured with a piezoelectric pressure transducer, which measures the pressure difference versus time, rather than absolute pressure values. Thus, the pressure signal was 'pegged' (i.e., referenced) to the manifold intake pressure. However, the raw pressure signal was noisy due to a combination of mechanical vibration noise, electric noise, thermal drift, etc. [69]. Hence, before 'pegging' in-cylinder pressure was filtered with a Matlab digital filter (Savitzky-Golay filter of order 3) to smooth the signal.

The pressure collection and data analysis system used motored pressure to synchronize crankshaft encoder data with engine position. Specifically, the pressure DAQ used the peak pressure in the motored pressure trace to determine the difference between the encoder $\mathrm{z}$-pulse and engine TDC. The determined difference was later used to align the combusting pressure traces with engine position. The procedure was repeated at the beginning, during and at the end of experiments to ensure that no encoder slippage may affect pressure measurements. Figure 16 shows an example of motored pressure trace after the TDC alignment procedure.

The throttle position in the experiments was fixed to limit the effect of variation of air flow rate on the combustion process. However, the amount of fuel injected changed with the ECU's fuel load, which was independent of the air flow into the cylinder. The data presented in this section is the average of at least 400 cycles. The COV of $\mathrm{P}_{\max }$ was under $7 \%$, hence the average pressure was considered representative for the condition investigated. Figure 17 shows 
an example of individual and average cycles at $-10^{\circ} \mathrm{CA}$ aTDC spark timing, $80 \%$ fuel load, and $900 \mathrm{rpm}$ for methane.

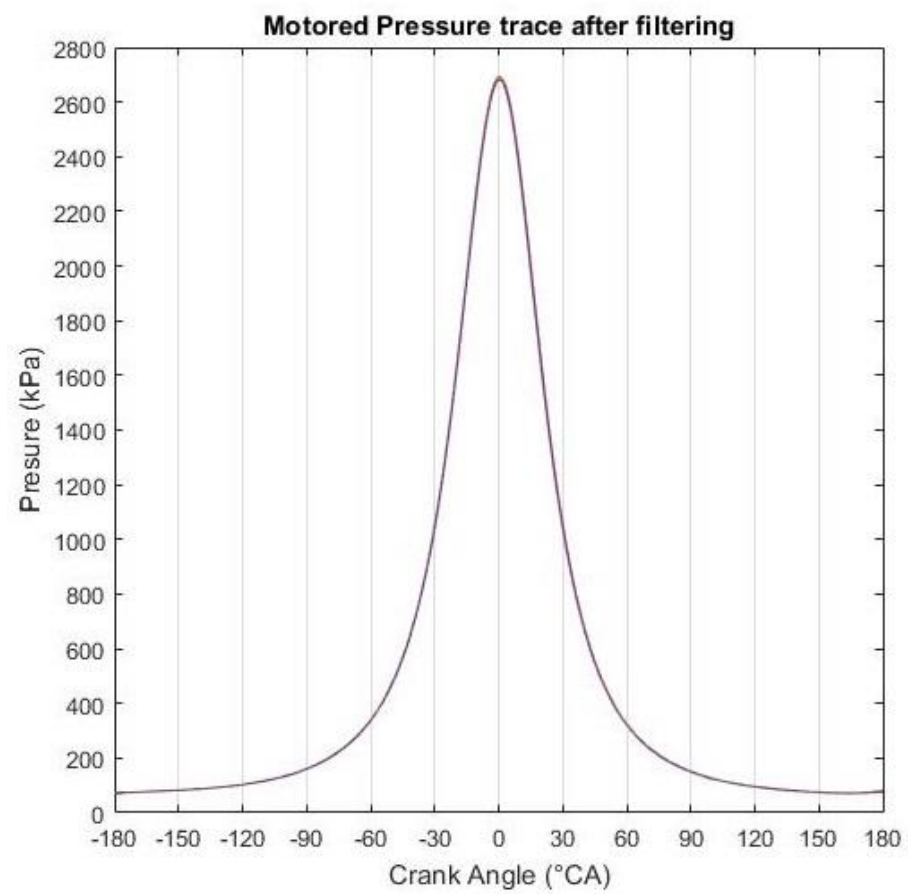

Figure 16: Motored pressure trace illustrating TDC alignment

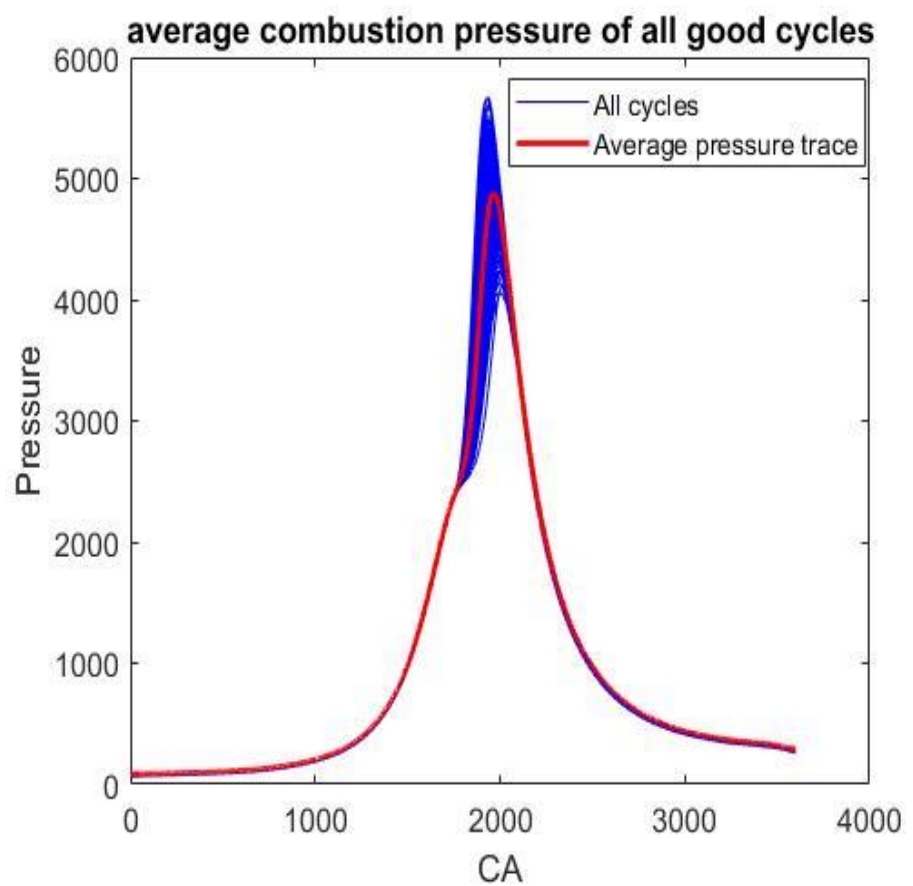

Figure 17: Individual and average pressure cycles (methane at $-10^{\circ} \mathrm{CA}$ aTDC spark timing, $80 \%$ fuel load, and $900 \mathrm{rpm}$ ) 


\subsection{Effect of spark timing}

Spark timing (ST) controls in-cylinder flame development and propagation, which affects combustion efficiency and stability. Advancing the ST can advance peak cylinder pressure before TDC, which would oppose the piston's upward movement. Therefore, work will be done during the compression stroke against the piston movement, which can reduce the amount of power delivered to the crankshaft. However, retarding the ST can result in peak cylinder pressure to occur later in the expansion stroke. This can reduce the magnitude of peak pressure and decrease the work done on the piston. The point at which both the cases compensate each other is regarded as optimum and generally called as maximum brake torque (MBT) spark timing. Figure 18 shows the effect of spark timing on engine torque and MBT from this study compared with a similar figure in Figure 19 referenced from Heywood [70]. As mentioned earlier in the test conditions section, NG was tested only at one spark timing, hence there is no MBT plot for NG.

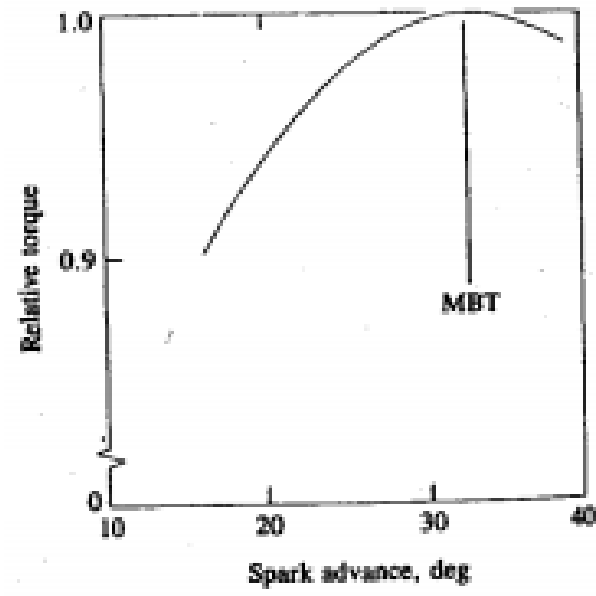

Figure 18: Effect of spark timing on MBT

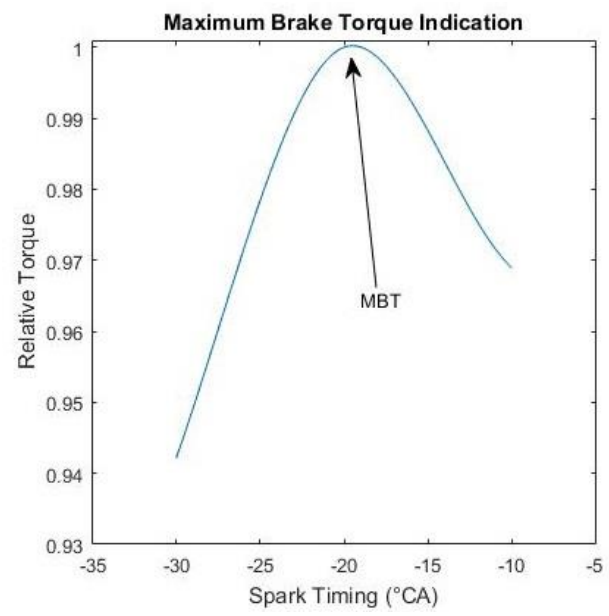

Figure 19: Effect of spark timing on MBT (methane at $900 \mathrm{rpm}$ and $80 \%$ fuel load)

Figure 20 shows the effect of ST on in-cylinder pressure for methane tests. Retarding the ST from $-30^{\circ} \mathrm{CA}$ aTDC to $-10^{\circ} \mathrm{CA}$ aTDC decreased the peak cylinder pressure from $6.5 \mathrm{MPa}$ to 4.3 MPa, a 34\% drop in peak pressure. This was due to delayed SOC, with SOC changing from $10.4^{\circ} \mathrm{CA}$ aTDC to $7.6^{\circ} \mathrm{CA}$ aTDC, as ST was retarded. Though the highest cylinder pressure was at $-30^{\circ} \mathrm{CA}$ aTDC, the highest imep was obtained at $-20^{\circ} \mathrm{CA}$ aTDC, i.e., the MBT-ST. 


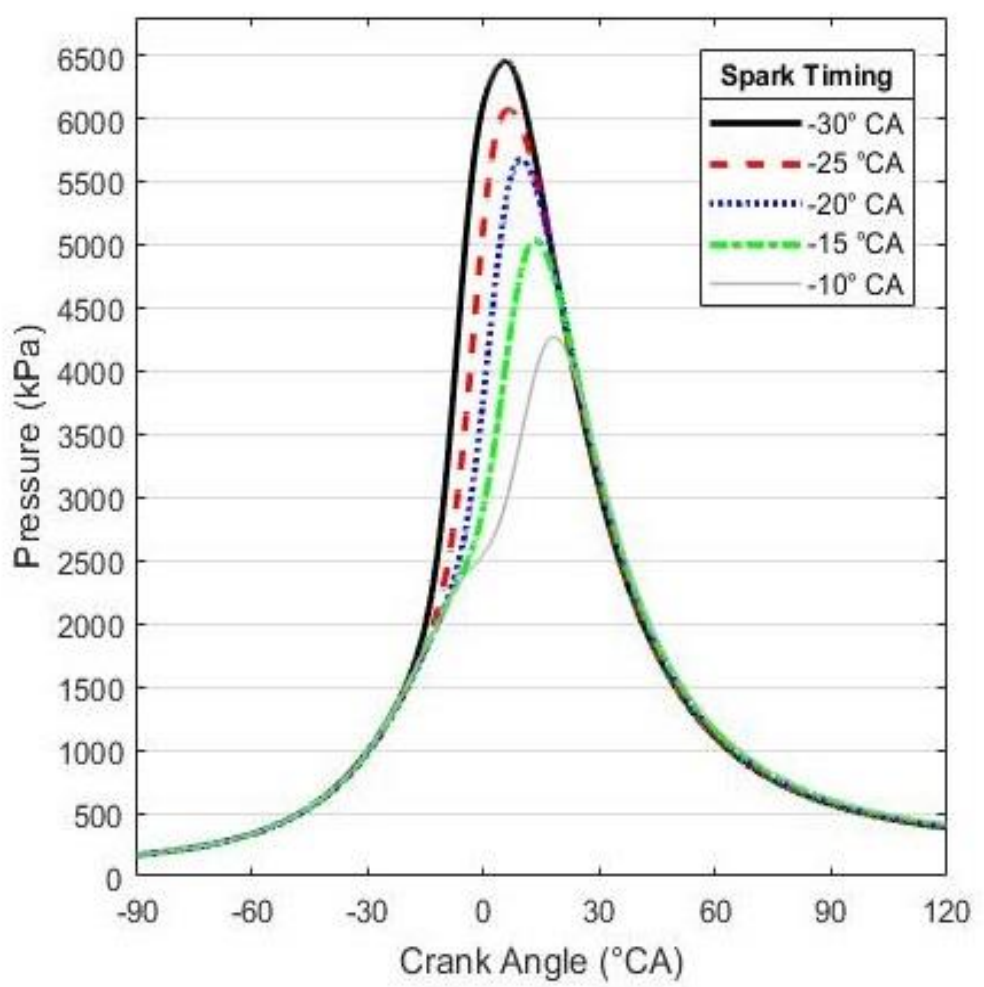

Figure 20: Effect of spark timing on cylinder pressure (methane at $900 \mathrm{rpm}$ and $80 \%$ fuel load)

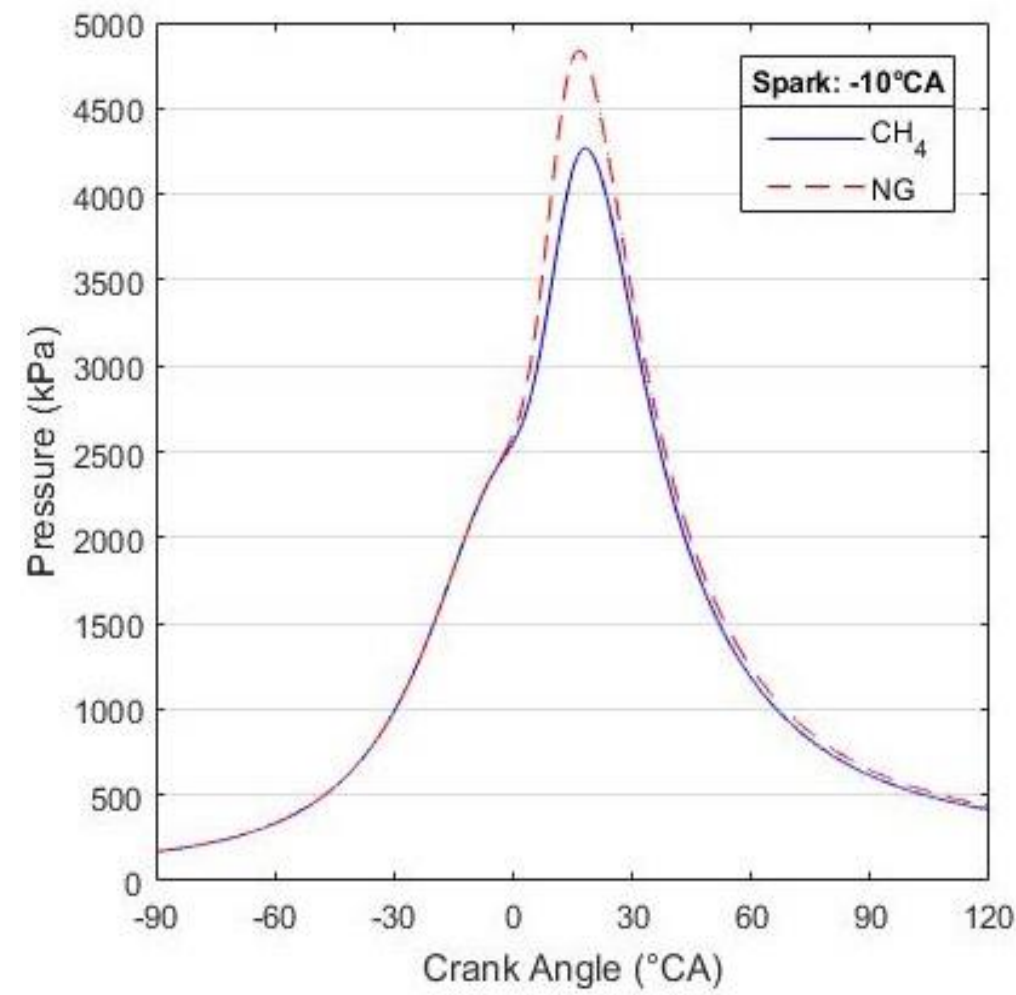

Figure 21: Effect of fuel on cylinder pressure (at $900 \mathrm{rpm}$ and $80 \%$ fuel load) 
Figure 21 presents the effect of fuel on in-cylinder pressure of the engine at $\mathrm{ST}-10^{\circ} \mathrm{CA}$ aTDC. It shows that the addition of higher alkanes to methane increased the peak pressure by 13\%. More results are tabulated in Table 7.

Table 7: Effect of spark timing and fuel on combustion parameters

\begin{tabular}{|l|l|l|l|l|l|l|l|l|}
\hline Fuel & $\begin{array}{l}\text { Spark } \\
\text { timing }(\mathrm{deg} \\
\text { aTDC) }\end{array}$ & $\begin{array}{l}\mathrm{P}_{\max } \\
(\mathrm{MPa})\end{array}$ & $\begin{array}{l}\mathrm{P}_{\max } \text { location } \\
(\mathrm{deg} \text { aTDC })\end{array}$ & $\begin{array}{l}\text { SOC } \\
(\mathrm{deg} \\
\text { aTDC) }\end{array}$ & $\begin{array}{l}\text { EOC } \\
(\mathrm{deg} \\
\text { aTDC })\end{array}$ & $\phi$ & $\begin{array}{l}\text { Imep } \\
(\mathrm{kPa})\end{array}$ & $\eta_{\text {th, }}$ \\
\hline \multirow{3}{*}{$\mathrm{CH}_{4}$} & -30 & 6.45 & 5.5 & -10.4 & 54.3 & 0.74 & 765.65 & 31.0 \\
\cline { 2 - 9 } & -25 & 6.07 & 6.3 & -5.9 & 53.7 & 0.73 & 795.12 & 32.1 \\
\cline { 2 - 9 } & -20 & 5.68 & 9.7 & -1.5 & 52.9 & 0.74 & 812.67 & 32.9 \\
\cline { 2 - 9 } & -15 & 5.04 & 13.6 & 1.0 & 54.1 & 0.73 & 803.13 & 32.5 \\
\hline NG & -10 & 4.27 & 18.4 & 7.6 & 55.7 & 0.74 & 787.44 & 31.8 \\
\hline
\end{tabular}

Imep is representative of work done on the piston and generally used to describe engine power. The area bound to P-V diagram represents the indicated work done by the engine, and imep is calculated from the indicated work using the equation:

$$
\text { imep }=\frac{W_{i}}{v_{d}}=\frac{\int P * d V}{v_{d}}
$$

where $W_{i}$ is the indicated work output of the engine, in $\mathrm{kJ}$, and $v_{d}$ is the engine displacement volume, in $\mathrm{m}^{3}$

The engine volume at each crank angle $\theta$ is calculated as:

$$
V=\frac{v_{d}}{r-1}+\frac{v_{d}}{2}\left[1+R-\cos \theta-\left(R^{2}-\sin ^{2} \theta\right)^{-1 / 2}\right]
$$

where $r$ is the compression ratio, and $R$ is the ratio of the connecting rod length to the crank radius

Figure 22 shows imep against ST. As explained earlier, the highest imep was achieved at MBT-ST, and the imep decreased with further advancing or retarding the spark timing from this 
position. From Table 7, the decrease in imep due to advancing or retarding the ST from MBT timing was 6\% and 3\%, respectively. It can be observed from Figure 23 that the imep of NG was higher than methane. This is because of the presence of higher carbon species along with methane in NG enhanced the fuel properties (i.e., flame speed, adiabatic flame temperature) [51, 52], which generated higher peak pressures and produced higher imep. A significant increase of 9.4\% had been observed in imep, due to change in the gaseous fuel composition.

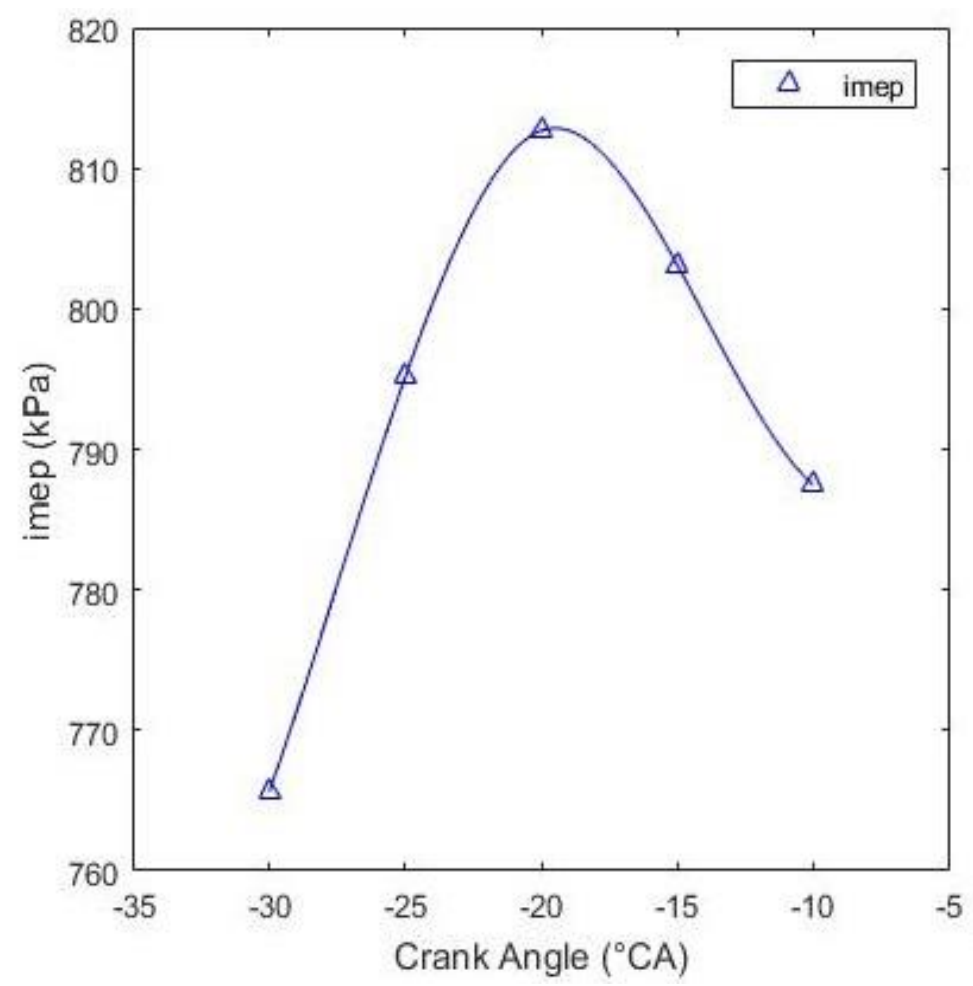

Figure 22: Effect of spark timing on imep (methane at $900 \mathrm{rpm}$ and $80 \%$ fuel load)

According to first law of thermodynamics

$$
\delta Q=d U+\delta W
$$

where $\delta Q$ is the chemical energy provided to the system, $d U$ is the change in internal energy (kJ), and $\delta W$ is the work done by the system $(\mathrm{kJ})$.

Using equation 4.3 along with ideal gas law [70], equation 4.4 is used to calculate the rate of heat transfer in the system: 


$$
\frac{\delta Q}{\delta \theta}=\frac{1}{k-1}\left(\frac{V * d P}{d \theta}\right)+\frac{k}{k-1}\left(\frac{P * d V}{d \theta}\right)
$$

where $\delta Q / \delta \theta$ is the heat release rate $\left(\mathrm{kJ} /{ }^{\circ} \mathrm{CA}\right), k$ is the ratio of specific heats, $V$ is the volume $\left(\mathrm{m}^{3}\right)$, and $\delta P / \delta \theta$ is the rate of change of pressure $\left(\mathrm{kPa} /{ }^{\circ} \mathrm{CA}\right)$

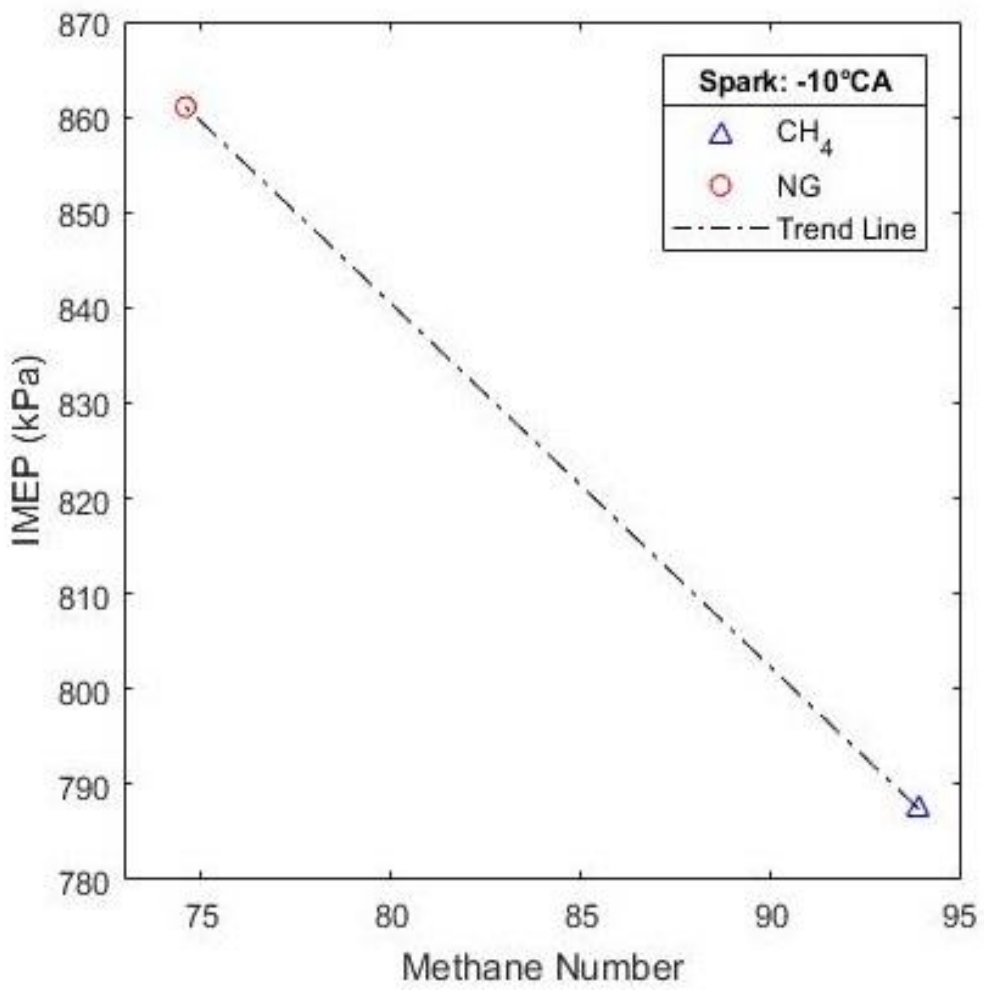

Figure 23: Effect of spark timing and fuel on imep (900 rpm and $80 \%$ fuel load)

Heat release analysis can directly describe the conversion efficiency of thermal energy into work done by the engine. For a constant supply of chemical energy, a higher heat release indicates that more work is done by the system, which means the engine is more efficient. From Figure 24 , it can be observed that the heat release rate of methane at a ST of $-20^{\circ} \mathrm{CA}$ aTDC is greater than any other spark timing, at constant chemical energy intake into the system. This is because the work done by the system at this ST is higher than any other ST tested. This directly explains the higher thermal efficiency of the engine at $-20^{\circ} \mathrm{CA}$ aTDC. Another observation that can be made from the heat release analysis is that there was a second peak on the heat release rate plot at $\mathrm{ST}-30^{\circ} \mathrm{CA}$ aTDC, which is probably due to the effect that the piston bowl edges had on redirecting the flame front. 


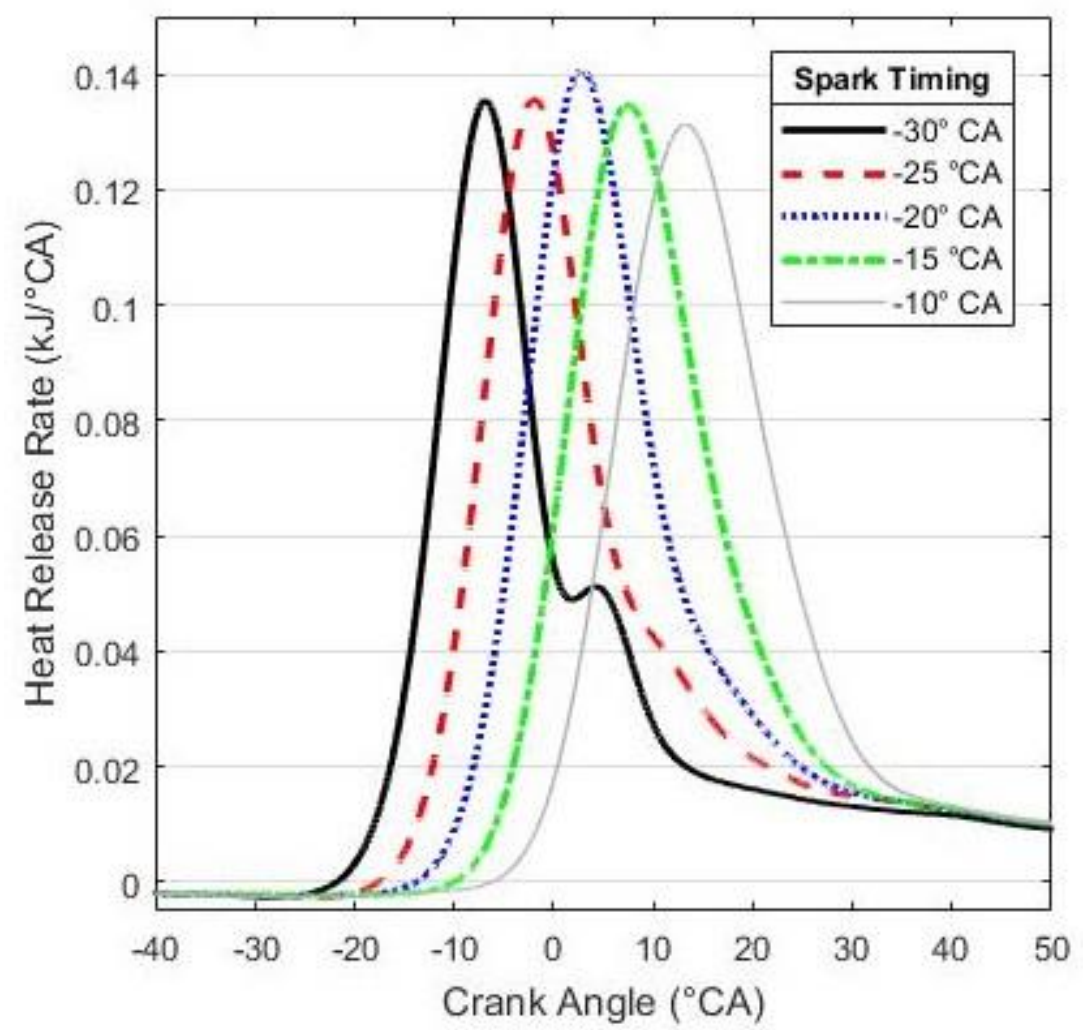

Figure 24: Effect of spark timing on heat release rate (methane at $900 \mathrm{rpm}$ and $80 \%$ fuel load)

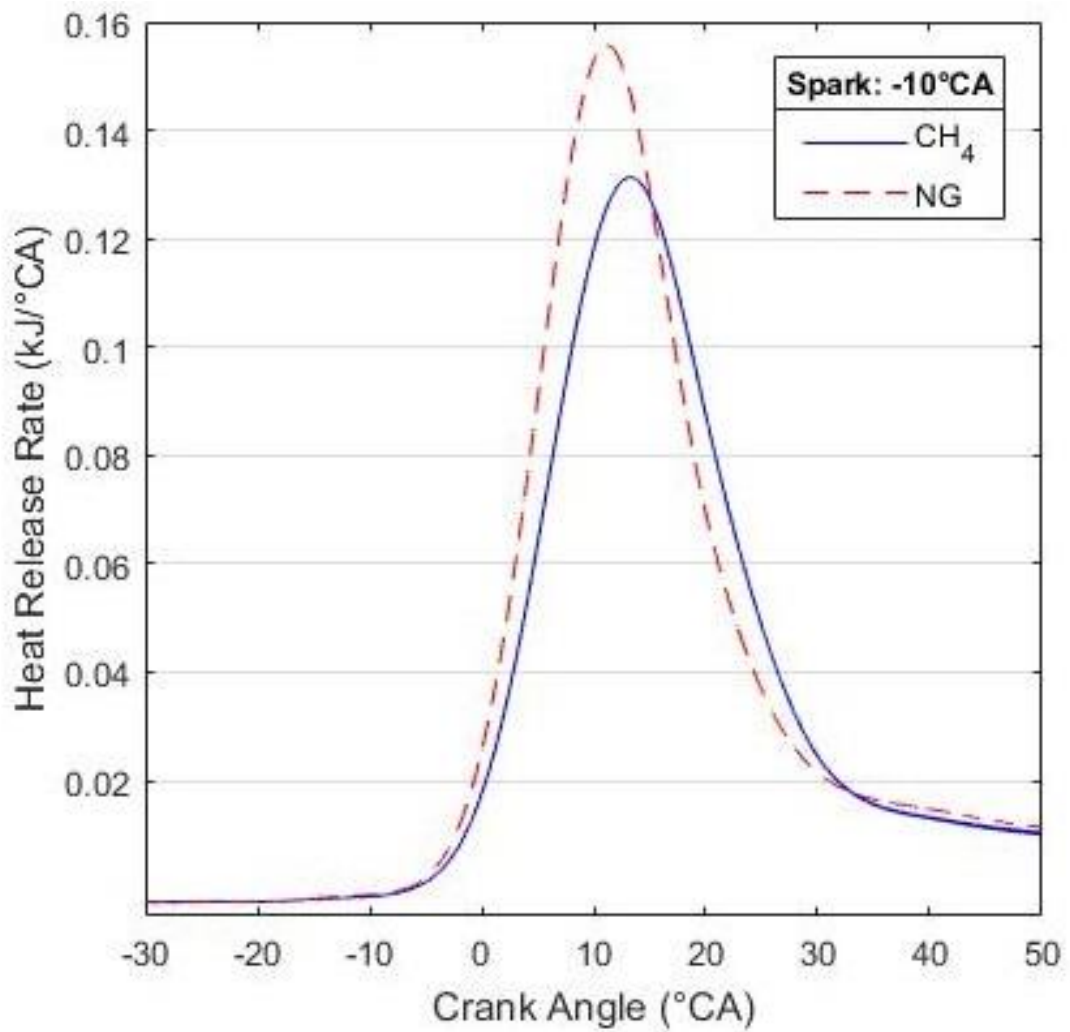

Figure 25: Effect of fuel on AHRR (at $900 \mathrm{rpm}$ and 80\% fuel load) 
While the apparent heat release rate denotes the rate of heat transfer at every crank angle position, the cumulative heat release rate or net heat release rate defines the total amount of heat transferred over the cycle. Cumulative heat release rate can be calculated by summing up the apparent heat release rate values over the entire cycle as shown in Equation 4.5.

$$
N H R R=\sum_{\theta=-180^{\circ}}^{180^{\circ}} \frac{\delta Q}{\delta \theta}
$$

where $N H R R$ is the net heat release rate $(\mathrm{kJ})$, and $\theta$ is the crank angle from $-180^{\circ}$ to $180^{\circ} \mathrm{CA}$

The upper limit of the plot indicates the maximum heat energy or the theoretical heat energy that can be obtained by burning the fuel at ideal conditions $\left(m_{f} * Q_{L H V}\right)$, which accounts for all other inefficiencies of the engine. Moreover, the NHRR analysis can also help in estimating the SOC. As seen in Figure 26, the SOC is more advanced with more advanced spark timings which resulted in less heat release due to less overall work done; and therefore, the efficiency is low.

The rate of heat release was higher in case of NG, which can be observed from Figure 25, because the heating values of higher hydrocarbon species were greater than methane's. Hence, the NHRR of NG was also higher in case of NG, which implies more heat is transferred when NG is combusted. All these reasons explain the higher thermal efficiency of NG over methane. 


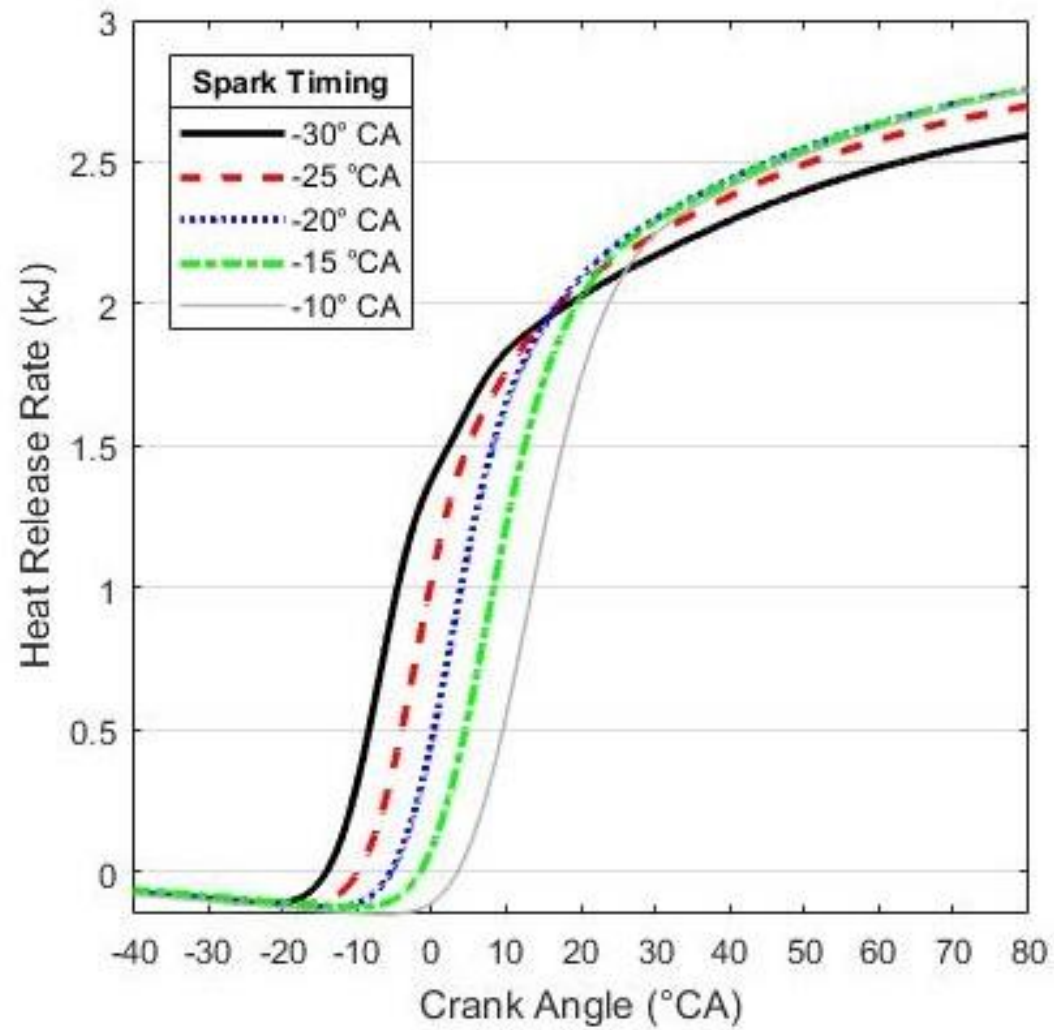

Figure 26: Effect of spark timing on NHRR (methane at $900 \mathrm{rpm}$ and $80 \%$ fuel load)

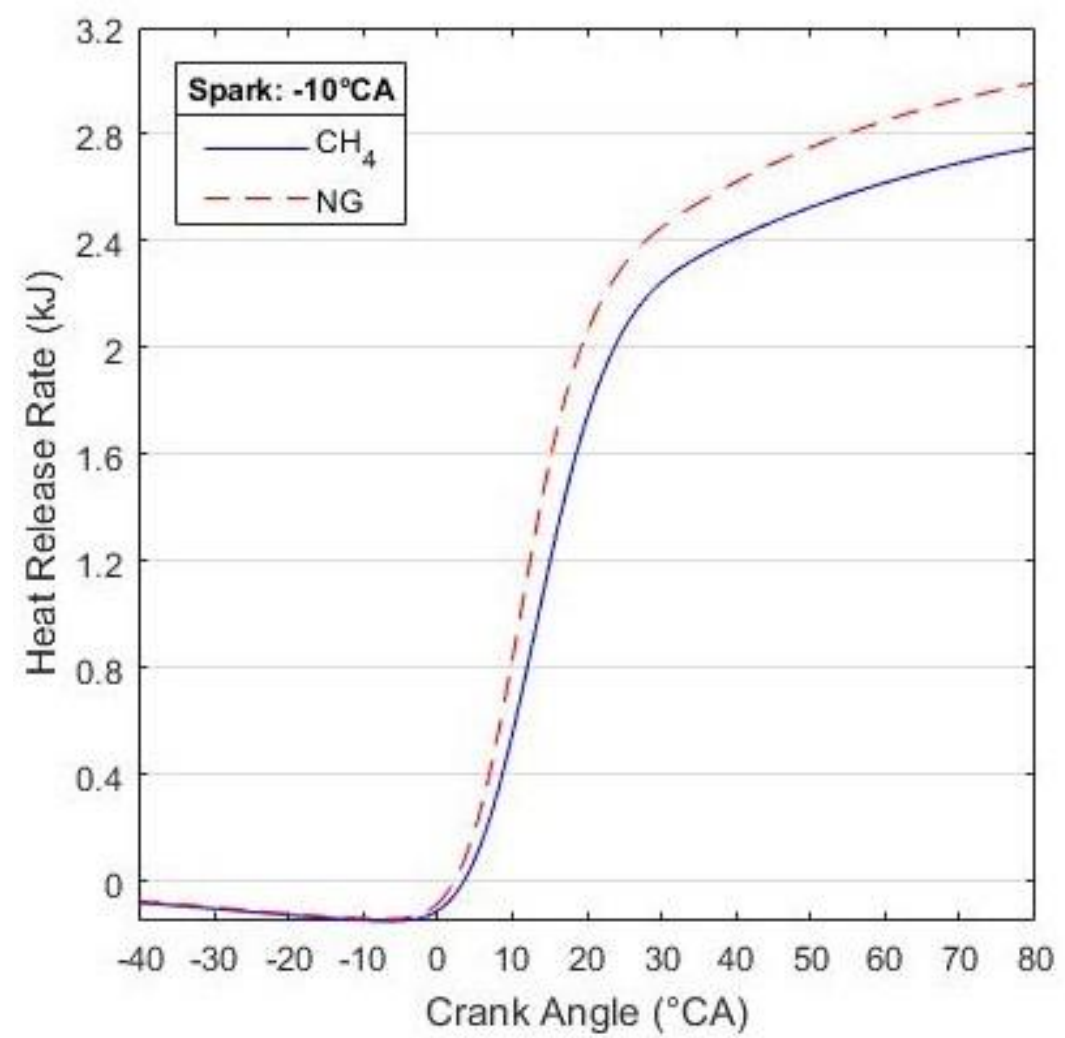

Figure 27: Effect of fuel on NHRR (at $900 \mathrm{rpm}$ and $80 \%$ fuel load) 
Another important parameter to determine the behavior of combustion is the amount of mass fraction burnt of air-fuel mixture. Mass fraction burnt is calculated by using Wiebe function, given in equation 4.6

$$
x_{b}(\theta)=1-e^{\left[-a *\left(\frac{\theta-\theta_{s}}{\theta_{d}}\right)^{n}\right]}
$$

where $x_{b}$ is the mass fraction burnt, $\theta$ is the instantaneous crankshaft angle $\left({ }^{\circ} \mathrm{CA}\right), \theta_{s}$ is the crankshaft angle at the start of heat addition $\left({ }^{\circ} \mathrm{CA}\right), \theta_{d}$ is the duration of heat addition $\left({ }^{\circ} \mathrm{CA}\right), n$ is the Wiebe form factor (usually 3), and $a$ is the Wiebe efficiency factor (usually 5).

Mass fraction burnt for methane at various spark timings is plotted in Figure 28. It can be observed that, the SOC (defined as the crank angle corresponding to $10 \%$ heat release) of the process was retarded with retarded spark timings, but the EOC (defined as crank angle corresponding to $90 \%$ heat release) of combustion was nearly same, which implies that the DOC decreased with spark timing retardation. Decreasing DOC suggests that flame speed increased with retarded spark timings.

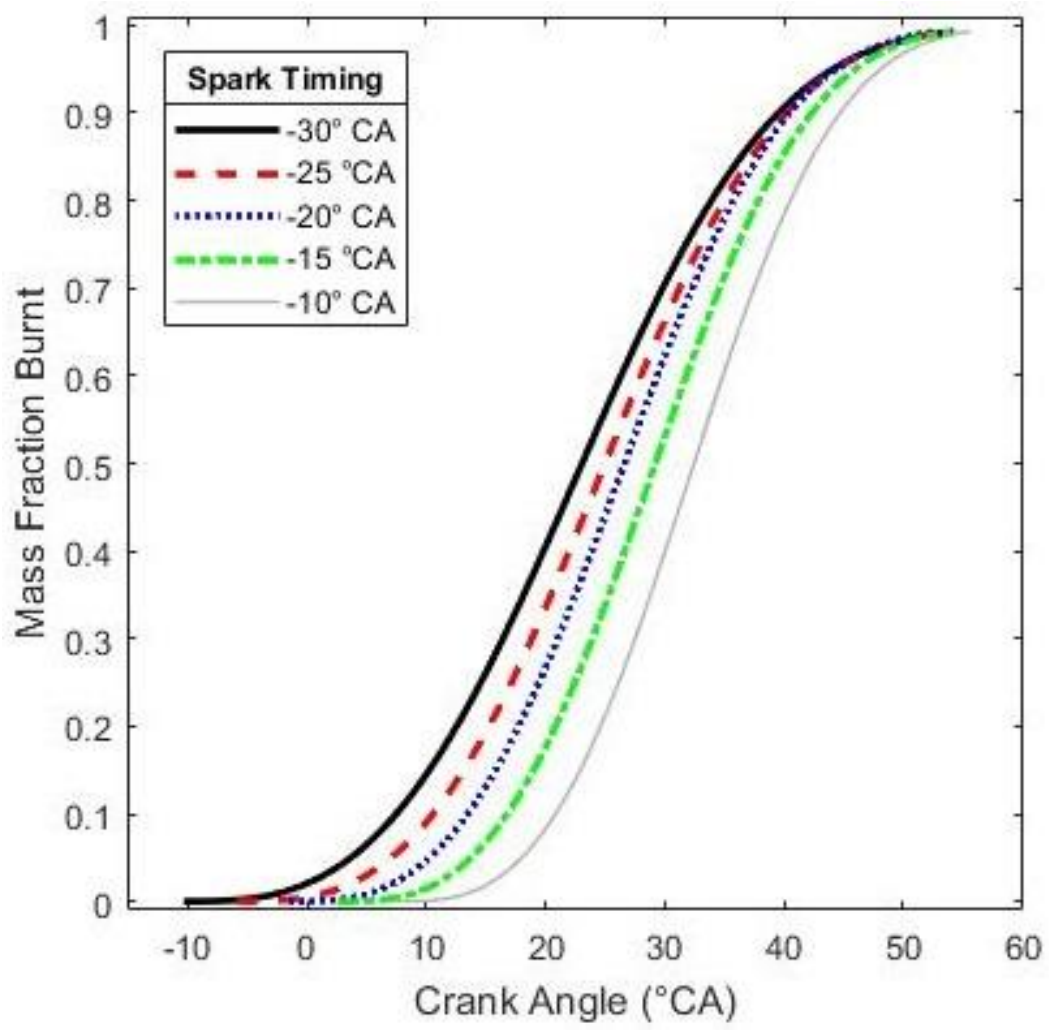

Figure 28: Effect of spark timing on mass fraction burnt (methane at $900 \mathrm{rpm}$ and $80 \%$ fuel load) 
Mass fraction burnt for methane and $\mathrm{NG}$ at spark timing $-10^{\circ} \mathrm{CA}$ aTDC is plotted in Figure 29. The time gap between actual spark timing and SOC of combustion is called flame development time, and this is found to be less when NG was used. This is due to the presence of higher hydrocarbon species in NG. The energy required to break a C-H bond is higher than the energy required to break a $\mathrm{C}-\mathrm{C}$ bond [64]. As methane does not contain any $\mathrm{C}-\mathrm{C}$ bonds unlike other hydrocarbon species, the time required to initiate the combustion process for methane is higher than any other alkanes, which increases the flame development time for methane.

Moreover, methane is less reactive than any other heavier hydrocarbons. For all these reasons, methane burns slower than NG. With slower SOC, the combustion process is shifted more towards expansion stroke leading to reduced pressure rise rate, thereby producing lesser power output and efficiency.

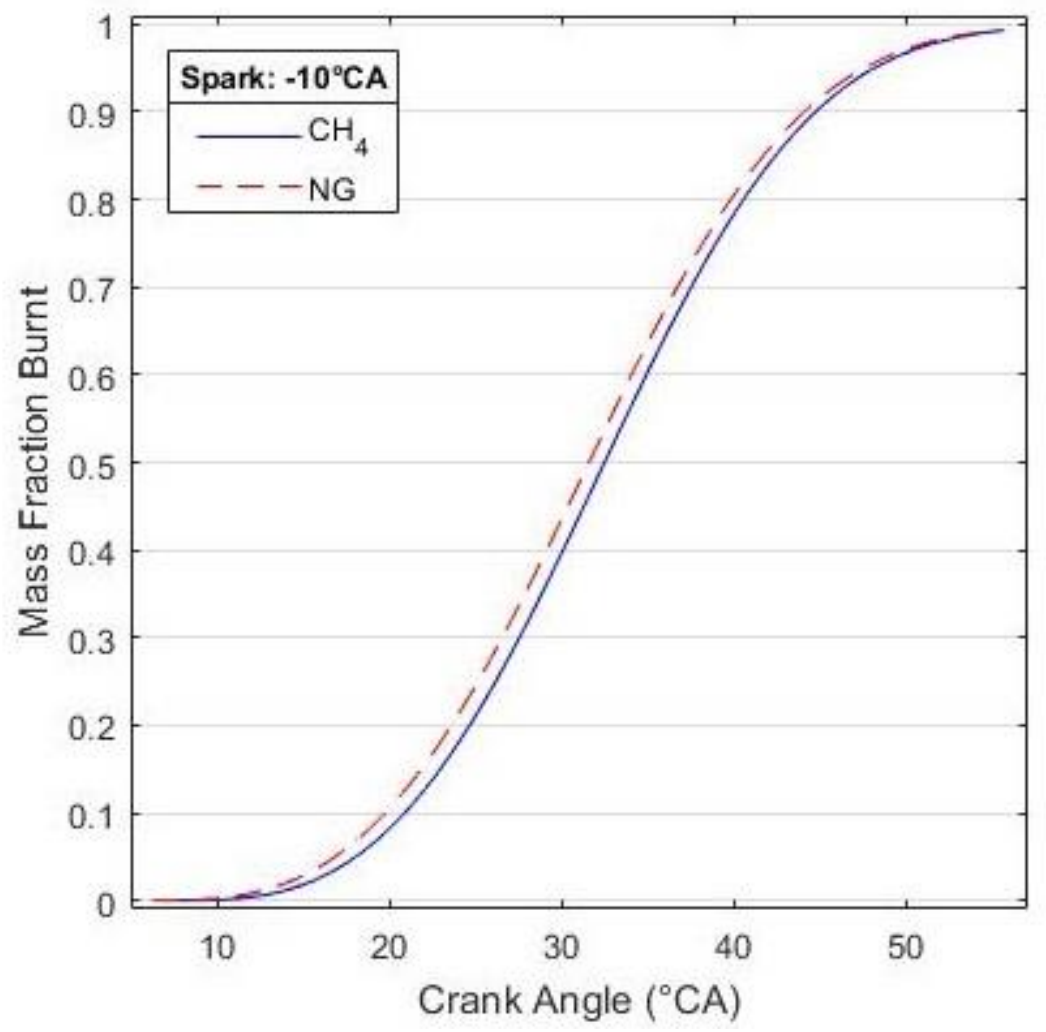

Figure 29: Effect of fuel on mass fraction burnt at $-10^{\circ}$ aTDC (at $900 \mathrm{rpm}$ and $80 \%$ fuel load) 


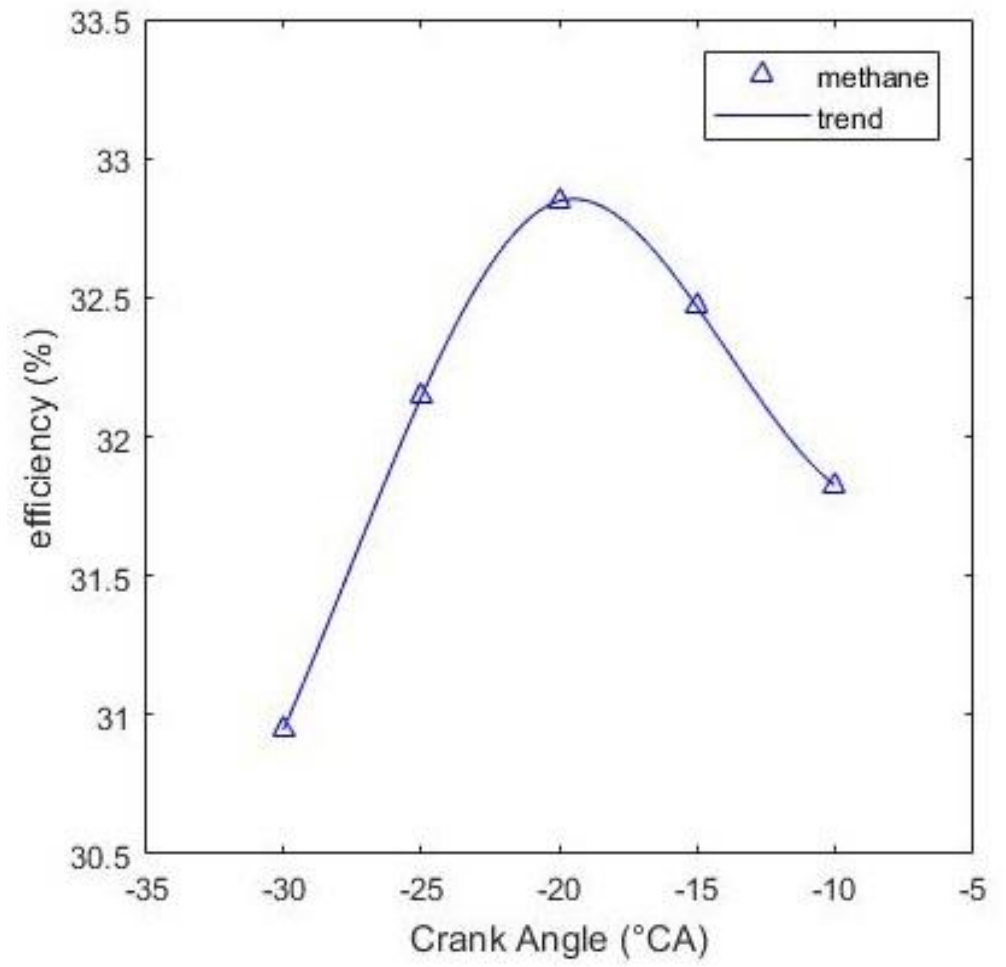

Figure 30: Effect of spark timing on indicated thermal efficiency (methane at $900 \mathrm{rpm}$ and $80 \%$ fuel load)

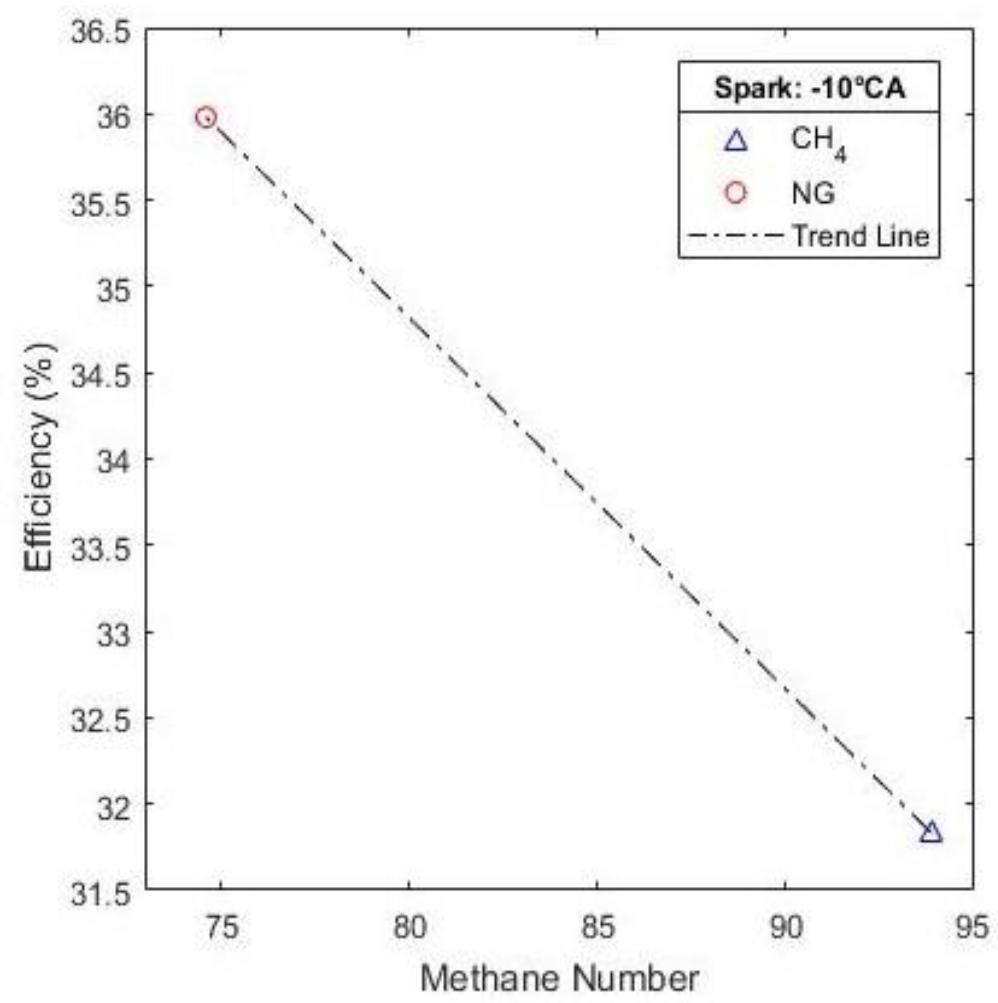

Figure 31: Effect of fuel on indicated thermal efficiency (at $900 \mathrm{rpm}$ and $80 \%$ fuel load) 
The experimental results show that as the spark timing was shifted away from the MBT timing, the efficiency decreased from the maximum efficiency at MBT spark timing, as illustrated in Figure 30. Besides, the addition of higher carbon species to methane should help in achieving higher heat release rates, which relates to higher thermal efficiency of the engine, as shown in Figure 31. It can be noticed that, the efficiency of the engine decreased by $12 \%$ due to change in chemical composition of fuel.

\subsection{Effect of Speed}

Increasing the engine speed reduces the time required for proper combustion of the mixture. Generally, the torque output increases with engine speed to a certain level, and then starts to decrease, due to increased frictional losses and inadequate time for complete combustion process. The engine speed sweep test with speed varying from $900 \mathrm{rpm}$ to $1300 \mathrm{rpm}$, was performed at constant spark timing of $-10^{\circ} \mathrm{CA}$ aTDC and a constant equivalence ratio (varies with composition of gas used), which indicates that the engine was not optimized at higher speeds. As a result, the combustion process was incomplete at higher speeds, resulting in decreased cylinder pressure, as shown in Figure 32, for both the gases.

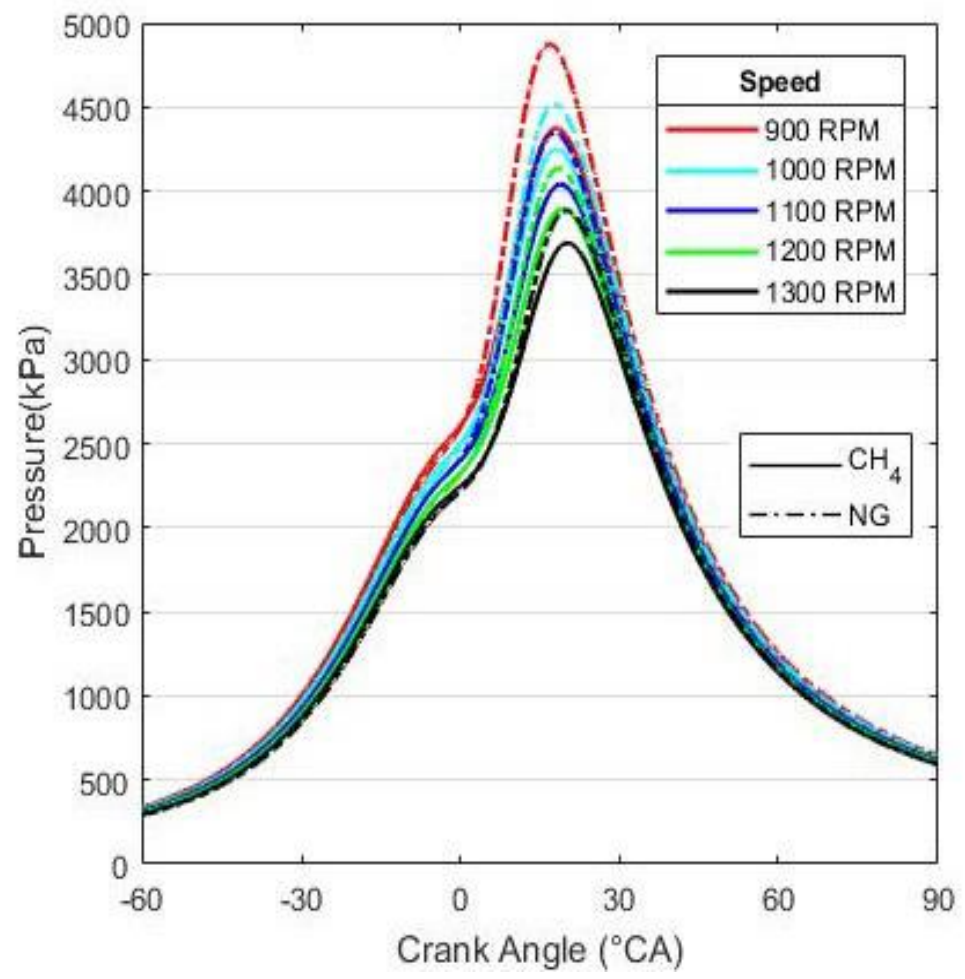

Figure 32: Effect of speed on cylinder pressure (at $-10^{\circ} \mathrm{CA}$ aTDC and $80 \%$ fuel load) 
Engine speed generally affects the combustion phenomena through its effect on incylinder gas motion, friction, time available to complete combustion, and heat transfer rates [70]. With higher speeds, the heat release rates are predominantly affected by the frictional losses of the engine, and hence the pressure drops after certain speed. On the other hand, engine running at low speeds produce less peak pressure, and consequently producing lesser power output. Hence, engine speeds are to be maintained in mid-range, where higher pressures compensate the frictional losses and provide better engine operating conditions. Also, increased engine speeds have advanced spark timings to counter the late start of combustion process, and provide more time for completing the combustion.

In this test, as seen in Figure 32, the peak pressure decreased significantly with increase in engine speed. This can be explained by the fact that the engine was not optimized at higher speeds, which means it had a fixed spark timing, and that may have resulted in improper combustion. Since, ethane and propane have higher laminar flame speeds and better ignition qualities than methane, NG had earlier SOC producing higher peak pressures and heat release rates than methane, which can be seen from Figure 33 and Table 8.

Table 8: Effect of engine speed and fuel on combustion parameters

\begin{tabular}{|l|l|l|l|l|l|l|l|l|}
\hline Fuel & $\begin{array}{l}\text { Speed } \\
(\mathrm{rpm})\end{array}$ & $\begin{array}{l}\mathrm{P}_{\max } \\
(\mathrm{MPa})\end{array}$ & $\begin{array}{l}\mathrm{P}_{\max } \\
\text { location } \\
(\mathrm{deg} \text { aTDC })\end{array}$ & $\begin{array}{l}\text { SOC } \\
(\mathrm{deg} \\
\mathrm{aTDC})\end{array}$ & $\begin{array}{l}\text { EOC } \\
(\mathrm{deg} \\
\mathrm{aTDC})\end{array}$ & $\begin{array}{l}\text { Imep } \\
(\mathrm{kPa})\end{array}$ & $\begin{array}{l}\eta_{\text {th, }} \\
(\%)\end{array}$ & $\begin{array}{l}\text { BTE } \\
(\%)\end{array}$ \\
\hline \multirow{5}{*}{$\mathrm{CH}_{4}$} & 900 & 4.24 & 17.9 & 7.0 & 54.4 & 815.65 & 33.0 & 23.9 \\
\cline { 2 - 9 } & 1000 & 4.25 & 18.3 & 7.6 & 55.9 & 802.49 & 32.4 & 23.3 \\
\cline { 2 - 9 } & 1100 & 4.04 & 19.0 & 8.0 & 56.9 & 789.60 & 31.9 & 22.3 \\
\cline { 2 - 9 } & 1200 & 3.90 & 19.5 & 8.3 & 56.5 & 775.28 & 31.3 & 21.5 \\
\cline { 2 - 9 } & 1300 & 3.69 & 20.4 & 9.0 & 57.1 & 753.64 & 30.4 & 20.5 \\
\cline { 2 - 9 } NG & 900 & 4.84 & 16.7 & 6.2 & 55.2 & 861.03 & 36.0 & 32.4 \\
\cline { 2 - 9 } & 1000 & 4.52 & 18.0 & 7.1 & 54.6 & 846.68 & 35.4 & 30.8 \\
\cline { 2 - 9 } & 1100 & 4.35 & 17.9 & 7.1 & 55.7 & 815.69 & 34.1 & 29.2 \\
\cline { 2 - 9 } & 1200 & 4.14 & 18.6 & 7.5 & 54.6 & 794.59 & 33.2 & 27.7 \\
\cline { 2 - 9 } & 1300 & 3.89 & 20.1 & 8.6 & 52.4 & 784.09 & 32.7 & 26.5 \\
\hline
\end{tabular}


Though the highest cylinder pressure was observed at $900 \mathrm{rpm}$ for both the gases, NG was $11 \%$ higher than methane. And this difference reduced to 5.5\% at $1300 \mathrm{rpm}$. This suggests that the differences would get smaller with increase in engine speeds.

With increased frictional losses and reduced peak pressures, the heat release rates also decreased. It can be inferred from the heat release rate plot that the SOC and EOC of NG was slightly earlier than methane, and therefore, better imeps and thermal efficiencies were achieved with NG, which are shown in Figure 35 and Figure 36.

Cumulative heat release plot shows that the total amount of heat released from the fuel was inversely proportional to engine speed. The highest heat release was at $900 \mathrm{rpm}$, where maximum efficiency for this sweep test was recorded. Decreasing pressure and heat release rate traces implies that lesser work is done with increase in mean piston speeds, which affects imep of the engine. Hence, the imep decreased linearly with increase in speed. However, the decrease was not the same for both the fuels. The imep of NG was reduced by $10 \%$ and methane was reduced by $8.5 \%$, from Table 8 and Figure 35 .

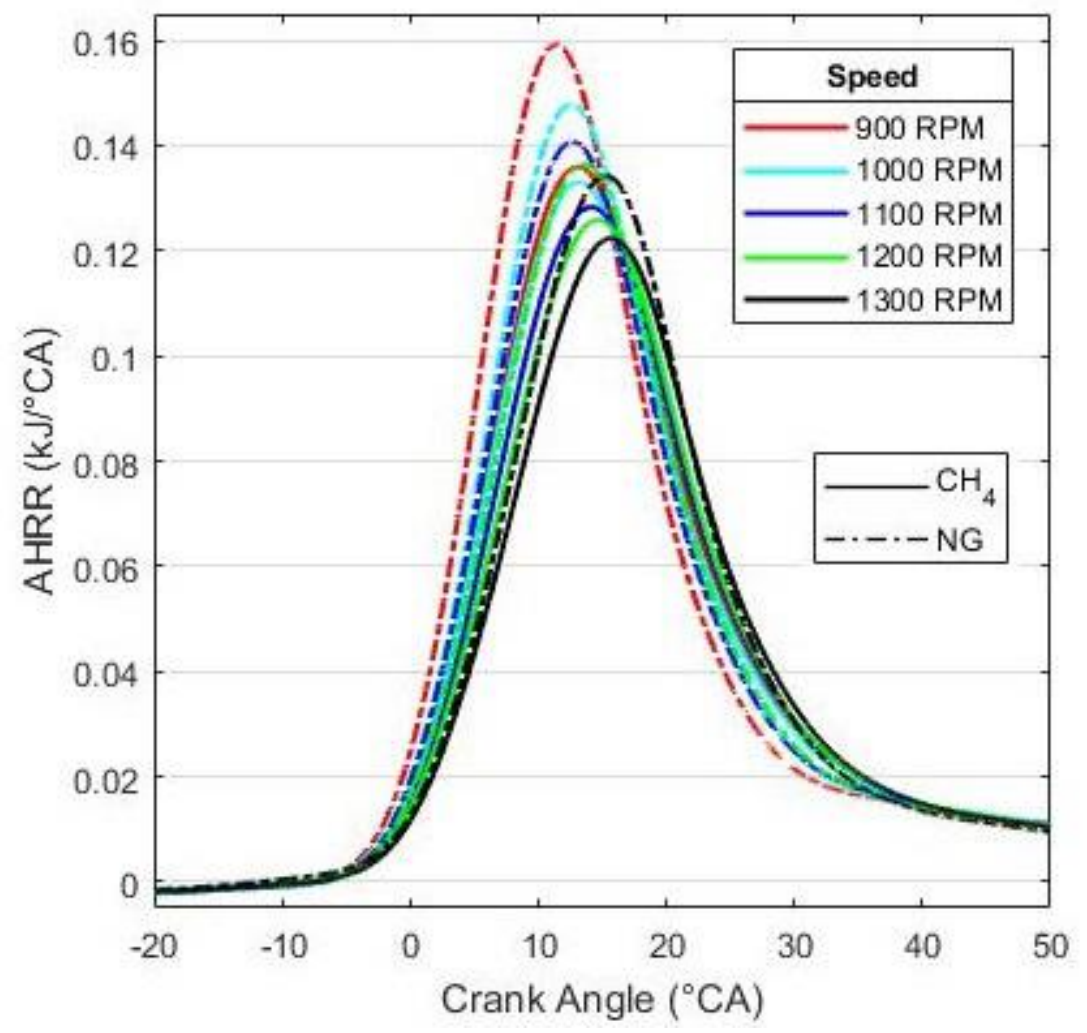

Figure 33: Effect of engine speed on AHRR (at $-10^{\circ} \mathrm{CA}$ aTDC and $80 \%$ fuel load) 


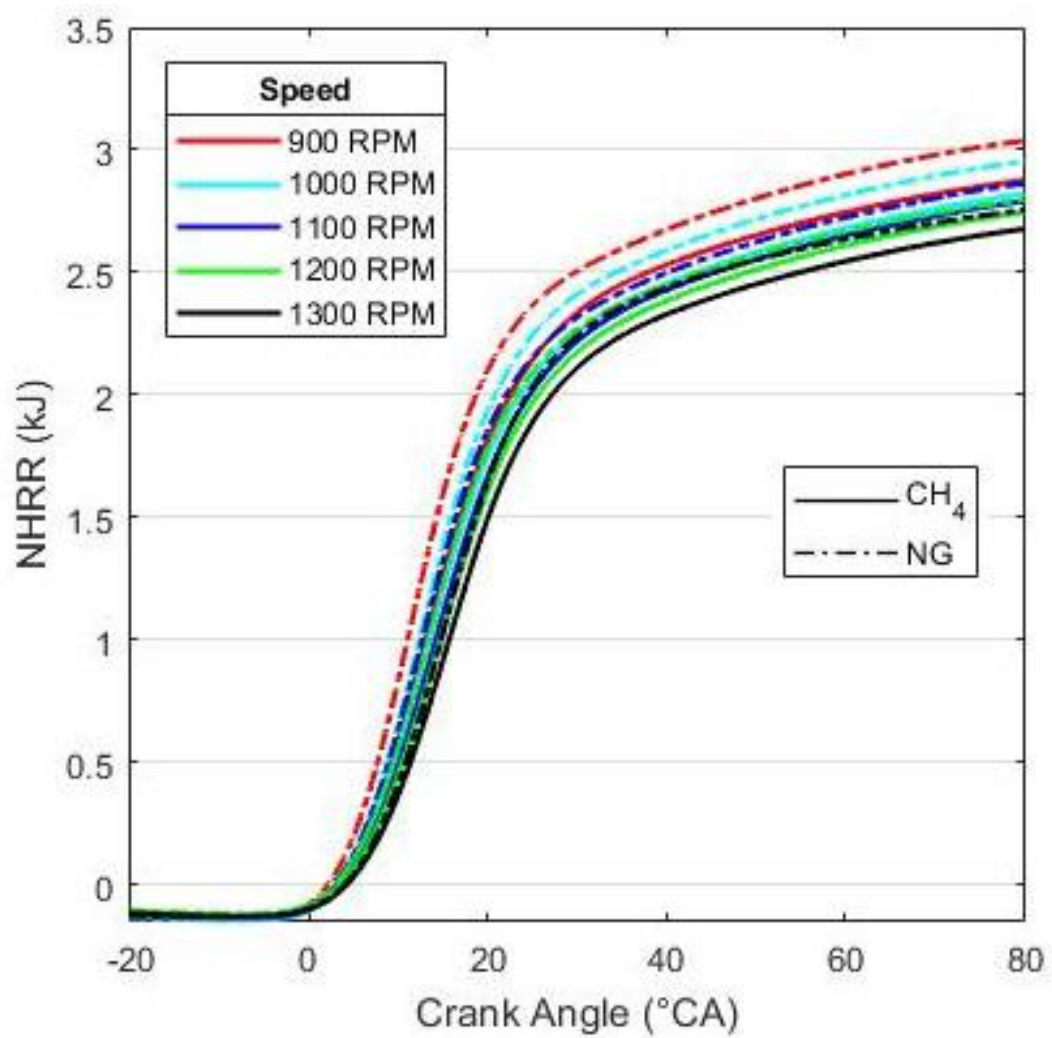

Figure 34: Effect of engine speed on NHRR (at $-10^{\circ} \mathrm{CA}$ aTDC and $80 \%$ fuel load)

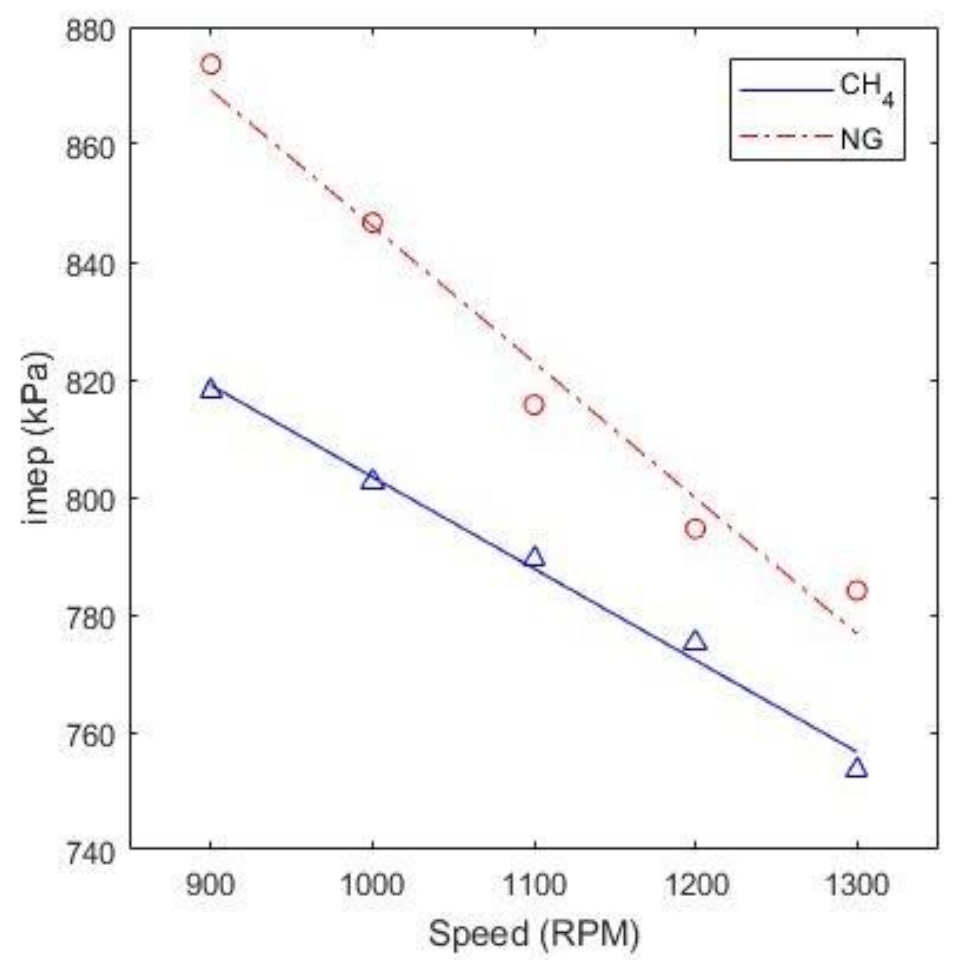

Figure 35: Effect of engine speed on imep (at $-10^{\circ} \mathrm{CA}$ aTDC and $80 \%$ fuel load) 


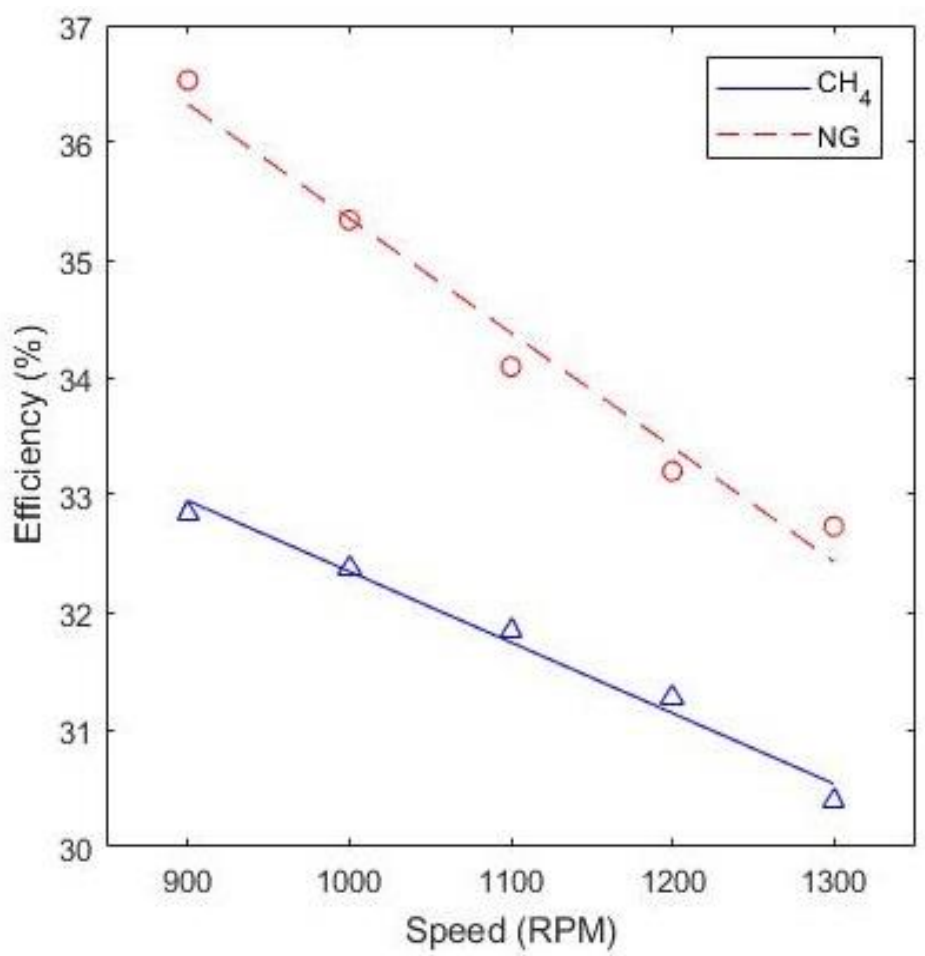

Figure 36: Effect of fuel and speed on indicated thermal efficiency (at $-10^{\circ} \mathrm{CA}$ aTDC and $80 \%$ fuel load)

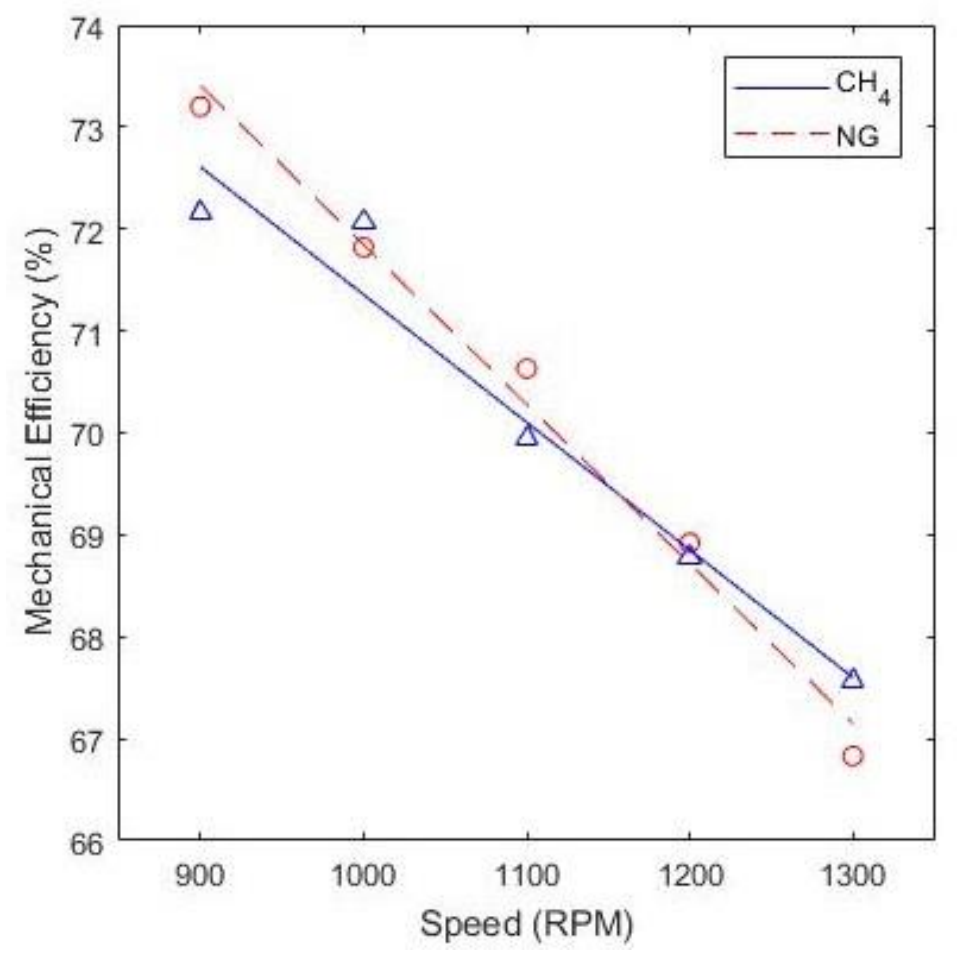

Figure 37: Effect of fuel and speed on mechanical efficiency of the engine (at $-10^{\circ} \mathrm{CA}$ aTDC and $80 \%$ fuel load) 
The efficiency of the engine for both the fuels decreased linearly with increase in speed, but the slope of NG is higher than methane. That is, the decrease in efficiency of NG from 900 rpm to $1300 \mathrm{rpm}$ was higher, 9.1\%, when compared to methane's $7.8 \%$. Also, the mechanical efficiency of NG reduced significantly lower than methane. All the above explanations suggest that methane is more suitable than NG at higher engine speeds.

\subsection{Effect of Fuel load}

Equivalence ratio is one of the fundamental engine operating variables which commands the performance and emissions of an engine. Development of combustion process depends highly on the equivalence ratio, since higher amount of fuel in the combustion chamber helps in faster flame development and propagation. This leads to increased pressure and heat release inside the cylinder, resulting in higher power output from the engine. But, increased cylinder temperatures provide more favorable conditions for $\mathrm{NO}_{\mathrm{x}}$ formation. As $\phi$ tends more towards leaner side, the amount of air to fuel ratio increases, resulting in lower adiabatic flame speeds and occasional flame quenching, leading to improper combustion. If $\phi$ tends toward richer side, then fuel to air ratio increases, where the amount of air present is not sufficient to oxidize all the fuel, resulting in incomplete combustion process, and the unburnt fuel is pushed out through exhaust, resulting in higher $\mathrm{HC}$ emissions. Hence, it is essential to maintain a desired $\phi$ under all operating conditions, such that higher performance is achieved with lower emissions. In this study, a parameter called 'percentage of fuel load' was used to control the $\phi$ of the mixture. And this parameter was varied from $75 \%$ to $90 \%$, at constant speed of $900 \mathrm{rpm}$ and spark timing of $-10^{\circ} \mathrm{CA}$ aTDC.

Percentage of fuel load is a parameter in TunerStudio that is used to vary the amount of fuel entering in to the cylinder, by varying the injector pulse width. Fuel load was varied from $75 \%$ to $90 \%$, with every $5 \%$ increase corresponding to approximately $2 \mathrm{~ms}$ increase in injector open duration. Hence, more amount of fuel is injected every cycle. A bench test was conducted to test the response of injector with varying fuel load \%, and the results are illustrated in Figure 38 and Figure 39. Figure 38 shows the variation in injector signal with change in percentage of fuel load, while Figure 39 shows that the pulse width increases almost linear with increase in fuel load $\%$. 

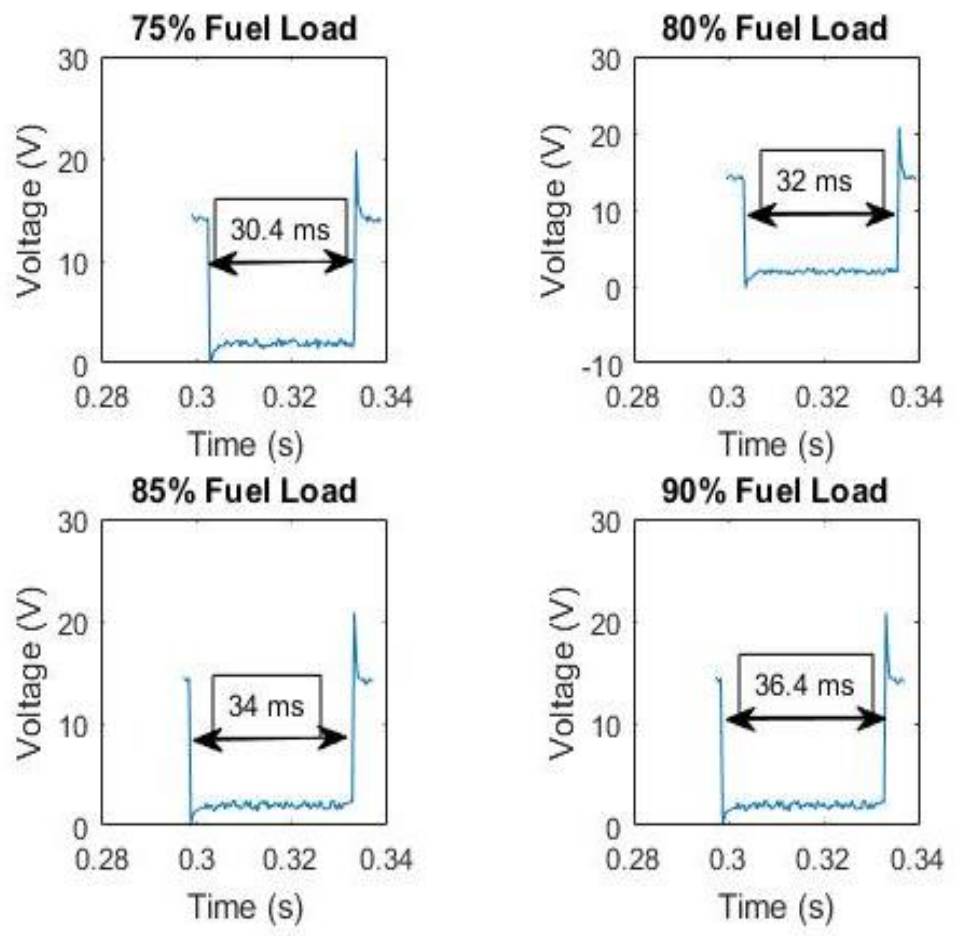

Figure 38: Injector signal variation with change in percentage of fuel load

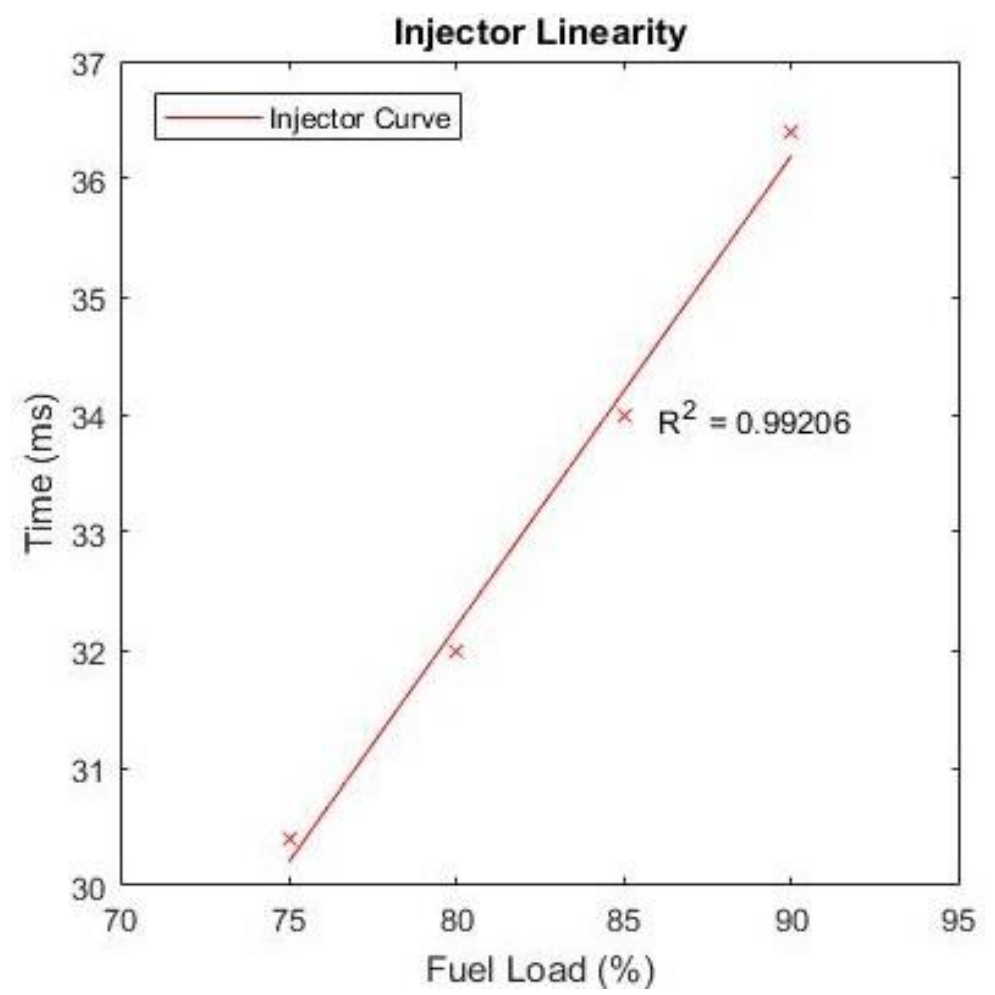

Figure 39: Linearity check of injector response 
Since, a fixed throttle position was maintained during the experiments, the amount of air flow rate in to the engine was always constant. And due to variation in fuel load \%, the amount of fuel increased, resulting in increasing equivalence ratios from $75 \%$ to $90 \%$. From the above discussion, due to higher $\phi$, the in-cylinder pressures also increased, which can be seen in Figure 40. Though both the gases achieved peak pressures at $90 \%$ load, the increase in NG was 12\%, which is slight lower than methane's increase of $17 \%$. Moreover, the difference in their peak pressures increased from $6 \%$ to $10 \%$, when the load $\%$ changed from $75 \%$ to $80 \%$, and then got down to $2 \%$ from $80 \%$ to $90 \%$ load. The differences got closer with increase in load \%, which suggests NG exhibits better performance than methane at low load conditions, while similar behavior can be noticed at high load conditions. A possible explanation for this could be the increasing gap in $\phi$ between methane and NG. Although, $\phi$ of methane was always higher than NG in this test, the trends got divergent with increase in load \%, which can be seen in Figure 44. This could also be supported by the fact that the engine was not optimized for higher load conditions, and hence arbitrary correlations for the two fuels were obtained.

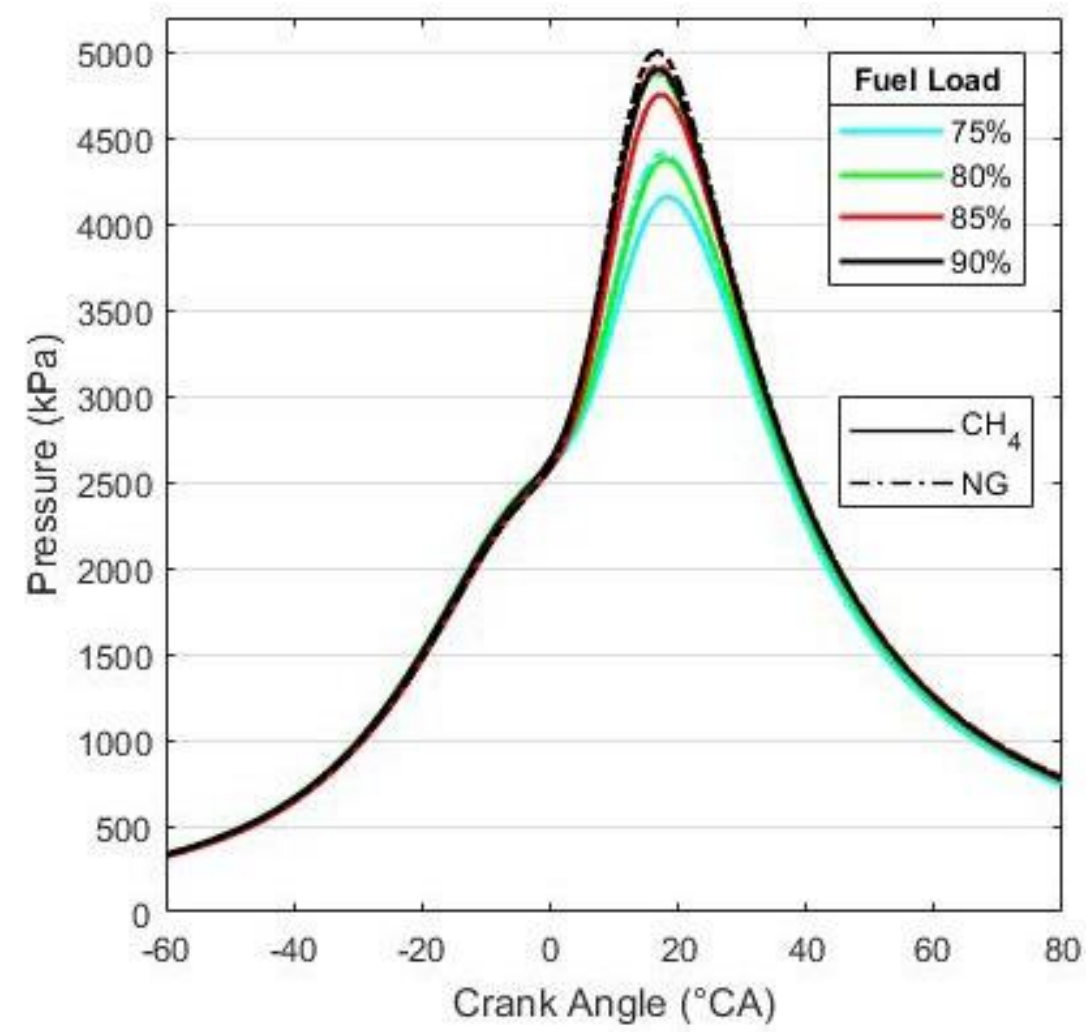

Figure 40: Effect of fuel and fuel load on pressure (at $-10^{\circ} \mathrm{CA}$ aTDC and $900 \mathrm{rpm}$ ) 
Change in imep was very similar to pressure change with an exception for NG at $90 \%$ load, though the trend was not linear, as seen in Figure 41. There was no significant change in imep for NG from $85 \%$ to $90 \%$, less than $0.1 \%$ increase. The effect of load\% on imep of NG was a $7 \%$ increase from $75 \%$ to $80 \%$, and $2.5 \%$ increase from $80 \%$ to $90 \%$, while for methane, an increment of $\sim 4.5 \%$ was observed from $75 \%$ to $80 \%$ load variation, and $6.5 \%$ increment in imep from $80 \%$ to $90 \%$. Whereas, the effect of fuel on imep was $3.1 \%$ at $75 \%$ load, and narrowed down to $1.6 \%$ at $90 \%$ load.

Heat release rate increased with increase in fuel load \%, due to addition of more chemical energy into the combustion chamber every cycle. It can also be observed that, the crank angle at which the peak cylinder pressure occurs, is being advanced with increase in fuel load \%. This is because, the higher $\phi$ helps in achieving faster flame propagation. As the higher hydrocarbons can burn much faster when compared to methane [53], NG had higher heat release rate than methane. And again, the rate of increase from $75 \%$ to $80 \%$ load was higher for both the fuels, and then the magnitude started to decrease.

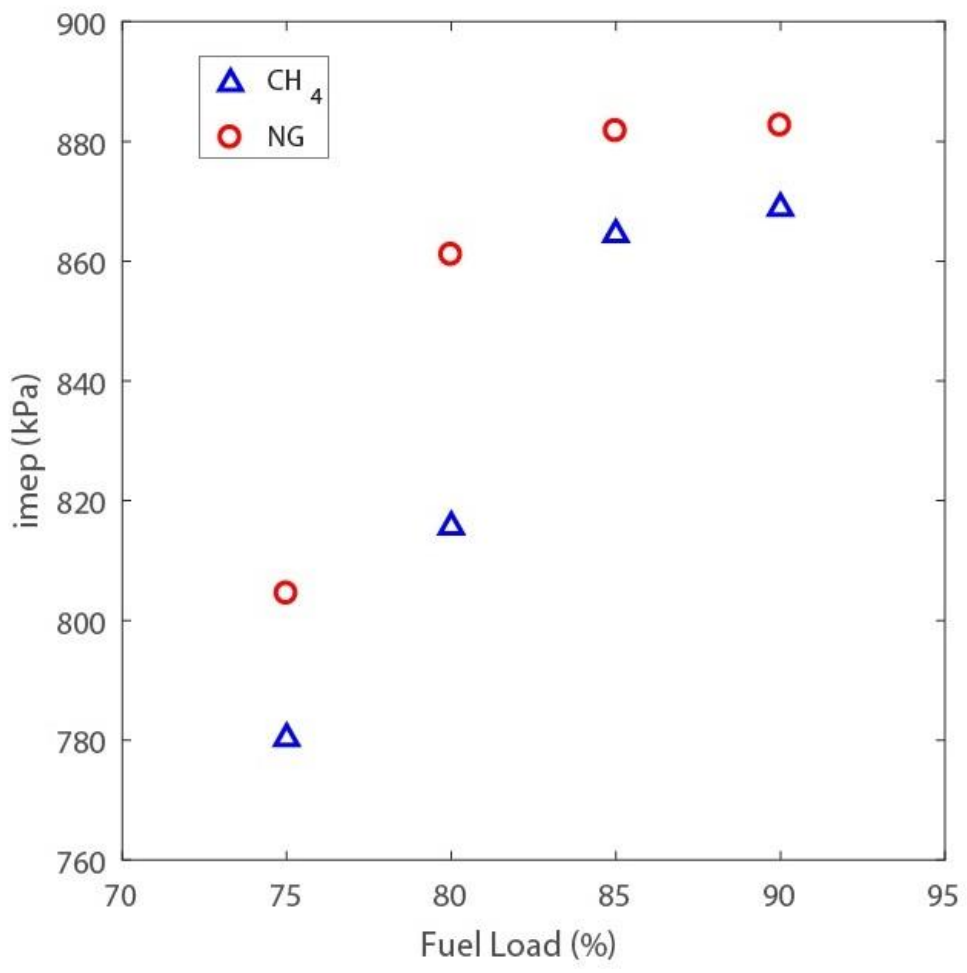

Figure 41: Effect of fuel and fuel load on imep (at $-10^{\circ} \mathrm{CA}$ aTDC and $900 \mathrm{rpm}$ ) 


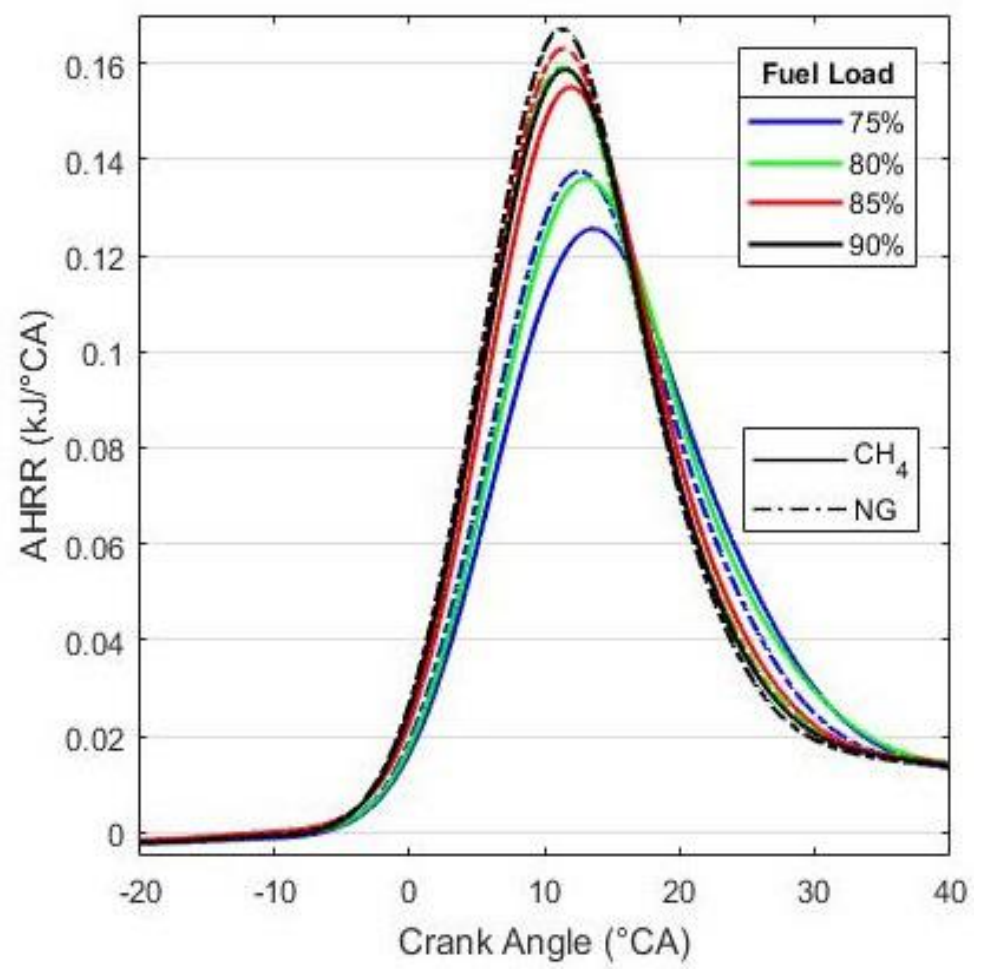

Figure 42: Effect of fuel load on heat release rate (at $-10^{\circ} \mathrm{CA}$ aTDC and $900 \mathrm{rpm}$ )

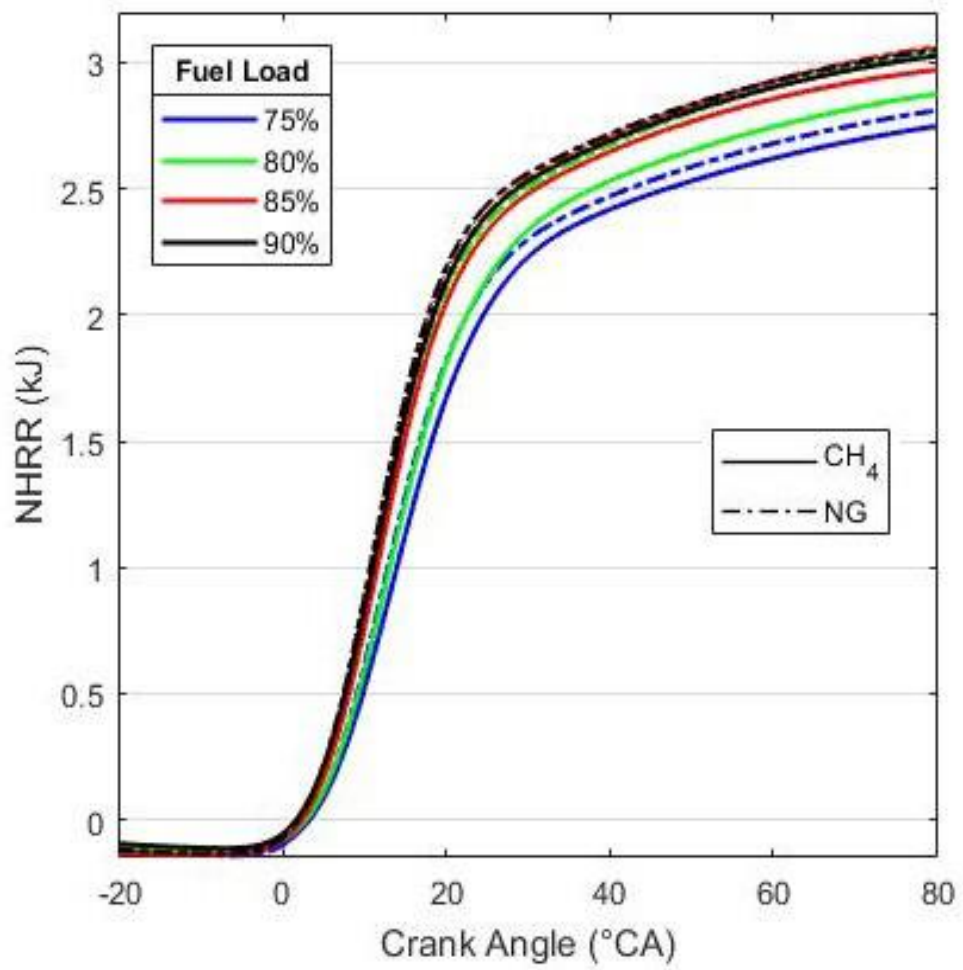

Figure 43: Effect of fuel and fuel load on NHRR (at $-10^{\circ} \mathrm{CA}$ aTDC and $900 \mathrm{rpm}$ ) 


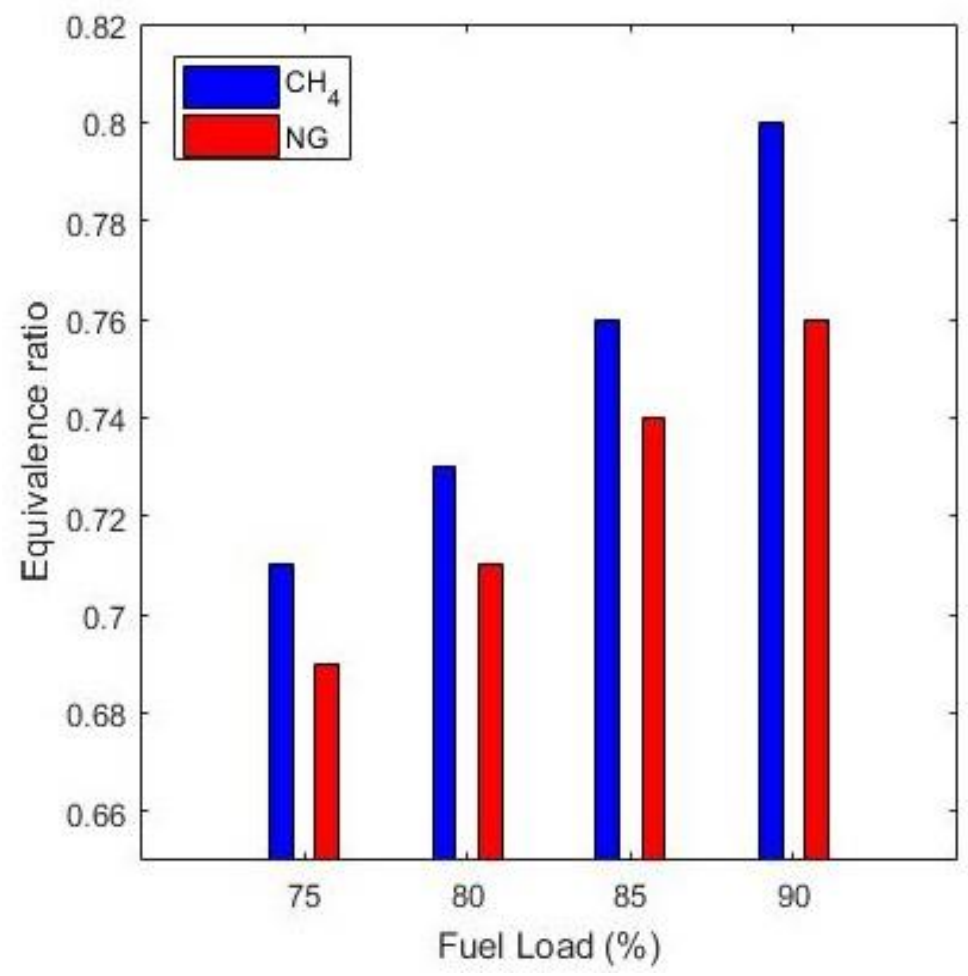

Figure 44: Effect of fuel and fuel load on equivalence ratio (at $-10^{\circ} \mathrm{CA}$ aTDC and $900 \mathrm{rpm}$ )

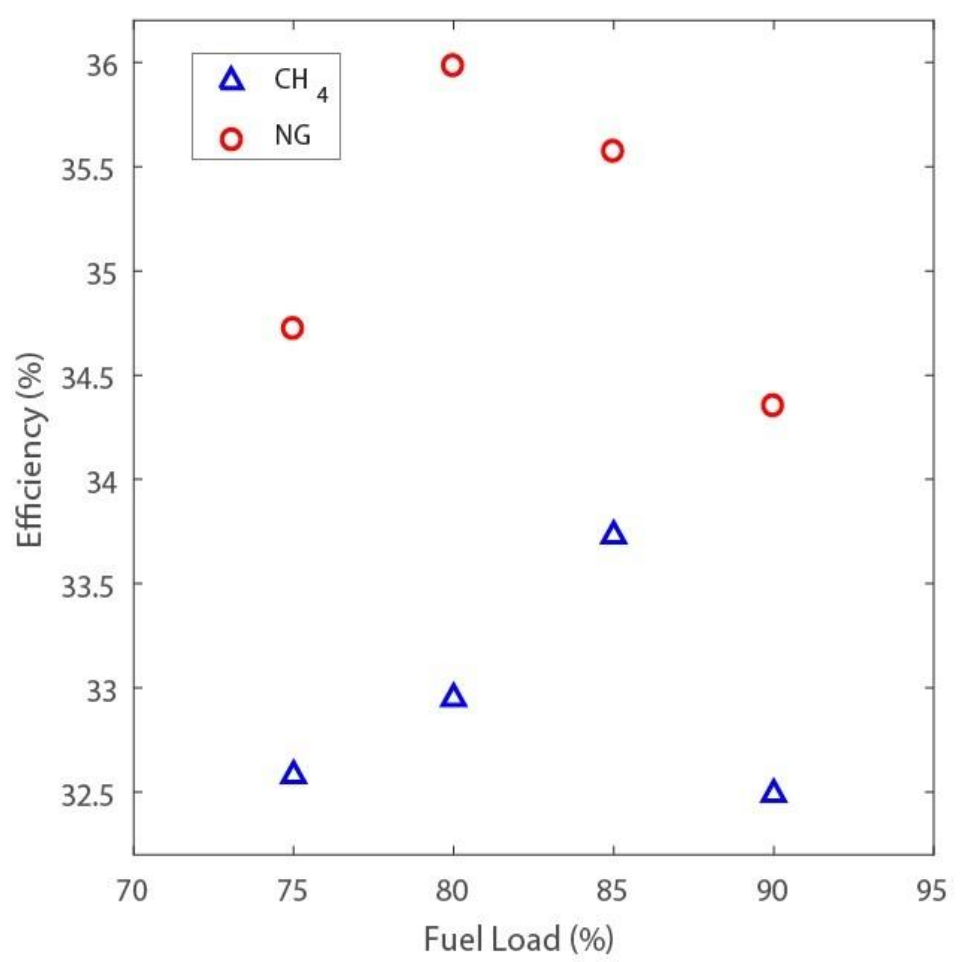

Figure 45: Effect of fuel and fuel load on indicated thermal efficiency (at $-10^{\circ} \mathrm{CA}$ aTDC and 900 rpm) 
Equivalence ratio $(\phi)$ in this study was not function of air intake and depended only on the value of fuel load \%. Hence, the $\phi$ was always constant for any operating conditions, at constant fuel load \%. It can be noticed from Figure 44 that the $\phi$ of methane was higher than that of NG. This was due to the higher molecular weight of NG and increased viscosity of higher alkanes present in NG, which reduced the flow of NG through injectors. One interesting observation that can be made from this point is that although the mass of methane was higher than NG, the power output and efficiency of NG was comparably higher than methane, which suggests that NG is more powerful and fuel efficient than methane at low speed conditions such as those in this work. Figure 45 shows the indicated thermal efficiency with change in fuel load $\%$. The NG efficiency increased from $75 \%$ and reached the maximum at $80 \%$ load, then started to decrease. For methane, the efficiency reached a maximum at $85 \%$ load and then decreased till 90\%. Though, while the flame speed and heat transfer increased with fuel load for both fuels, the efficiency decreased. This might be, probably, due to the increasing amount of trapped fuel in the crevices as the load \% increases, which could be checked using emissions data. But due to some equipment malfunction, the emissions are not presented here.

Table 9: Effect of fuel and fuel load on engine

\begin{tabular}{|l|l|l|l|l|l|l|l|l|}
\hline Fuel & $\begin{array}{l}\text { Fuel load } \\
(\%)\end{array}$ & $\begin{array}{l}\mathrm{P}_{\max } \\
(\mathrm{MPa})\end{array}$ & $\begin{array}{l}\mathrm{P}_{\max } \\
\text { location } \\
(\mathrm{deg} \\
\text { aTDC })\end{array}$ & $\begin{array}{l}\text { SOC } \\
(\mathrm{deg} \\
\text { aTDC })\end{array}$ & $\begin{array}{l}\text { EOC } \\
(\mathrm{deg} \\
\text { aTDC })\end{array}$ & $\Phi$ & $\begin{array}{l}\text { Imep } \\
(\mathrm{kPa})\end{array}$ & $\eta_{\text {th, }}$ \\
\hline \multirow{5}{*}{$\mathrm{CH}_{4}$} & 75 & 4.16 & 18.7 & 7.7 & 55.3 & 0.71 & 780.31 & 32.6 \\
\cline { 2 - 10 } & 80 & 4.42 & 18.0 & 7.0 & 54.4 & 0.74 & 815.65 & 33.0 \\
\cline { 2 - 10 } & 85 & 4.76 & 15.0 & 6.5 & 47.6 & 0.76 & 864.47 & 33.7 \\
\hline \multirow{5}{*}{ NG } & 90 & 4.89 & 17.1 & 6.0 & 50.3 & 0.80 & 868.88 & 32.5 \\
\cline { 2 - 9 } & 80 & 4.41 & 18.0 & 7.2 & 55.6 & 0.69 & 804.46 & 34.7 \\
\cline { 2 - 9 } & 85 & 4.84 & 16.7 & 6.2 & 55.2 & 0.71 & 861.03 & 36.0 \\
\cline { 2 - 9 } & 90 & 4.93 & 16.9 & 6.2 & 52.8 & 0.74 & 881.70 & 35.6 \\
\hline
\end{tabular}




\section{Summary and Conclusions}

\subsection{Summary}

Increasing demand for petroleum fuels and enforcement of stringent emission regulations have initiated the work on alternative fuels containing low carbon like NG; but its varying composition over geographical area is posing a threat to IC engines and its operation. Hence, this work had focused on studying the effects of change in NG composition on various combustion parameters like in-cylinder pressure, apparent heat release rate, IMEP, etc. An experimental investigation was conducted on a single cylinder CI engine modified to SI engine for NG operation, by replacing the fuel injector with a spark plug and adding port fuel injection to the intake manifold just before the intake valve for fuel delivery. An operating variable called fuel load $\%$ is varied to change the equivalence ratio of the mixture. The injector responded linearly with change in load $\%$, and produced a significant change in pressure from lower $\phi$ to higher $\phi$, though not much change in $\phi$ was observed. This study used two gases, methane and a $\mathrm{C}_{1}-\mathrm{C}_{4}$ alkane blend to study the effects of chemical composition of NG at several operating conditions.

Operating variables like spark timing, load \%, an engine speed were varied, and data was collected for both gases and compared. The conclusions of this study are presented below.

\subsection{Conclusions}

- NG blend had a higher peak pressure than methane at all operating conditions, which suggests that peak pressure is proportional to the fuel's WI.

- Higher carbon species like ethane and propane in NG helped in faster flame development and propagation, which increased the heat release rate compared to methane.

Subsequently, NG had higher thermal efficiencies than methane.

- The faster flame development for NG advanced SOC, which advanced the position of the peak pressures.

- Variation in spark timing for methane caused the imep to increase until it reached the MBT timing, and then decreased again. 
- Increasing engine speed reduced the peak pressures and apparent heat release rates, probably due to the higher friction losses in the engine.

- Imep and thermal efficiency decreased linearly with increasing engine speed, though these parameters were higher for NG at any instant.

- However, imep and thermal efficiency gaps between the two fuels decreased at higher engine speeds, which suggests that there is no significant effect of composition on performance at higher speeds for the loads investigated here.

- The two fuels had similar $\phi$, but methane had a slightly higher $\phi$ than NG.

- Imep for both fuels increased until certain $\phi$, and then remained constant. Thermal efficiencies also increased up to certain $\phi$, and then decreased. However, NG had its peak thermal efficiency at lower $\phi$ than methane, which suggests that NG should be run leaner than methane to achieve better performance and efficiency.

\subsection{Future work}

Emissions data was not available for this study. Collecting emissions data could provide better explanation of the irregular behavior of gases at certain conditions. Spark timing data was not available for NG, due to controller malfunction. Re-running the experiments with controlled spark timings would provide further insight on how the behavior of NG changes with spark timings. Optical investigation of the present work could help understand how the composition of gas effects the flame development and propagation process.

There are some points in this study that need further information by implementing various compositions to substantiate. Hence, the present study could be extended by implementing other compositions of NG, which would help in better understanding the influence of $\mathrm{MN}$ and WI on combustion parameters.

Also optimized engine testing can be conducted to reveal the actual behavior of the gases at various operating conditions. 


\section{Bibliography}

[1]. "Quadrennial Technology Review," 2015.

[2]. “U.S. Energy Information Administration,” [Online]. Available:

https://www.eia.gov/energyexplained/?page=us_energy_transportation. [Accessed: 18/9/2017].

[3]. M. Aslam, H. Masjuki, M. Kalam, M. Abdesselam, T. Mahlia and M. Amalina, “An experimental investigation of CNG as an alternative fuel for a retrofitted gasoline vehicle," Fuel, vol. 85, pp. 717-724, 2006.

[4]. M. I. Khan, T. Yasmin and A. Shakoor, "Technical overview of compressed natural gas (CNG) as a transportation fuel," Renewable and Sustainable Energy Review, vol. 51, pp. 785797, 2015.

[5]. M. Tuner, "Review and Benchmarking of Alternative Fuels in Conventional and Advanced Engine Concepts with Emphasis on Efficiency, $\mathrm{CO}_{2}$, and Regulated Emissions," $S A E$ Technical Paper 2016-01-0882, 2016.

[6]. “U.S. Energy Information Administration,” 19/5/2017. [Online]. Available: https://www.eia.gov/energyexplained/?page=us_energy_home. [Accessed: 12/9/2017]

[7]. M. I. Khan, "Policy options for the sustainable development of natural gas transportation fuel," Energy Policy, vol. 110, pp. 126-136, 2017.

[8]. “U.S. Energy Information Administration,” 2017. [Online]. Available: https://www.eia.gov/dnav/ng/ng_cons_sum_dcu_nus_a.htm. [Accessed: 12/9/2017]

[9]. "U.S. Energy Information Administration,” 20/7/2017. [Online]. Available: https://www.eia.gov/state/print.php?sid=WV. [Accessed: 18/9/2017].

[10]. “CNG Prices,” [Online]. Available: http://www.cngprices.com/stations/CNG/WestVirginia/. [Accessed: 18/9/2017].

[11]. C. Blazek, J. Grimes, P. Freeman, B. Bailey and C. Colucci, "Fuel Composition Effects on Natural Gas Vehicle Emissions," in $207^{\text {th }}$ ACS national meeting-division of fuel chemistry, San Diego, 1994 
[12]. B. Johansson and K. Olsson, "Combustion Chambers for Natural Gas SI Engines Part 1: Fluid Flow and Combustion," SAE Technical Paper 950469, 1995

[13]. G. B. Machado, T. Cordeiro de Melo and L. F. Lastres, "Panorama of Natural Gas Usage in Heavy-Duty Vehicles in Brazil,” SAE Technical Paper 2005-01-2192, 2005

[14]. M. Graboski, R. McCormick, A. Newlin, D. Dunnuck, M. Kamel and W. Ingle, "Effect of Fuel Composition and Altitude on Regulated Emissions from a Lean-Burn, Closed Loop Controlled Natural Gas Engine,” SAE Technical Paper 971707, 1997

[15]. A. Kakee, A. Paykani and M. Ghajar, "The influence of fuel composition on the combustion and emission characteristics of natural gas fueled engines," Renewable and Sustainable Energy Review, vol. 38, pp. 64-78, 2014

[16]. C. Dumitrescu, V. Padmanaban and J. Liu, "An experimental investigation of early flame development in an optical SI engine fueled with natural gas," Internal Combustion Fall Technical Conference, Seattle, 2016

[17]. K. Bhandari, A. Bansal, A. Shukla and M. Khare, "Performance and emissions of natural gas fueled internal combustion engine: A review," Journal of Scientific and Industrial Research, 2005

[18]. A. Paykani, R. Khoshbakthi Saray, M. Shervani-Tabar and A. Mohammadi-Kousha, "Effect of exhaust gas recirculation and intake pre-heating on performance and emission characteristics of dual fuel engines at part load,” J. Cent. South Univ., vol 19, pp. 1346-1352, 2012

[19]. R. L. Evans and J. Blaszczyk, "A comparative study of the performance and exhaust emissions of a spark ignition engine fueled by natural gas and gasoline," Journal of Automobile Engineering, vol. 211, no. 1, pp. 39-47, 1997

[20]. A. Demirbas, "Methane Gas Hydrate (Green Energy and Technology)," Springer, 2010

[21]. L. T. Baldassarri, C. L. Battistelli, L. Conti, R. Crebelli, B. de Berardis, A. L. Iamiceli, M. Gambino and S. Iannaccone, "Evaluation of emission toxicity of urban bus engines:

Compressed natural gas and comparison with liquid fuels," Science of the Total Environment, vol. 355, pp. 64-77, 2006 
[22]. T. Hesterberg, C. Lapin and W. Bunn, "A Comparison of Emissions from Vehicles fueled with Diesel or Compressed Natural Gas," Environmental Science and Technology, 2008

[23]. M. I. Jahirul, H. H. Masjuki, R. Saidur, M. A. Kalam, M. H. Jayed and M. A. Wazed, "Comparative engine performance and emission analysis of CNG and gasoline in a retrofitted car engine," Applied Thermal Engineering, vol. 30, pp. 2219-2226, 2010

[24]. H. Muk Cho and B. Quan He, "Combustion and Emission Characteristics of a Natural Gas Engine under Different Operating Conditions,” Environ. Eng. Res., vol. 14, no. 2, pp. $95-$ 101,2009

[25]. S. R. King, "The Impact of Natural Gas Composition on Fuel Metering and Engine Operational Characteristics,” in International Congress and Exposition, Detroit, 1992

[26]. L. Dondero and J. Goldemberg, "Environmental implications of converting light gas vehicles: the Brazilian experience," Energy Policy, vol. 33, pp. 1703-1708, 2005

[27]. P. Mello, G. Pelliza, R. Cataluna and R. da Silva, "Evaluation of the maximum horsepower of vehicles converted for use with natural gas fuel," Fuel, vol. 85, pp. 2180-2186, October 2006

[28]. G. Karavalakis, T. Durbin, M. Villela and W. Miller, "Air pollutant emissions of lightduty vehicles operating on various natural gas compositions," Journal of Natural Gas Science and Engineering, vol. 4, pp. 8-16, 2011

[29]. R. McCormick, M. Graboski, T. Alleman, A. Herring and P. Nelson, "In-Use Emissions from Natural Gas Fueled Heavy-Duty Vehicles,” SAE Technical Paper 1999-01-1507, 1999 [30]. G. McTaggart, S. Rogak, S. Munshi, P. Hill and W. Bushe, "The influence of fuel composition on a heavy-duty, natural gas direct-injection engine," Fuel, vol. 89, pp. 752-759, 2010

[31]. D. Yossefi, M. R. Belmont, S. J. Ashcroft and S. J. Maskell, “A comparison of the relative effects of fuel composition and ignition energy on the early stages of combustion in a natural gas spark ignition engine using simulation," Proceedings of the Institution of Mechanical Engineers, Part D, vol. 214, no. 4, pp. 383-393, 2000 
[32]. A. J. W. Headlee, "The composition and properties of natural gas in the Appalachian fields," Appalachian Geological Society, 1949

[33]. M. Feist, M. Landau and E. Harte, "The Effect of Fuel Composition on Performance and Emissions of a Variety of Natural Gas Engines,” SAE Int. J. Fuels Lubr, vol. 3, no. 2, 2010

[34]. J. Chen, "Auto ignition of Natural Gas Fuels with Ethane and Propane Additives at Low to Intermediate Temperature," 2003

[35]. Khalil and Karim, "A Kinematic Investigation of the Role of changes in the composition of Natural Gas in Engine Applications," Engineering of Gas Turbines and Power, vol. 124, no. 2, 2002

[36]. J. D. Naber, D. L. Siebers, S. S. Di Julio and C. K. Westbrook, "Effects of Natural Gas Composition on Ignition Delay under Diesel Conditions," Combustion and Flame, vol. 99, pp. 192-200, 1994

[37]. N. Lamoureux and C. Paillard, "Natural gas ignition delay times behind reflected shock waves: Applications to modelling and safety," Shock Waves, vol. 13, pp. 57-68, 2003

[38]. U. Kramer, T. Lorenz, C. Hofmann, H. Ruhland, R. Klein and C. Weber, "Methane Number Effect on the Efficiency of a Downsized, Dedicated, High Performance Compressed Natural Gas (CNG) Direct Injection Engine,” SAE Technical Paper 2017-01-0776, 2017 [39]. R. Crawford, J. Lyons and J. Heiken, "Effect of Gas Composition on Emissions of Heavy-Duty Natural Gas Engines," Sacramento, 2009

[40]. J. Kubesh, S. King and W. Liss, "Effect of Gas Composition on Octane Number of Natural Gas Fuels,” SAE Technical Paper 922359, 1992

[41]. G. McTaggart, J. Huang and S. Munshi, "Impacts and Mitigation of Varying Fuel Composition in a Natural Gas Heavy-Duty Engine,” SAE Int. J. Engines, vol. 10, no. 4, 2017

[42]. A. Javaheri, V. Esfahanian, A. Zadeh, M. Darzi and S. Mirsoheil, "Investigation of Natural Gas Composition Effects on Knock Phenomenon in SI Gas Engines using Detailed Chemistry," Applied Mechanics and Materials, vol. 493, pp. 239-244, 2014 
[43]. C. Park, A. Raju, S. Franco, P. Roy and H. Jung, "Development of a fuel sensor technology for a Variable-blend Natural Gas Vehicle,” Journal of Natural Gas Science and Engineering, vol. 31, pp. 149-155, 2016

[44]. B. H. Min, J. T. Chung, H. Y. Kim and S. Park, "Effects of Gas Composition on the Performance and Emissions of Compressed Natural Gas Engines," KSME International Journal, vol. 16, no. 2, pp. 219-226, 2002

[45]. J. Vavra, M. Takats, V. Klir and M. Skaohlid, "Influence of Natural Gas Composition on Turbocharged Stoichiometric SI Engine Performance," SAE Technical Paper 2012-01-1647, 2012

[46]. K. Kim, K. Lee, H. Kim, K. Lee and B. Kim, "Effect of Natural Gas Composition on the Performance of Compressed Natural Gas Engines," Oil and Gas Science and Technology, vol. 64, no. 2, pp. 199-206, 2009

[47]. Y. Lee and G. Kim, "Effect of Gas Composition on NGV Performance," SAE Technical Paper 2000-05-0169, 2000

[48]. K. Bosschaart and L. de Goey, "The laminar burning velocity of flames propagating in mixtures of hydrocarbons and air measured with the heat flux method," Combustion and Flame, vol. 136, pp. 261-269, 2004

[49]. E. Ranzi, A. Frassoldati, R. Grana, T. Cuoci, T. Kelley and C. Law, "Hierarchical and comparative kinetic modeling of laminar flame speed of hydrocarbon and oxygenated fuels," Progress in Energy and Combustion Science, vol. 38, pp. 468-501, 2012

[50]. P. Dirrenberger, H. Le Gall, R. Bounanceur, O. Herbinet, P. A. Glaude, A. Konnov and F. Battin-Leclerc, "Measurements of Laminar Flame Velocity for Components of Natural Gas," Energy Fuels, vol. 25, pp. 3875-3884, 2011

[51]. Y. Kochar, J. Seitzman, T. Lieuwen, W. Metcalfe, S. Burke, H. Curran, M. Krejci, W. Lowry, E. Petersen and G. Bourque, "Laminar Flame Speed Measurements and Modeling of Alkaline Blends at Elevated Pressures with Various Diluents," in Proceedings of ASME Turbo Expo 2011, Vancouver, British Columbia, 2011 
[52]. A. El-Sherif, "Effects of natural gas composition on the nitrogen oxide, flame structure and burning velocity under laminar premixed flame conditions," Fuel, vol. 77, no. 14, pp. 15391547,1998

[53]. R. Amirante, E. Distaso, S. Di Iorio, P. Sementa, P. Tamburrano, B. Vaglieco and R. Reitz, "Effects of natural gas composition on performance and regulated, greenhouse gas and particulate emissions in spark0ignition engines," Energy Conversion and Management, vol. 143, pp. 338-347, 2017

[54]. H. K. Kayadelen, "Effect of natural gas components on its flame temperature, equilibrium combustion products and thermodynamic properties," Journal of Natural Gas Science and Engineering, vol. 45, pp. 456-476, 2017

[55]. G. A. Karim and I. Wierzba, "Comparative Studies of Methane and Propane as Fuels for Spark Ignition and Compression Ignition Engines," SAE Technical Paper 831196, 1983

[56]. L. Spadaccini and M. Colket III, "Ignition Delay Characteristics of Methane Fuels," Progress in Energy and Combustion Science, vol. 20, no. 5, pp. 431-460, 1994

[57]. A. Manivannan, P. Tamil Porai, S. Chandrasekaran and R. Ramprabhu, "Lean Burn Natural Gas Spark Ignition Engine - An Overview," SAE Technical Paper 2003-01-0638, 2003 [58]. R. Crookes, "Comparative bio-fuel performance in internal combustion engines," Biomass and Bioenergy, vol. 30, pp. 461-468, 2006

[59]. G. Karavalakis, M. Hajbabaei, T. Durbin, Z. Zheng and K. Johnson, "Influence of Different Natural Gas Blends on the Regulated Emissions, Particle Number and Size Distribution Emissions from a Refuse Hauler Truck,” SAE Int. J. Fuels Lubr, vol. 5, no. 3, 2012

[60]. M. Hajbabaei, G. Karavalakis, K. Johnson, L. Lee and T. Durbin, "Impact of natural gas fuel composition on criteria, toxic, and particle emissions from transit buses equipped with lean burn and stoichiometric engines," Energy, vol. 62, pp. 425-434, 2013

[61]. G. Karavalakis, M. Hajbabaei, Y. Jiang, J. Yang, K. Johnson, D. Cocker and T. Durbin, "Regulated, greenhouse gas, and particulate emissions from lean-burn and stoichiometric natural gas heavy-duty vehicles on different fuel compositions,” Fuel, vol. 175, pp. 146-156, 2016 
[62]. G. Karavalakis, N. Gysel, M. Hajbabaei, T. Durbin, K. Johnson and W. Miller, "Influence of Different Natural Gas Compositions on the Regulated Emissions, Aldehydes, and Particulate Emissions from a Transit Bus," SAE Technical Paper 2013-01-1137, 2013

[63]. B. Min, K. H. Bang, H. Y. Kim, J. T. Chung and S. Park, "Effects of Gas Composition on the Performance and Hydrocarbon Emissions for CNG Engines," SAE Technical Paper 981918, 1998

[64]. A. Burcat, K. Scheller and A. Lifshitz, "Shock-tube investigation of comparative ignition delay times for $\mathrm{C}_{1}-\mathrm{C}_{5}$ alkanes," Combustion and Flame, vol. 16, no. 1, pp. 29-33, 1971

[65]. C. Caillol, T. Delorme, P. Denis, G. Berardi and B. Porterie, "A Combustion Model for Analyzing the Effects of Natural Gas Composition on the Operation of a Spark Ignition Engine," SAE Technical Paper 2002-01-2236, 2002

[66]. P. Hill and D. Zhang, "The effects of swirl and tumble on combustion in spark ignition engines,” Progress in Energy and Combustion Science, vol. 20, pp. 373-429, 1994

[67]. R. Sommer and P. Engeler, "Piezoelectric Pressure Sensors," in Sensor Technology Handbook, J. S. Wilson, Ed., Newnes, 2005

[68]. “Megasquirt,” DIY Auto Tune, 16/1/2017. [Online]. Available:

http://www.msextra.com/doc/pdf/Megasquirt3_Setting_Up-1.5.pdf. [Accessed: 31/7/2017]

[69]. F. Payri, J. Lujan, A. Martin and A. Abbad, "Digital signal processing of in-cylinder pressure for combustion diagnosis of internal combustion engines," Mechanical Systems and Signal Processing, vol. 24, pp. 1767-1784, 2010

[70]. J. Heywood, “Internal Combustion Engines Fundamentals,” McGraw Hill, 1988 


\section{Appendix}

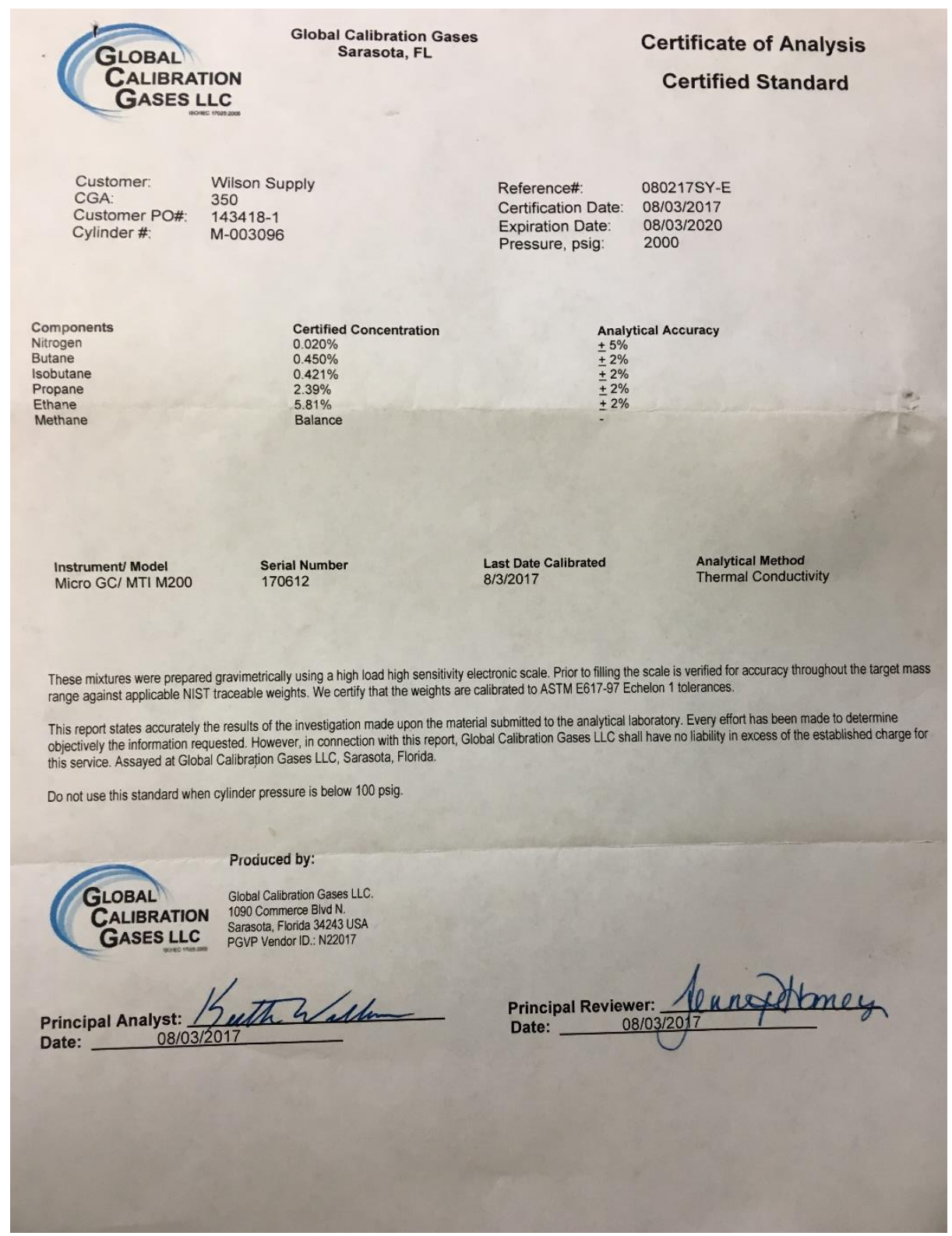

Figure 46: Certificate of Analysis of NG composition 